\title{
Biosynthesis and biological function of phosphonates in Fusarium spp.
}

\author{
Dissertation \\ to obtain the $\mathrm{Ph}$. D. degree \\ in the International Ph. D. Program for Agricultural Sciences in Goettingen \\ (IPAG) \\ at the Faculty of Agricultural Sciences, \\ Georg-August-University Göttingen, Germany
}

presented by

\section{María de los Ángeles VINAS Meneses}

born in San José, Costa Rica

Göttingen, February 2018 
D7

1. Name of supervisor: Prof. Dr. Petr Karlovsky

2. Name of co-supervisor: Dr. Franz Hadacek

Date of dissertation: 06 February 2018 


\section{Contents}

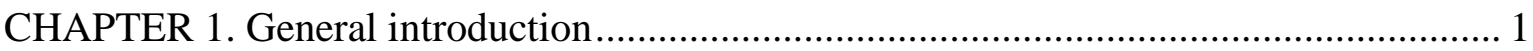

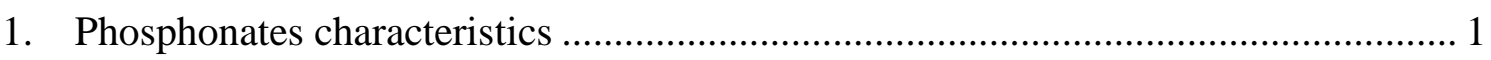

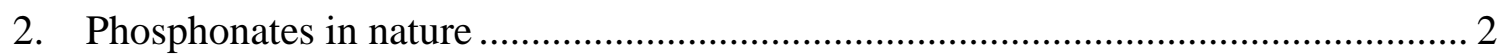

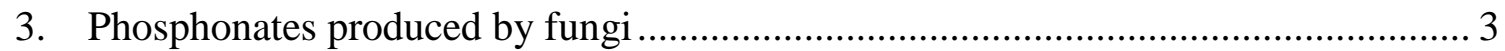

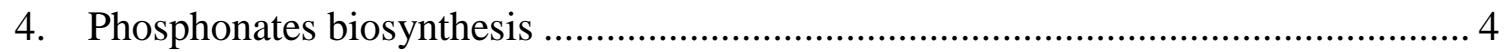

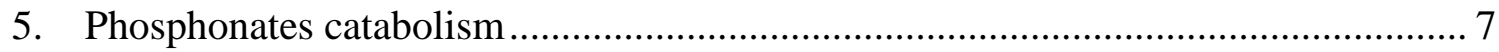

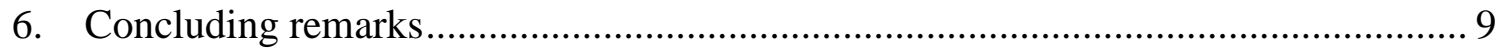

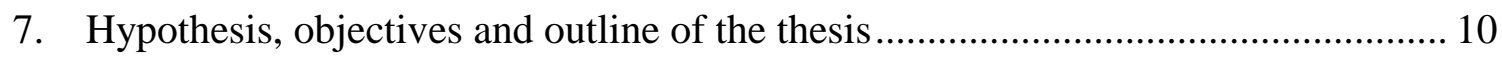

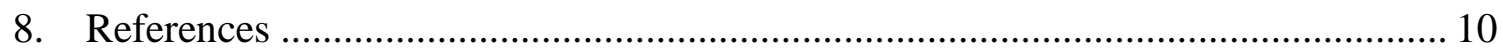

CHAPTER 2. Identification of the phosphonates-genome cluster in F. oxysporum and the

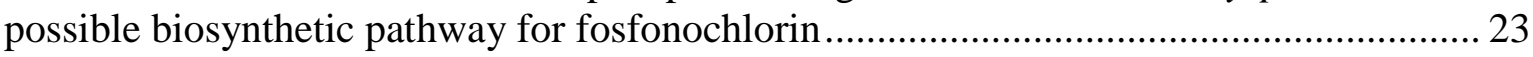

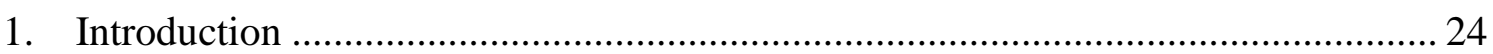

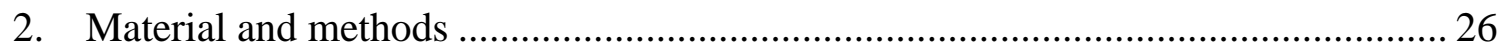

2.1. Identification of the putatively phosphonate genomic cluster in F.oxysporum 26

2.2. Gene expression of phosphonate-related genes in F. oxysporum ..................... 27

2.3. Heterologous pepm protein expression in E. coli ............................................ 29

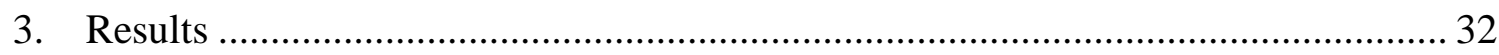

3.1. Identification of the putatively phosphonate genomic cluster in F.oxysporum 32

3.2. Gene expression of phosphonate-related genes in F. oxysporum .................... 40

3.3. Heterologous pepm protein expression in E. coli ........................................... 43

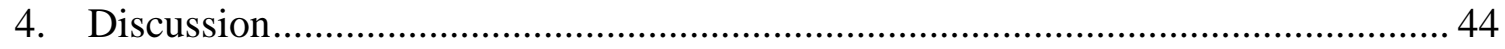

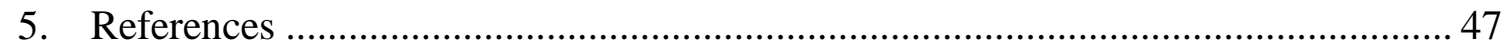

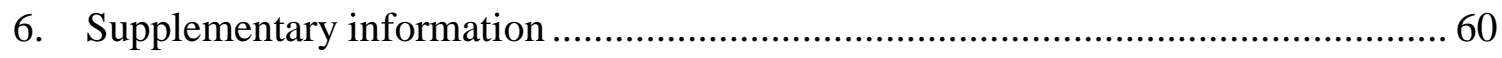

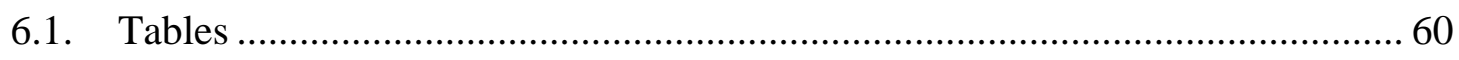

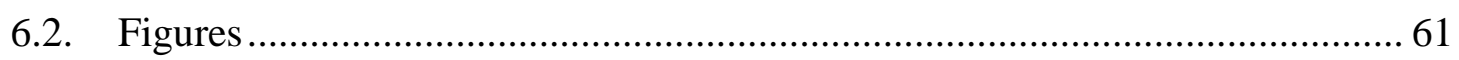

CHAPTER 3. The biological function of phosphonates in F. oxysporum .......................... 62

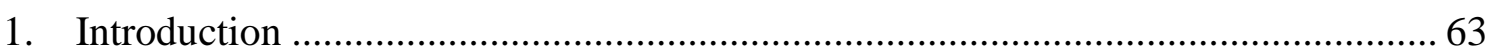

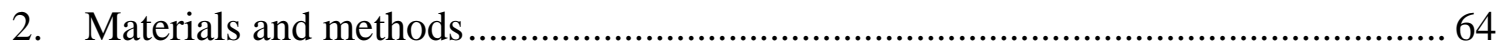

2.1. Disruption of phosphonates biosynthesis in F. oxysporum .............................. 64

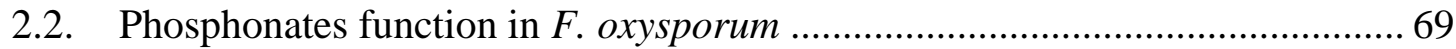

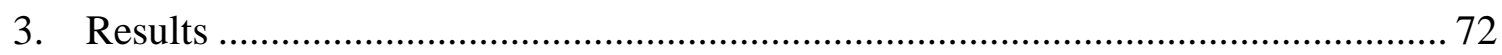

3.1. Disruption of phosphonates biosynthesis in F. oxysporum ............................. 72

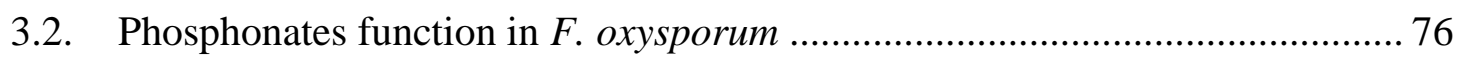




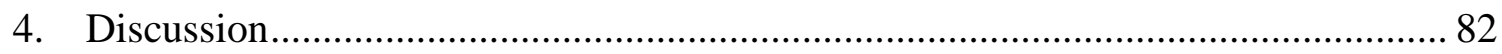

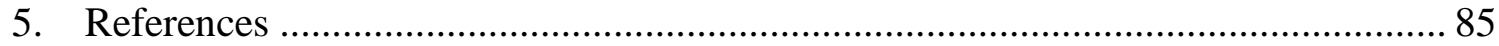

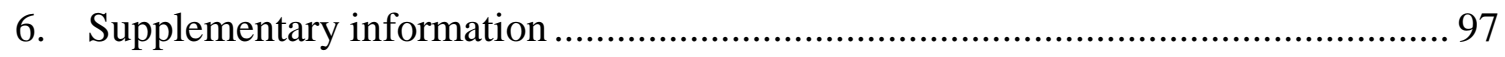

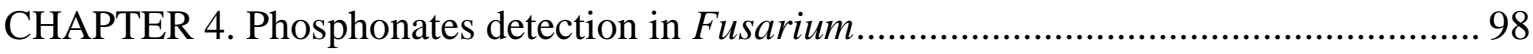

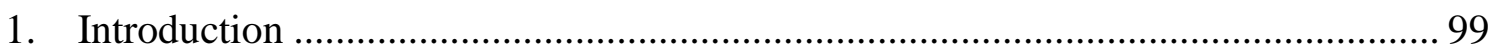

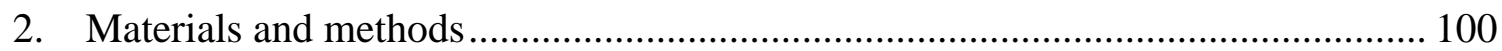

2.1. Establishment of a method for detection of phosphonates on TLC plates ...... 100

2.2. Phosphonates extraction and detection by TLC and HPLC-MS .................... 101

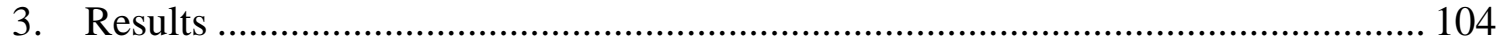

3.1. Establishment of a method for detection of phosphonates on TLC plates ...... 104

3.2. Phosphonates extraction and detection by TLC and HPLC-MS. ................... 104

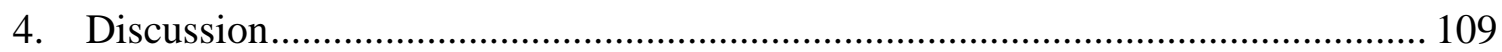

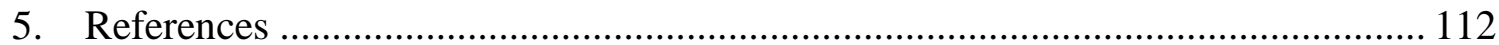

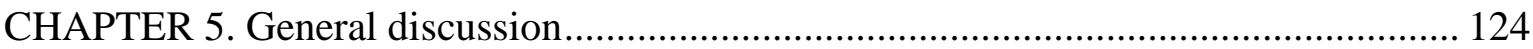

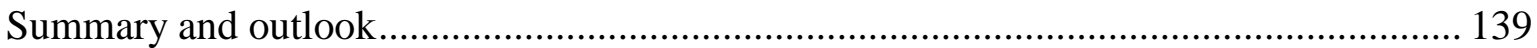

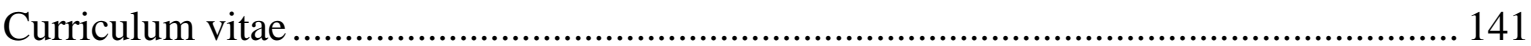

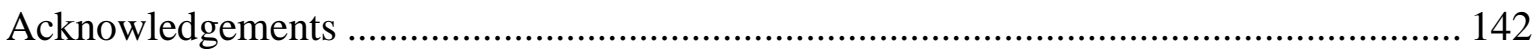

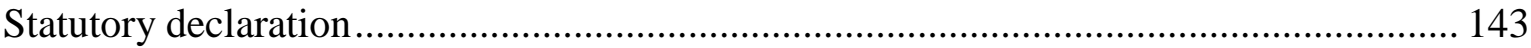




\section{Important abbreviations}

AEP: aminoethylphosphonate

C-P: carbon-phosphorus

DHEP: hydroxyethylphosphonate

Ect: Ectopic

ESI-MS: Electrospray Ionization-Mass Spectrometry

FL: Flanking Region

GFP: Green Fluorescent Protein

HEP: hydroxyethylphosphonate

HILIC: Hydrophilic Interaction Chromatography

HMP: hydroxymethylphosphonate

HPP: hydroxypropilphosphonate

Hph: Hygromycin B phosphotransferase

IPTG: Isopropyl $\beta-D-1-$ thiogalactopyranoside

OHEP: oxo-2-hydroxyethylphosphonate

PEP: phosphoenolpyruvate

Pepm: phosphoenolpyruvate mutase

PnAA: phosphonoacetaldehyde

PnA: phosphonoacetate

PnPy: phosphonopyruvate

Ppd: phosphonopyruvate decarboxylase

Pi: inorganic phosphate

$\mathrm{PO}_{4}$ : phosphates

SDS-PAGE: Sodium Dodecyl Sulfate Polyacrylamide Gel Electrophoresis

T-DNA: Transfer DNA

TLC: Thin Layer Chromatography

Wt: Wild Type

Аpepm: pepm gene knock-out 


\section{CHAPTER 1. General introduction}

\section{Phosphonates characteristics}

Phosphonates and phosphonic acids, also known as $\mathrm{C}-\mathrm{P}$ compounds, are organic molecules that contain a direct carbon-phosphorus bond. This type of boundingpresents a large stability toward thermal and chemical degradation, and enzymatic hydrolysis (Metcalf and van der Donk 2009; McGrath et al. 2013). Moreover, phosphonates are potent inhibitors of enzymes due to their structural similarity to analogous substrates of phosphate-esters and carboxylic acids (Metcalf and van der Donk 2009; Peck and van der Donk 2013; Yu et al. 2013). Based on those characteristics, phosphonates could provide competitive advantages to the producing species.

Some microorganisms can synthesize phosphonates, though they can be also artificially man-made. Nowadays, both natural and synthetic phosphonates are used in agriculture as herbicides (e.g.,glufosinate, glyphosate) and insecticides [e.g., metrifonate or trichlorfon(McGrath et al. 2013)], as well in medicine as antibiotics[e.g., fosfomycin under Monurol $^{\circledR}\left(\right.$ Woodyer et al. 2006)], antiviral compounds[e.g., tenofovir under $\operatorname{Viread}^{\circledR}$ and phosphonoformate under Foscarnet ${ }^{\circledR}$ (Ferguson et al. 2000; Woo et al. 2010)] and for osteoporosis treatment [e.g., alendronate under Fosamax ${ }^{\circledR}$ (Black et al. 2000)].

Natural phosphonates are considered as ancient molecules since they can be produced by primitive life forms (McGrath et al. 2013) and their biochemistry resembles that one from primary metabolism (Horsman and Zechel 2017). It has been suggested that phosphonates predominated over phosphates $\left(\mathrm{PO}_{4}\right)$ on Earth when a low oxygen concentration prevailed inthe ancient atmosphere (McGrath et al. 2013). Despite the presumed long history of these compounds on Earth, only few natural phosphonates have been described so far. Presumably, their chemical characteristics have prevented successful extraction by standards protocols. Natural phosphonates are highly water-soluble molecules andlack chromophores (Ju et al. 2014; Horsman and Zechel 2017). 


\section{Phosphonates in nature}

Natural phosphonates are produced by organisms, including bacteria such as Bacillus subtilis(Borisova et al. 2010), Bacteroides fragilis(Zhang et al. 2003), Pseudomonas syringae(Kim et al. 2012), P. viridiflava (Katayama et al. 1990; Kim et al. 2012), Saccharothrix sp. (Takahashi et al. 1995), Streptomycesfradiae (Woodyer et al. 2006), S. hygroscopicus(Seto et al. 1982), S. lavendofoliae(Gao et al. 2014), S. luridus (Circello et al. 2010), S. plumbeus (Park et al. 1977), S. rubellomurinus(Eliot et al. 2008) and $S$. viridochromogenes (Blodgett et al. 2005); marine invertebrates (Liang and Rosenberg 1968; Kittredge and Roberts 1969; Kim et al. 1998; Martinez et al. 2010)and by medically important parasites such as Trypanosoma cruzi(Sarkar et al. 2003).

In nature, the most abundant and ubiquitous phosphonate, i.e. aminoethylphosphonate (AEP) (Figure 1a), has a structural function(phosphonolipids, phosphonoglycans) in the membranes of certain organisms such as marine invertebrates and bacteria (Liang and Rosenberg 1968; Kittredge and Roberts 1969; Kennedy and Thompson 1970; Park et al. 1977; Creamer and Bostock 1986; Kim et al. 2002; Zhang et al. 2003). Other natural phosphonates, mainly produced by bacteria, are bioactive molecules thatexhibit a variety of activities.For instance, argolaphos (Ju et al. 2015), dehydrophos (Figure 1b) (Circello et al. 2010), fosfomycin (Figure 1c) (Woodyer et al. 2006) and plumbemycins (Park et al. 1977) are compounds with an antibiotic activity; fosmidomycin and FR900098 are antimalarial and antibacterial compounds (Eliot et al. 2008); and fosfazinomycin (Gunji et al. 1983) and rhizocticins (Borisova et al. 2010) are compounds with antifungal activity. Additionally, some herbicides, as for instancephosphinothricin-containing molecules (Figure 1d) (phosalacine and phosphinothricin tripeptide or bialaphos) and phosphonothrixin (Omura et al. 1984; Takahashi et al. 1995; Blodgett et al. 2005), are also phosphonates produced by bacteria.The case of the compound phosphinothricin (commercially known as glufosinate), is particularly interesting since presents a $\mathrm{C}-\mathrm{P}-\mathrm{C}$ bond array rarely found in natural molecules. Phosphinothricinis a structural analog of glutamine and glutamic acid that inhibitsglutamine synthase activity.Consequently, glutamine synthesis and ammonia detoxification are disrupted in plants exposed to this compound(Lea et al. 1984; Blodgett et al. 2005). 


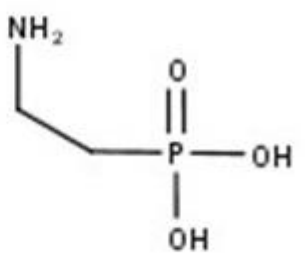

AEP

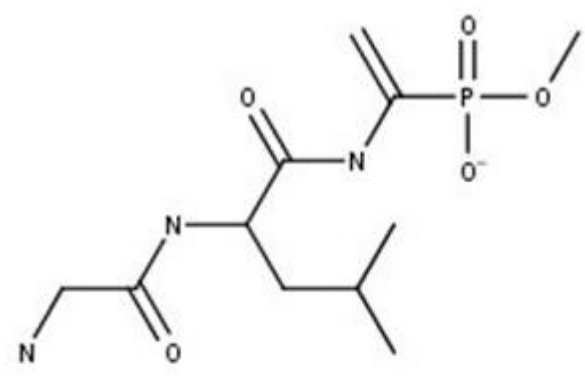

Dehydrophos

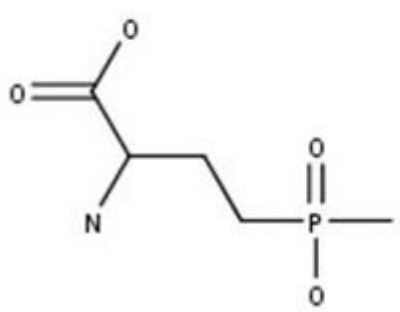

Phosphinothrixin

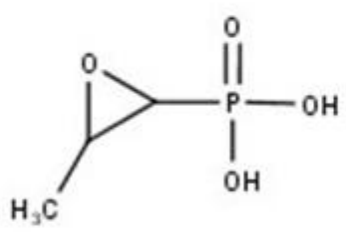

Fosfomycin<smiles>O=C(CCl)P(=O)(O)O</smiles>

Fosfonochlorin

Figure 1. Molecular structure of some naturally occurring phosphonates

Although phosphonates of biogenic origin were discovered more than 50 years ago in protozoa (Horiguchi and Kandatstu 1959), it was not until recently that the abundance and diversity in the biosphere mainly in marine environments (McGrath et al. 2013; Yu et al. 2013) and in soils (Turner et al. 2004; Stutter et al. 2015) have been discovered and described.The presence of phosphonates in non-agricultural soils and the fact that the already described phosphonates producers are not always abundant in soils where phosphonates have been found (Tate and Newman 1982; Turner et al. 2004; Yu et al. 2013), infers that these compounds could be produce by other organisms such as soilborne fungi.

\section{Phosphonates produced by fungi}

There is only little information regarding the synthesis of phosphonatesby fungi. In 1989, Takeuchi and collaborators (Takeuchi et al. 1989) found a low-molecular-weight phosphonic acid, called fosfonochlorin (Figure 1e), produced by Fusarium avenaceum (Fr) Sacc,F. oxysporum Schlecht, F. tricinctum (Corda) Saccand Talaromyces flavus (Klöcker) 
Stolk et Samson. This study was the first and the only publication on a phosphonate produced by fungi. More recently (Koukol et al. 2006, 2008; Maciejczyk et al. 2015) demonstrated that $\mathrm{C}-\mathrm{P}$ compounds can be accumulated by saprotrophic ascomycetes and basidiomycetes.However, it is not clear whether these phosphonates were all synthesized by the fungi themselves, or instead, are from bacterial or anthropogenic origin. So far, no other phosphonates produced by fungi have been described.

Fosfonochlorin, 2-chloroacetylphosphonic acid (Takeuchi et al. 1989; Kim et al. 2012), is a chlorine-containing organohalogen (Figure 1e). Some natural organohalogens, such as chloramphenicol and aureomycin, are antibiotics, whereas some others, such as sporidesmin and ochratoxin A, are mycotoxins (Gribble 2004). Fosfonochlorin has been shown to have antibiotic activity(Takeuchi et al. 1989). In terms of biological activity this compound is biologically similar to fosfomycin (Figure 1d): a broad-spectrum antibiotic against both gram-negative and gram-positive bacteria that is produced by streptomycetes and pseudomonads (Reeves 1994). Both compounds, fosfonochlorin and fosfomycin,are low-molecular-weight phosphonic acids that inhibit cell wall biogenesis in bacteria. According to (Takeuchi et al. 1989), fosfonochlorin probably mimics phosphoenolpyruvate (PEP) in PEP-GlcNAc-3-O-enolpyruvate transferase reaction and alkylates the enzyme UDP- $N$-acetylglucosamine-3-O-enolpyruvyltransferase (MurA), which is an essential enzyme that catalyzes the first step in cell wall biosynthesisin bacteria. MurA is also the target of fosfomycin. This compound alkylates a cysteine residue in the active site of the enzyme (Marquardt et al. 1994; Woodyer et al. 2006).

\section{Phosphonates biosynthesis}

The first two steps of phosphonates biosynthesis share the same enzymes in most organisms [except, in fosfomycin fromP. syringae (Kim et al. 2012) and in FR900098 fromS. rubellomurinus (Eliot et al. 2008)]. During these first steps,PEP is isomerized to phosphonopyruvate (PnPy) by the enzyme phosphoenolpyruvate mutase (pepm) (Figure 2). In a following step, PnPy is decarboxylated to form phosphonoacetaldehyde (PnAA) by the enzyme phosphonopyruvate decarboxylase (ppd), which moves the reaction forward since the equilibrium is in favor of PEP (Takeuchi et al. 1989; Nakashita et al. 1997; Seto et al. 1999; Zhang et al. 2003; Blodgett et al. 2005; Eliot et al. 2008; Ju et al. 2014). 


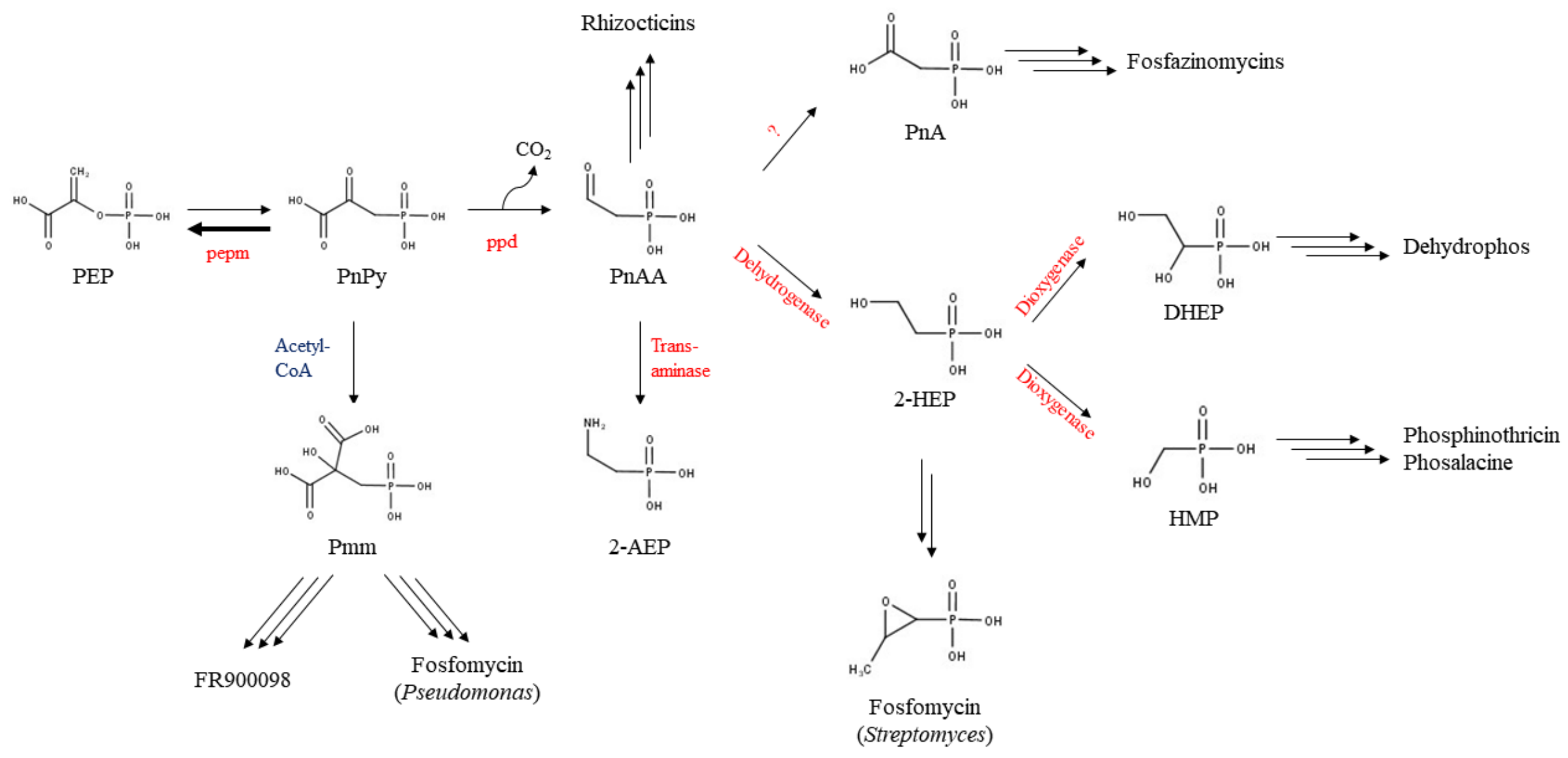

Figure 2. Summary of the biosynthetic pathways for some representative naturalphosphonates 
The key step in phosphonates biosynthesis is driven by pepm.Actually, organisms carrying the pepm-encoding gene have been categorized as phosphonate producers (Yu et al. 2013; Cioni et al. 2014; Ju et al. 2015). The importance of this enzymerelies in the C-P bond formation through a dissociative mechanism, in which the phosphomutase catalyzes the transfer of the phosphoryl group from the oxygen in PEP to the carbon in PnPy (Liu et al. 2002; Xu et al. 2005) using mainly $\mathrm{Mg}^{2+}$ as a cofactor. Pepm enzyme was firstly isolated from the protozoa Tetrahymena pyriformis(Bowman et al. 1988; Seidel et al. 1988) and later described by Hidaka and collaborators in 1989 (Hidaka et al. 1989)in a study carried out on the biosynthesis of bialaphos in S. hygroscopicus. This enzyme is a member of the PEP mutase/isocitrate lyase superfamily which belonging enzymes are responsible for the formation or cleavage of $\mathrm{C}-\mathrm{C}$ and $\mathrm{C}-\mathrm{P}$ bonds.

The second most important enzyme for phosphonates biosynthesis is ppd.This enzyme is a member of the $\alpha$-ketodecarboxylase family and was described in 2003 by Zhang et al. (2003). The decarboxylase requires thiamine pyrophosphate (TPP) and certain divalent metal ions as cofactors to produce PnAA (Zhang et al. 2003).

The steps, following the formation reaction of PnAA, are highly diverse amongst species. This acetaldehyde is located at the centralpoint from where the biosynthetic pathways diversify to form most of the already described phosphonates (Figure 2). In organisms where phosphonates have a structural function, PnAA is converted to AEP by a transaminase (Sarkar et al. 2003).However, in the case of some bioactive molecules, PnAA can beeither reduced to phosphonoacetate $(\mathrm{PnA})$ in the case of fosfazinomycins(Gao et al. 2014; Huang et al. 2015), or to hydroxyethylphosphonate (2-HEP) in the case of dehydrophos, phosphinothricin and fosfomycin (from Streptomyces) (Blodgett et al. 2005; Woodyer et al. 2006, 2007; Shao et al. 2008; Metcalf and van der Donk 2009; Circello et al. 2010). Further steps involve diverse enzymatic reactions.For example, the next biosynthetic step in dehydrophos is the hydroxylation of 2-HEP to form hydroxyethylphosphonate (DHEP) by a dioxygenase enzyme (Circello et al. 2010), while in phosphinothricin and phosalacine, 2-HEP is converted to hydroxymethylphosphonate (HMP) by another dioxygenase enzyme (Blodgett et al. 2016). In the case of fosfomycin (fromStreptomyces), 2-HEP is attacked by a methyl anion to produce 2hydroxypropylphosphonate (HPP), the subsequently oxidation of HPP produces 
fosfomycin (Woodyer et al. 2007). A different pathway from PnAA exists in B. subtilis and it is the aldol reaction with oxaloacetate followed by other reactions such as dehydration and aminotransferto form Rhizocticins (Borisova et al. 2010).

In the exceptional cases of fosfomycin from Pseudomonas and FR900098, the reaction from PnPy is moved forward through a different mechanism. In the case of fosfomycin an acetyl group is added to the carbonyl group in PnPy to generate phosphonomethylmalate (Pmm). A series of steps from here -decarboxylation, tautomerization, reduction and epoxidation- results in fosfomycin (Kim et al. 2012). The next steps from PnPy during the biosynthesis of FR900098 are not fully characterized yet (Eliot et al. 2008; Kim et al. 2012).

\section{Phosphonates catabolism}

In 1963, Zeleznick et al. (1963)demonstrated that E. coli can use methyl- and ethylphosphonic acids as the sole sources for phosphorus. Later, the catabolic pathway of $2-$ AEP was elucidatedin B. cereus(Roseberg and La Nauze 1967; La Nauze et al. 1970, 1977; Olsen et al. 1992). In this catabolic pathway, 2-AEP is converted to 2-PnAA by the enzyme 2-AEP pyruvate aminotransferase, followed by a hydrolytic cleavage of PnAA catalyzed by the enzyme phosphonoacetaldehyde hydrolase (a phosphonatase)to form inorganic phosphate $(\mathrm{Pi})$ and acetaldehyde.

Nowadays, it is known that many microorganisms, mainly bacteria, but also yeasts and fungi, can catabolize phosphonates (Kononova and Nesmeyanova 2002; Fox and Mendz 2006; Kamat and Raushel 2013; Seweryn et al. 2015; Sosa et al. 2017). In recent years, the interest in this catabolic process has been widely revised due to the large amount of artificially synthetized organophosphonates that are accumulated in the environment. In this context, microorganism could be used as biological remedies to degrade phosphonates. Organisms can usethese compounds as a source of $\mathrm{Pi}$, but also as a source of other elements such as nitrogen and carbon (Kononova and Nesmeyanova 2002; Horsman and Zechel 2017). 
Three groups of enzymes have been already identified which are implicatedin phosphonates degradation. The first group includes the substrate-specific phosphonates hydrolases, to which phosphonoacetaldehyde, phosphonoacetate and phosphonopyruvate hydrolases belongs to(Kamat and Raushel 2013). A second group is the C-P lyase, which can catabolize a broad range of substrates including alkyl, amino-alkyl and aryl phosphonates (Wackett et al. 1987; Schowanek and Verstraete 1990). The third group is related with an oxidative process using an Fe(II)-dependent mechanism (McSorley et al. 2012; Peck and van der Donk 2013).

Within the group of the hydrolases, phosphonoacetaldehyde hydrolase (also known as phosphonatase) is involved in the degradation of PnAA to produce acetaldehyde and $\mathrm{Pi}$; its encoding genes are members of the Pho regulon (Lee et al. 1992).Thus, the activity of this enzyme increases under $\mathrm{Pi}$ starvation. On the other hand, phosphonoacetate hydrolase catalyzes the formation of acetate and orthophosphate from phosphonoacetate, while phosphonopyruvate hydrolase converts phosphonopyruvate to pyruvate and orthophosphate (Peck and van der Donk 2013).The latter enzyme belongs to the pepm/isocitrate lyase superfamily and, interestingly, it shares homology with pepm (Chen et al. 2006; Peck and van der Donk 2013).

C-P lyase is mainly involved in the degradation of different organophosphonates to release $\mathrm{Pi}$ and alkanes, its encoding genes are also members of the Pho regulon (Kononova and Nesmeyanova 2002). The C-P lyase has been recently described as a core complex, in which four proteins are assembledtogether and associated with another one, called PhnK, to form a complex structure with two potential active sites that modulates the $\mathrm{C}-\mathrm{P}$ bond cleavage in E. coli(Seweryn et al. 2015; Zechel 2016). C-P lyase enzymes are mainly found in gram-negative bacteria belonging to the classes of Arthrobacteriaceae, Bacillaceae, Rhodobacteriaceae, Alcaligenaceae, Pseudomonadaceae, Enterobacteriaceae (Escherichia, Enterobacter, Klebsiella, Kluyvera), and Rhizobiaceae (Rhizobium, Agrobacterium) (Wackett et al. 1987; Kononova and Nesmeyanova 2002). Recently, the high abundance of phosphonate degrading $\mathrm{C}-\mathrm{P}$ lyase mechanism in marine bacteria was demonstrated (Sosa et al. 2017). 
Within the third group of phosphonates catabolic process are the enzymes related with an oxidative mechanism specific for the most abundant phosphonate: 2-AEP. In this process, 2-AEP is hydroxylated to produce 2-amino-1-HEP followed by the $\mathrm{C}-\mathrm{P}$ bond cleavage catalyzed by a special hydrolase to yield $\mathrm{Pi}$ and glycine.This hydrolase requires $\mathrm{Fe}$ and $\mathrm{O}_{2}$ to oxidase the substrates (McSorley et al. 2012; Peck and van der Donk 2013).

\section{Concluding remarks}

Phosphonates are considered as ancient molecules with unusual biochemistry synthetized by organisms such as bacteria and marine invertebrates. In the case of fungi, only one phosphonate was discovered some time ago (Takeuchi et al. 1989). The biosynthetic pathways of some phosphonates have been already described, mainly in bacteria, from where several bioactive phosphonates were identified and characterized for their use in medicine and agriculture (Seto et al. 1999; Metcalf and van der Donk 2009; Ju et al. 2015; Horsman and Zechel 2017). Interestingly, the first biosynthetic steps are conserved among species being pepm and ppd the responsible enzymes in most species (Horsman and Zechel 2017).

Despite the extensive research performed, the biological role of these compounds for the producing organism is still not clear. For instance, organisms in which phosphonates are part of membrane phosphonolipids andphosphonoglycans, a host recognition function has been pointed out (Kittredge and Roberts 1969; Kim et al. 1998). On the other hand, bioactive phosphonates could be implicated in defense against other organisms, due to the $\mathrm{C}-\mathrm{P}$ bond stability and their enzymatic inhibitor characteristic.

Recent evidence suggests that the number of phosphonates on Earth has been underestimated (Yu et al. 2013; Ju et al. 2014; Horsman and Zechel 2017).Accordingly, the number of fungal species capable of biosynthesize phosphonates could be higher than expected. The case of fosfonochlorin,the only fungal phosphonate described so far, was the starting point for the present study. 


\section{Hypothesis, objectives and outline of the thesis}

We hypothesize that, based on the collected evidence, phosphonates biosynthesis is a conserved process in Fusarium and that more than one fungal phosphonate with a still unknown biological function could exist.

The main objectives of this study were to (1) demonstrate the genomic potential of Fusarium to biosynthesize phosphonates, (2) clarify their biological function in the fungus and (3) identify some of these compounds in Fusarium cultures. To achieve this, the phosphonates genomic cluster in Fusarium spp. was identified and the main enzymes involved in phosphonates biosynthesis (pepm and ppd) were in silico characterized. The expression of some of the identified genes were evaluated during bacteria- $F$. oxysporum interaction in order to determine whether the genes are active (chapter 2). The biological function of phosphonates in $F$. oxysporum was investigated using phosphonates-disrupted fungal strains, generated in the present study. The knock-outs strains together with the wild type strain were used against different organisms to determine a phosphonate-related effect in the evaluated species (gram positive and negative bacteria, mycoparasitic fungi and mealworms) (Chapter 3). Finally, some potentially novel phosphonates were induced, extracted and detected in $F$. oxysporum and $F$. avenaceum liquid cultures using hydrophilic interaction liquid chromatography (HILIC) coupled to ESI-MS (Chapter 4).

\section{References}

Bai G, Shaner G (1996) Variation in Fusarium graminearum and cultivar resistance to wheat scab. Plant Dis 80:975-979

Bauer A, Luetjohann J, Rohn S, et al (2017) Determination of fosetyl and phosphonic acid at $0.010 \mathrm{mg} / \mathrm{kg}$ level by ion chromatography tandem mass spectrometry (IC-MS/MS). J Agric Food Chem 66:346-350

Bertani G (1951) Studies on lysogenesis. I. The mode of phage liberation by lysogenic Escherichia coli. J Bacteriol 62:293-300

Biasini M, Bienert S, Waterhouse A, et al (2014) SWISS-MODEL: modelling protein tertiary and quaternary structure using evolutionary information. Nucleic Acids Res 42:W252-W258

Black DM, Thompson DE, Bauer DC, et al (2000) Fracture risk reduction with alendronate 
in women with osteoporosis: the fracture intervention trial. J Clin Endocrinol Metab $85: 4118-4124$

Blodgett JA, Zhang JK, Yu X, Metcalf WW (2016) Conserved biosynthetic pathways for phosalacine, bialaphos and newly discovered phosphonic acid natural products. $\mathbf{J}$ Antibiot (Tokyo) 69:15-25

Blodgett JA V, Zhang JK, Metcalf WW (2005) Molecular cloning, sequence analysis, and heterologous expression of the phosphinothricin tripeptide biosynthetic gene cluster from Streptomyces viridochromogenes DSM 40736. Antimicrob Agents Chemother 49:230-40

Borisova SA, Circello BT, Zhang JK, et al (2010) Biosynthesis of rhizocticins, antifungal phosphonate oligopeptides produced by Bacillus subtilis ATCC6633. Chem Biol $17: 28-37$

Bowman E, McQueney M, Barry RJ, Dunaway-Mariano D (1988) Catalysis and thermodynamics of the phosphoenolpyruvate/phosphonopyruvate rearrangement. Entry into the phosphonate class of naturally occurring organophosphorus compounds. J Am Chem Soc 110:5575-5576

Bowman ED, McQueney MS, Scholten JD, Dunaway-Mariano D (1990) Purification and characterization of the Tetrahymena pyriformis $\mathrm{P}-\mathrm{C}$ bond forming enzyme phosphoenolpyruvate phosphomutase. Biochemistry 29:7059-7063

Brandfass C, Karlovsky P (2008) Upscaled CTAB-based DNA extraction and real-time PCR assays for Fusarium culmorum and F. graminearum DNA in plant material with reduced sampling error. Int J Mol Sci 9:2306-2321

Brown DW, Butchko RAE, Busman M, Proctor RH (2007) The Fusarium verticillioides FUM gene cluster encodes a $\mathrm{Zn}(\mathrm{II}) 2 \mathrm{Cys} 6$ protein that affects FUM gene expression and fumonisin production. Eukaryot Cell 6:1210-8

Bustin SA, Benes V, Garson JA, et al (2009) The MIQE guidelines: minimum information for publication of quantitative real-time PCR experiments. Clin Chem 55:611-22

Buszewski B, Noga S (2012) Hydrophilic interaction liquid chromatography (HILIC)-a powerful separation technique. Anal Bioanal Chem 402:231-247

Cech NB, Enke CG (2001) Practical implications of some recent studies in electrospray ionization fundamentals. Mass Spectrom Rev 20:362-387 
Chen CCH, Han Y, Niu W, et al (2006) Structure and kinetics of phosphonopyruvate hydrolase from Voriovorax sp. Pal2: new insight into the divergence of catalysis within the PEP mutase/isocitrate lyase superfamily. Biochemistry 45:11491-11504

Chomczynski P, Sacchi N (2006) The single-step method of RNA isolation by acid guanidinium thiocyanate-phenol-chloroform extraction: twenty-something years on. Nat Protoc 1:581-585

Cioni JP, Doroghazi JR, Ju K-S, et al (2014) Cyanohydrin phosphonate natural product from Streptomyces regensis. J Nat Prod 77:243-249

Circello BT, Eliot AC, Lee J-H, et al (2010) Molecular cloning and heterologous expression of the dehydrophos biosynthetic gene cluster. Chem Biol 17:402-411

Covert SF, Kapoor P, Lee M, et al (2001) Agrobacterium tumefaciens-mediated transformation of Fusarium circinatum. Mycol Res 105:259-264

Creamer JR, Bostock RM (1986) Characterization and biological activity of Phytophthora infestans phospholipids in the hypersensitive response of potato tuber. Physiol Mol Plant Pathol 28:215-225

Cubbon S, Antonio C, Wilson J, Thomas-Oates J (2010) Metabolomic applications of HILIC-LC-MS. Mass Spectrom Rev 29:671-684

de Groot MJA, Bundock P, Hooykaas PJ., Beijersbergen AGM (1998) Agrobacterium tumefaciens-mediated transformation of filamentous fungi. Nat Biotechnol 16:839842

Demain AL, Vaishnav P (2009) Production of recombinant proteins by microbes and higher organisms. Biotechnol Adv 27:297-306

Duyvesteijn RGE, Van Wijk R, Boer Y, et al (2005) Frp1 is a Fusarium oxysporum F-box protein required for pathogenicity on tomato. Mol Microbiol 57:1051-1063

Eliot AC, Griffin BM, Thomas PM, et al (2008) Cloning, expression, and biochemical characterization of Streptomyces rubellomurinus genes required for biosynthesis of antimalarial compound FR900098. Chem Biol 15:765-770

Evans BS, Zhao C, Gao J, et al (2013) Discovery of the antibiotic phosacetamycin via a new mass spectrometry-based method for phosphonic acid detection. ACS Chem Biol 8:908-913 
Ferguson CG, Gorin BI, Thatcher GRJ (2000) Design of novel derivatives of phosphonoformate (Foscarnet) as prodrugs and antiviral agents. J Org Chem 65:12181221

Finn RD, Attwood TK, Babbitt PC, et al (2017) InterPro in 2017-beyond protein family and domain annotations. Nucleic Acids Res 45:D190-D199

Fox EM, Mendz GL (2006) Phosphonate degradation in microorganisms. Enzyme Microb Technol 40:145-150

Frandsen RJN (2011) A guide to binary vectors and strategies for targeted genome modification in fungi using Agrobacterium tumefaciens-mediated transformation. $\mathbf{J}$ Microbiol Methods 87:247-262

Gao J, Ju K-S, Yu X, et al (2014) Use of a phosphonate methyltransferase in the identification of the fosfazinomycin biosynthetic gene cluster. Angew Chemie Int Ed 53:1334-1337

Geisen R, Schmidt-Heydt M, Karolewiez A (2006) A gene cluster of the ochratoxin A biosynthetic genes in Penicillium. Mycotoxin Res 22:134-141

Georgiou G, Segatori L (2005) Preparative expression of secreted proteins in bacteria: status report and future prospects. Curr Opin Biotechnol 16:538-545

Gioumouxouzis CI, Kouskoura MG, Markopoulou CK (2015) Negative electrospray ionization mode in mass spectrometry: A new perspective via modeling. $\mathrm{J}$ Chromatogr B 998-999:97-105

Glish GL, Vachet RW (2003) The basics of mass spectrometry in the twenty-first century. Nat Rev Drug Discov 2:140-150

Greco G, Letzel T (2013) Main interactions and influences of the chromatographic parameters in HILIC separations. J Chromatogr Sci 51:684-693

Gribble GW (2004) Natural organohalogens. Science Dossiers, Brussels, Belgium

Gunji S, Arima K, Beppu T (1983) Screening of antifungal antibiotics according to activities inducing morphological abnormalities. Agric Biol Chem 47:2061-2069

Guo Z, Döll K, Dastjerdi R, et al (2014) Effect of fungal colonization of wheat grains with Fusarium spp. on food choice, weight gain and mortality of meal beetle larvae (Tenebrio molitor). PLoS One 9:e100112 
Hanahan D (1983) Studies on transformation of Escherichia coli with plasmids. J Mol Biol $166: 557-580$

Hao Z, Xiao B, Weng N (2008) Impact of column temperature and mobile phase components on selectivity of hydrophilic interaction chromatography (HILIC). J Sep Sci 31:1449-1464

Hemström P, Irgum K (2006) Hydrophilic interaction chromatography. J Sep Sci 29:17841821

Henriksen T, Juhler RK, Svensmark B, Cech NB (2005) The relative influences of acidity and polarity on responsiveness of small organic molecules to analysis with negative ion electrospray ionization mass spectrometry (ESI-MS). J Am Soc Mass Spectrom $16: 446-455$

Hidaka T, Mori M, Imai S, et al (1989) Studies on the biosynthesis of bialaphos (SF-1293). 9. Biochemical mechanism of C-P bond formation in bialaphos: Discovery of phosphoenolpyruvate phosphomutase which catalyzes the formation of phosphonopyruvate from phosphoenolpyruvete. J Antibiot (Tokyo) 42:491-494

Horiguchi M, Kandatstu M (1959) Isolation of 2-aminoethane phosphonic acid from rumen protozoa. Nature 184:901-902

Horsman GP, Zechel DL (2017) Phosphonate biochemistry. Chem Rev 117:5704-5783

Hothorn T, Bretz F, Westfall P (2008) Simultaneous inference in general parametric models. Biometrical J 50:346-363

Hove-Jensen B, Zechel DL, Jochimsen B (2014) Utilization of glyphosate as phosphate source: biochemistry and genetics of bacterial carbon-phosphorus lyase. Microbiol Mol Biol Rev 78:176-97

Huang Z, Wang K-KA, Lee J, van der Donk WA (2015) Biosynthesis of fosfazinomycin is a convergent process. Chem Sci 6:1282-1287

Jia Y, Lu Z, Huang K, et al (1999) Insight into the mechanism of phosphoenolpyruvate mutase catalysis derived from site-directed mutagenesis studies of active site residues. Biochemistry 38:14165-14173

Ju K-S, Doroghazi JR, Metcalf WW (2014) Genomics-enabled discovery of phosphonate natural products and their biosynthetic pathways. J Ind Microbiol Biotechnol 41:345356 
Ju K-S, Gao J, Doroghazi JR, et al (2015) Discovery of phosphonic acid natural products by mining the genomes of 10,000 actinomycetes. Proc Natl Acad Sci U S A $112: 12175-80$

Kamat SS, Raushel FM (2013) The enzymatic conversion of phosphonates to phosphate by bacteria. Curr Opin Chem Biol 17:589-596

Katayama N, Tsubotani S, Nosaki Y, et al (1990) Fosfadecin and fosfocytocin, new nucleotide antibiotics produced by bacteria. J Antibiot (Tokyo) 43:238-246

Kaysser L, Bernhardt P, Nam S-J, et al (2012) Merochlorins A-D, cyclic meroterpenoid antibiotics biosynthesized in divergent pathways with vanadium-dependent chloroperoxidases. J Am Chem Soc 134:11988-11991

Kennedy K, Thompson G (1970) Phosphonolipids: localization in surface membranes of Tetrahymena. Science (80- ) 168:989-991

Kim A, Kim J, Martin BM, Dunaway-Mariano D (1998) Isolation and characterization of the carbon-phosphorus bond-forming enzyme phosphoenolpyruvate mutase from the mollusk Mytilus edulis. J Biol Chem 273:4443-8

Kim AD, Baker AS, Dunaway-Mariano D, et al (2002) The 2-aminoethylphosphonatespecific transaminase of the 2-aminoethylphosphonate degradation pathway. $\mathbf{J}$ Bacteriol 184:4134-40

Kim J-E, Jin J, Kim H, et al (2006) GIP2, a putative transcription factor that regulates the aurofusarin biosynthetic gene cluster in Gibberella zeae. Appl Environ Microbiol $72: 1645-52$

Kim J, Dunaway-Mariano D (1996) Phosphoenolpyruvate mutase catalysis of phosphoryl transfer in phosphoenolpyruvate: kinetics and mechanism of phosphorus-carbon bond formation. Biochemistry 35:4628-4635

Kim SY, Ju K-S, Metcalf WW, et al (2012) Different biosynthetic pathways to fosfomycin in Pseudomonas syringae and Streptomyces species. Antimicrob Agents Chemother $56: 4175-83$

Kittredge JS, Roberts E (1969) A carbon-phosphorus bond in nature. Science (80- ) $164: 37-42$

Kleinboelting N, Huep G, Appelhagen I, et al (2015) The structural features of thousands of T-DNA insertion sites are consistent with a double- strand break repair-based 
insertion mechanism. Mol Plant 8:1651-1664

Kononova S V., Nesmeyanova MA (2002) Phosphonates and their degradation by microorganisms. Biochem 67:184-195

Koukol O, Novák F, Hrabal R (2008) Composition of the organic phosphorus fraction in basidiocarps of saprotrophic and mycorrhizal fungi. Soil Biol Biochem 40:2464-2467

Koukol O, Novák F, Hrabal R, Vosátka M (2006) Saprotrophic fungi transform organic phosphorus from spruce needle litter. Soil Biol Biochem 38:3372-3379

La Nauze JM, Coggins JR, Dixon HB (1977) Aldolase-like imine formation in the mechanism of action of phosphonoacetaldehyde hydrolase. Biochem J 165:409-11

La Nauze JM, Rosenberg H, Shaw DC (1970) The enzymic cleavage of the carbonphosphorus bond: Purification and properties of phosphonatase. Biochim Biophys Acta - Enzymol 212:332-350

Lea P, Joy K, Ramos J, Guerrero M (1984) The action of 2-amino-4-(methylphosphinyl)butanoic acid (phosphinothricin) and its 2-oxo-derivative on the metabolism of cyanobacteria and higher plants. Phytochemistry 23:1-6

Lee KS, Metcalf WW, Wanner BL (1992) Evidence for two phosphonate degradative pathways in Enterobacter aerogenes. J Bacteriol 174:2501-10

Lelliott RA, Stead DE (1987) Methods for the diagnosis of bacterial diseases of plants. Blackwell Scientific Publications, Oxford, UK

Liang C-R, Rosenberg H (1968) On the distribution and biosynthesis of 2aminoethylphosphonate in two terrestrial molluscs. Comp Biochem Physiol 25:673681

Liu S, Lu Z, Han Y, et al (2004) Conformational flexibility of PEP mutase. Biochemistry 43:4447-4453

Liu S, Lu Z, Jia Y, et al (2002) Dissociative phosphoryl transfer in PEP mutase catalysis: structure of the enzyme/sulfopyruvate complex and kinetic properties of mutants. Biochemistry 41:10270-10276

Lutz MP, Feichtinger G, Défago G, Duffy B (2003) Mycotoxigenic Fusarium and deoxynivalenol production repress chitinase gene expression in the biocontrol agent Trichoderma atroviride P1. Appl Environ Microbiol 69:3077-84 
Maciejczyk E, Wieczorek D, Zwyrzykowska A, et al (2015) Phosphorus profile of basidiomycetes. Phosphorus Sulfur Silicon Relat Elem 190:763-768

MacPherson S, Larochelle M, Turcotte B (2006) A fungal family of transcriptional regulators: the zinc cluster proteins. Microbiol Mol Biol Rev 70:583-604

Maier F, Malz S, Losch A, et al (2005) Development of a highly efficient gene targeting system for using the disruption of a polyketide synthase gene as a visible marker. FEMS Yeast Res 5:653-662

Maile R, Fischesser G, Anderson M (1977) Thin-layer chromatographic separation of phosphonic acid derivatives. J Chromatogr 132:366-368

Marquardt JL, Brown ED, Lane WS, et al (1994) Kinetics, stoichiometry, and identification of the reactive thiolate in the inactivation of UDP-GlcNAc enolpyruvoyl transferase by the antibiotic fosfomycin. Biochemistry 33:10646-10651

Martinez A, Tyson GW, Delong EF (2010) Widespread known and novel phosphonate utilization pathways in marine bacteria revealed by functional screening and metagenomic analyses. Environ Microbiol 12:222-238

McGrath JW, Chin JP, Quinn JP (2013) Organophosphonates revealed: new insights into the microbial metabolism of ancient molecules. Nat Rev Microbiol 11:412-419

McSorley FR, Wyatt PB, Martinez A, et al (2012) PhnY and PhnZ comprise a new oxidative pathway for enzymatic cleavage of a carbon-phosphorus bond. J Am Chem Soc $134: 8364-8367$

Metcalf WW, van der Donk WA (2009) Biosynthesis of phosphonic and phosphinic acid natural products. Annu Rev Biochem 78:65-94

Meyer V (2008) Genetic engineering of filamentous fungi — Progress, obstacles and future trends. Biotechnol Adv 26:177-185

Michielse CB, Hooykaas PJJ, van den Hondel CAMJJ, Ram AFJ (2005) Agrobacteriummediated transformation as a tool for functional genomics in fungi. Curr Genet 48:117

Nakashita H, Watanabe K, Hara O, et al (1997) Studies on the biosynthesis of bialaphos. Biochemical mechanism of C-P bond formation: discovery of phosphonopyruvate decarboxylase which catalyzes the formation of phosphonoacetaldehyde from phosphonopyruvate. J Antibiot (Tokyo) 50:212-219 
Nielsen ML, Pustinger J V., Strobel J (1964) Phosphorus-31 nuclear magnetic resonance chemical shifts of phosphorus compounds. J Chem Eng Data 9:167-170

Olsen DB, Hepburn TW, Lee S, et al (1992) Investigation of the substrate binding and catalytic groups of the P-C bond cleaving enzyme, phosphonoacetaldehyde hydrolase. Arch Biochem Biophys 296:144-151

Omura S, Murata M, Hanaki H, et al (1984) Phosalacine, a new herbicidal antibiotic containing phosphinothricin. Fermentation, isolation, biological activity and mechanism of action. J Antibiot (Tokyo) 37:829-835

Onorato JM, Langish R, Bellamine A, Shipkova P (2010) Applications of HILIC for targeted and non-targeted LC/MS analyses in drug discovery. J Sep Sci 33:923-929

Pan Z, Raftery D (2007) Comparing and combining NMR spectroscopy and mass spectrometry in metabolomics. Anal Bioanal Chem 387:525-527

Park BK, Hirota A, Sakai H (1977) Studies on new antimetabolite produced by microorganism. III. Structure of plumbemycin A and B, antagonists of L-threonine from Streptomyces plumbeus. Agric Biol Chem 41:573-579

Peck SC, van der Donk WA (2013) Phosphonate biosynthesis and catabolism: a treasure trove of unusual enzymology. Curr Opin Chem Biol 17:580-588

Pfaffl MW (2001) A new mathematical model for relative quantification in real-time RTPCR. Nucleic Acids Res 29:45e-45

Punt PJ, Dingemanse MA, Kuyvenhoven A, et al (1990) Functional elements in the promoter region of the Aspergillus nidulans gpdA gene encoding glyceraldehyde-3phosphate dehydrogenase. Gene 93:101-109

R Core Team (2017) R: A language and environment for statistical computing. R Found. Stat. Comput.

Rai M, Padh H (2001) Expression systems for production of heterologous proteins. Curr Sci 80:1121-1128

Rao RN, Allen NE, Hobbs JN, et al (1983) Genetic and enzymatic basis of hygromycin B resistance in Escherichia coli. Antimicrob Agents Chemother 24:689-95

Reeves DS (1994) Fosfomycin trometamol. J Antimicrob Chemother 34:853-858

Rice P, Longden I, Bleasby A (2000) EMBOSS: the European molecular biology open 
software suite. Trends Genet 16:276-277

Rosano GL, Ceccarelli EA (2014) Recombinant protein expression in Escherichia coli: advances and challenges. Front Microbiol 5:172

Roseberg H, La Nauze JM (1967) The metabolism of phosphanates by microorganisms. The transport of aminoethylphosphonic acid in Basillus cereus. Biochim Biophys Acta 141:79-90

Rost B (1999) Twilight zone of protein sequence alignments. Protein Eng Des Sel 12:8594

Sander C, Schneider R (1991) Database of homology-derived protein structures and the structural meaning of sequence alignment. Proteins Struct Funct Genet 9:56-68

Sarkar M, Hamilton CJ, Fairlamb AH (2003) Properties of phosphoenolpyruvate mutase, the first enzyme in the aminoethylphosphonate biosynthetic pathway in Trypanosoma cruzi. J Biol Chem 278:22703-8

Schiesel S, Lämmerhofer M, Lindner W (2010) Multitarget quantitative metabolic profiling of hydrophilic metabolites in fermentation broths of $\beta$-lactam antibiotics production by HILIC-ESI-MS/MS. Anal Bioanal Chem 396:1655-1679

Schowanek D, Verstraete W (1990) Phosphonate utilization by bacterial cultures and enrichments from environmental samples. Appl Environ Microbiol 56:895-903

Seidel HM, Freeman S, Seto H, Knowles JR (1988) Phosphonate biosynthesis: isolation of the enzyme responsible for the formation of a carbon-phosphorus bond. Nature $335: 457-458$

Seidel HM, Pompliano DL, Knowles JR (1992) Phosphonate biosynthesis: molecular cloning of the gene for phosphoenolpyruvate mutase from Tetrahymena pyriformis and overexpression of the gene product in Escherichia coli. Biochemistry 31:25982608

Seto H, Imai S, Tsuruoka T, et al (1982) Studies on the biosynthesis of bialaphos (SF1293) 1. Incorporation of $13 \mathrm{C}$ - and $2 \mathrm{H}$-labeled precursors into bialaphos. J Antibiot (Tokyo) 35:1719-1721

Seto H, Kuzuyama T, Seto H, Kuzuyama T (1999) Bioactive natural products with carbonphosphorus bonds and their biosynthesis. Nat Prod Rep 16:589-596 
Seweryn P, Van LB, Kjeldgaard M, et al (2015) Structural insights into the bacterial carbon-phosphorus lyase machinery. Nature 525:68-72

Shao Z, Blodgett JA V, Circello BT, et al (2008) Biosynthesis of 2hydroxyethylphosphonate, an unexpected intermediate common to multiple phosphonate biosynthetic pathways. J Biol Chem 283:23161-8

Sievers F, Wilm A, Dineen D, et al (2011) Fast, scalable generation of high-quality protein multiple sequence alignments using Clustal Omega. Mol Syst Biol 7:539

Sosa OA, Repeta DJ, Ferrón S, et al (2017) Isolation and characterization of bacteria that degrade phosphonates in marine dissolved organic matter. Front Microbiol 8:1786

Stead MB, Agrawal A, Bowden KE, et al (2012) RNAsnap : a rapid, quantitative and inexpensive, method for isolating total RNA from bacteria. Nucleic Acids Res 40:e156-e156

Stutter MI, Shand CA, George TS, et al (2015) Land use and soil factors affecting accumulation of phosphorus species in temperate soils. Geoderma 257-258:29-39

Suchfort R (2016) Biological detoxification of enniatins. Georg-August-Universität Göttingen

Sugui JA, Chang YC, Kwon-Chung KJ (2005) Agrobacterium tumefaciens-mediated transformation of Aspergillus fumigatus: an efficient tool for insertional mutagenesis and targeted gene disruption. Appl Environ Microbiol 71:1798-802

Takahashi E, Kimura T, Nakamura K, et al (1995) Phosphonothrixin, a novel herbicidal antibiotic produced by Saccharothrix sp. ST-888. I. Taxonomy, fermentation, isolation and biological Properties. J Antibiot (Tokyo) 48:1124-1129

Takeuchi M, Nakajima M, Ogita T, et al (1989) Fosfonochlorin, a new antibiotic with spheroplast forming activity. J Antibiot (Tokyo) 42:198-205

Tate KR, Newman RH (1982) Phosphorus fractions of a climosequence of soils in New Zealand tussock grassland. Soil Biol Biochem 14:191-196

Terpe K (2006) Overview of bacterial expression systems for heterologous protein production: from molecular and biochemical fundamentals to commercial systems. Appl Microbiol Biotechnol 72:211-222

The Gene Ontology Consortium (2015) Gene Ontology Consortium: going forward. 
Nucleic Acids Res 43:D1049-D1056

Turner BL, Baxter R, Mahieu N, et al (2004) Phosphorus compounds in subarctic

Fennoscandian soils at the mountain birch (Betula pubescens)-tundra ecotone. Soil Biol Biochem 36:815-823

Utermark J, Karlovsky P (2007) Role of zearalenone lactonase in protection of

Gliocladium roseum from fungitoxic effects of the mycotoxin zearalenone. Appl

Environ Microbiol 73:637-42

Vary PS, Biedendieck R, Fuerch T, et al (2007) Bacillus megaterium-from simple soil bacterium to industrial protein production host. Appl Microbiol Biotechnol 76:957967

Wackett LP, Shames SL, Venditti CP, Walsh CT (1987) Bacterial carbon-phosphorus lyase: products, rates, and regulation of phosphonic and phosphinic acid metabolism. J Bacteriol 169:710-7

Wassef MK, Hendrix JW (1977) Ceramide aminoethylphosphonate in the fungus Pythium prolatum. Biochim Biophys Acta - Lipids Lipid Metab 486:172-178

Weld RJ, Plummer KM, Carpenter MA, Ridgway HJ (2006) Approaches to functional genomics in filamentous fungi. Cell Res 16:31-44

Wendler C, Barniske M, Wild A (1990) Effect of phosphinothricin (glufosinate) on photosynthesis and photorespiration of C3 and C4 plants. Photosynth Res 24:55-61

Woloshuk CP, Foutz KR, Brewer JF, et al (1994) Molecular characterization of aflR, a regulatory locus for aflatoxin biosynthesis. Appl Environ Microbiol 60:2408-14

Woo G, Tomlinson G, Nishikawa Y, et al (2010) Tenofovir and entecavir are the most effective antiviral agents for chronic hepatitis B: a systematic review and bayesian meta-analyses. Gastroenterology 139:1218-1229.e5

Woodyer RD, Li G, Zhao H, van der Donk WA (2007) New insight into the mechanism of methyl transfer during the biosynthesis of fosfomycin. Chem Commun 0:359-361

Woodyer RD, Shao Z, Thomas PM, et al (2006) Heterologous production of fosfomycin and identification of the minimal biosynthetic gene cluster. Chem Biol 13:1171-1182

Xu D, Guo H, Yun L, York DM (2005) Theoretical studies of dissociative phosphoryl transfer in interconversion of phosphoenolpyruvate to phosphonopyruvate: solvent 
effects, thio effects, and implications for enzymatic reactions. J Phys Chem B 109:13827-13834

Yin W, Keller NP (2011) Transcriptional regulatory elements in fungal secondary metabolism. J Microbiol 49:329-339

Yu X, Doroghazi JR, Janga SC, et al (2013) Diversity and abundance of phosphonate biosynthetic genes in nature. Proc Natl Acad Sci U S A 110:20759-64

Zechel DL (2016) PhnK: another piece of the carbon-phosphorus lyase puzzle. Structure 24:3-4

Zeleznick L, Myers T, Titchener E (1963) Growth of Escherichia coli on methyl-and ethylphosphonic acids. Biochim Biophys Acta 78:547-550

Zhang G, Dai J, Lu Z, Dunaway-Mariano D (2003) The phosphonopyruvate decarboxylase from Bacteroides fragilis. J Biol Chem 278:41302-8 


\title{
CHAPTER 2. Identification of the phosphonates-genome cluster in $F$. oxysporum and the possible biosynthetic pathway for fosfonochlorin
}

\begin{abstract}
Natural phosphonates are produced by several organisms, including bacteria, mollusk and protozoa, however only one study on the biosynthesis of one of these compounds in fungi exist, called fosfonochlorin. Bioactive phosphonates are mainly described from bacteria with antibiotic, herbicidal and antifungal activity. The genomic cluster and the biosynthetic pathways have been already described for some phosphonates. Phosphoenolpyruvate phosphomutase (pepm) and phosphonopyruvate decarboxylase (ppd) are the main enzymes involved in phosphonates biosynthesis. In the present study, we describe the presence of pepm-and ppd-encoding genes in some fungal species including Fusarium spp. The conserved regions within pepm protein, which have been used as molecular marker to predict phosphonates producers, are present in Fusarium spp. pepm protein. The similarity of $F$. oxysporum pepm and ppd sequences with the same enzyme from phylogenetically distant (bacteria, mollusk and protozoa) phosphonates producers is $31-40 \%$ and $43-53 \%$ respectively. Looking at the pepm gene neighbors in F. oxysporum genome we were able to identify the putative phosphonate cluster and to propose a biosynthetic pathway for fosfonochlorin in this fungus, which resembles that ones from bacterial phosphonates. Moreover, we demonstrated that the genes were up-regulated under bacteria-fungal interaction, supporting the fact that the genes are active, and that one of the fungal phosphonates functions could be predicted as a defense compounds against bacteria.
\end{abstract}

Keywords: phosphonates, C-P compounds, Fusarium spp., genomic cluster, biosynthetic pathway, gene expression 


\section{Introduction}

Phosphonates are molecules containing the stable $\mathrm{C}-\mathrm{P}$ bond. They can be of biogenic origin or synthetically produced. Natural phosphonates are present in the cell surfaces of some organisms such as bacteria [e.g., the human colon parasite Bacteroides fragilis, (Zhang et al. 2003)], mollusk [e.g., the blue mussel Mytilus edulis(Kim et al. 1998)] and protozoa [e.g., the parasite Tetrahymena pyriformis(Kennedy and Thompson 1970; Seidel et al. 1992)]. However, many of them are bioactive compounds produced by bacteria (e.g.,Streptomyces hygroscopicus, S. viridochromogenes) (Ju et al. 2015). In fungi, there is only one publication in which a phosphonate called fosfonochlorin was described as a lowmolecular-weight metabolite with antibiotic activity (Takeuchi et al. 1989). Recent information suggests that the number of organisms that can produce phosphonates in nature has been until now underestimated (Yu et al. 2013; Ju et al. 2014; Horsman and Zechel 2017).

The biosynthetic pathways of some phosphonates have been already described (Peck and van der Donk 2013; Ju et al. 2014; Horsman and Zechel 2017).The first two steps of phosphonates biosynthesis share the same enzymes in most organisms. During these steps, phosphoenolpyruvate(PEP) is isomerized to phosphonopyruvate (PnPy) by the enzyme phosphoenolpyruvate mutase (pepm) (Figure 1). In a next reaction, PnPy is decarboxylated to form phosphonoacetaldehyde (PnAA) by the enzyme phosphonopyruvate decarboxylase (ppd), which moves the reaction forward since the equilibrium is in favor of PEP (Hidaka et al. 1989; Nakashita et al. 1997; Seto et al. 1999; Sarkar et al. 2003; Blodgett et al. 2005; Eliot et al. 2008; Ju et al. 2014).

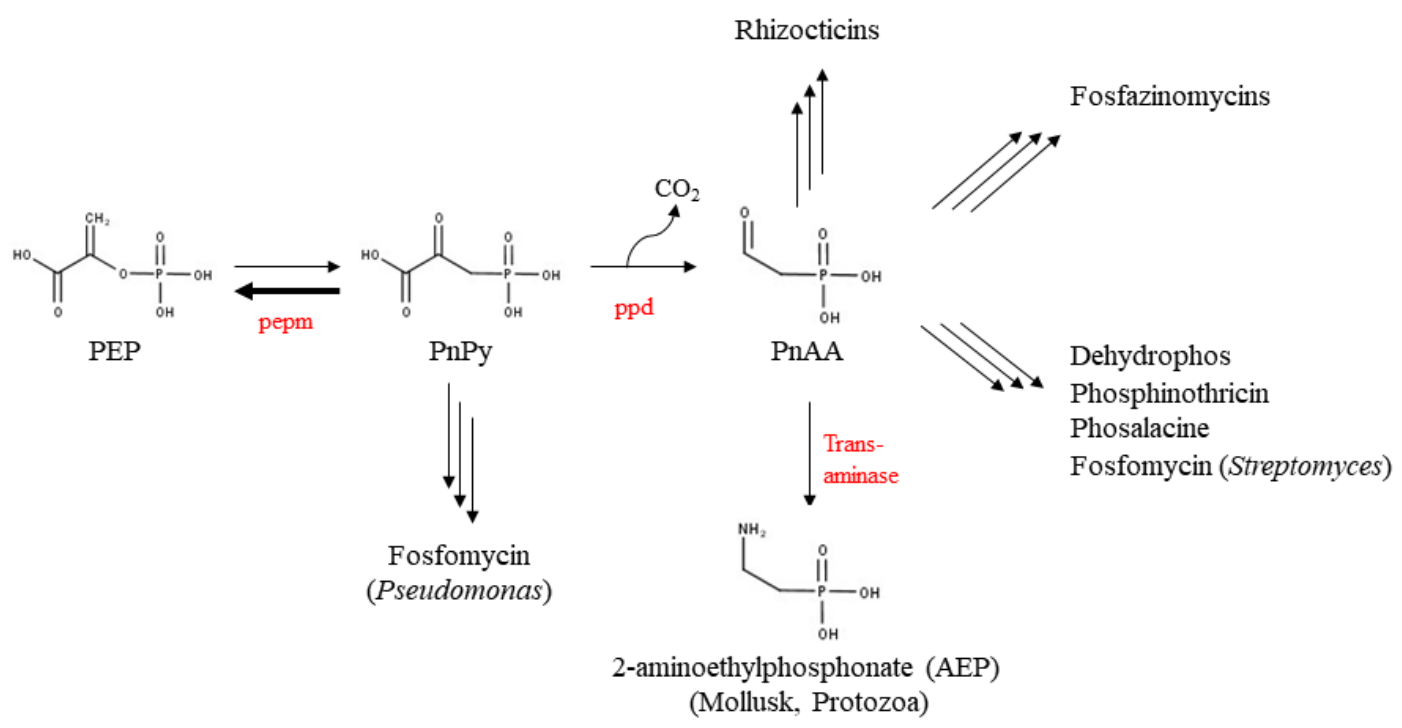


Figure 1. First steps of some phosphonates biosynthetic pathways

The steps, following the formation reaction of PnAA, are highly diverse amongst species. This acetaldehyde is located at the centralpoint from where the biosynthetic pathways diversify to form most of the already described phosphonates (for details see chapter 1). In the case of some bioactive molecules, PnAA can be reduced to either phosphonoacetate (PnA) or to hydroxyethylphosphonate (2-HEP). Further steps involve diverse enzymatic reactions.For instance, the next biosynthetic step in the phosphonate dehydrophos is the hydroxylation of 2-HEP to form dihydroxyethylphosphonate (DHEP) by a dioxygenase enzyme (Circello et al. 2010). In the case of fosfomycin (fromStreptomyces), 2-HEP is attacked by a methyl anion to produce 2-hydroxypropilphosphonate (HPP), the subsequently oxidation reaction of HPP produces fosfomycin (Woodyer et al. 2007).

Thanks to the great information obtained from genome sequences data and to the bioinformatic tools accessible nowadays, it is possible to presume the ability of an organism to biosynthesize a specific metabolite. Once homologous genes involved in a specific biosynthetic pathway are found and characterized inside a genomic cluster, one following step is to determine whether the genes are active and under which circumstances. In the specific case of phosphonates, genomic-based surveys have been used to predict the ability of an organism to produce these compounds. In this regard, the presence of the pepm gene in the genome and the highly conserved pepm protein catalytic motif: EDKXXXXXNS (Chen et al. 2006), have been used as molecular markers for this purpose(Yu et al. 2013; Cioni et al. 2014; Ju et al. 2015).

In the present chapter we identified the putative phosphonate cluster in $F$. oxysporum based on pepm and ppdproteins sequence characterization and on the presence of other proteins codified by pepm - and $p p d$-neighboring genes which are similar to those involved in phosphonate biosynthesis in bacteria. In this way, we found the potential genes involved in the biosynthesis of the already known fungal phosphonate fosfonochlorin. Additionally, we demonstrated that some of those genes, specifically the most important ones possibly related with phosphonates biosynthesis, are expressed in the fungus during $F$. oxysporumbacteria interaction. 
The main objective of this chapter was to identify the phosphonate genomic cluster in $F$. oxysporum and topropose a biosynthetic pathway for fosfonochlorin based on the genes inside the cluster and on their gene expression pattern.

\section{Material and methods}

\subsection{Identification of theputatively phosphonate genomic cluster in F.oxysporum}

Pepm and ppd proteins in F. oxysporumf.sp lycopersici 4287 were predicted by homology using as query the already revised protein sequences from the phosphonate producers $M$. edulis (UniProt acc. Number: P56839) and B. fragilis (UniProt acc. Number: EXZ28912) respectively. The pyruvate/phosphoenolpyruvate kinase-like protein domain in pepm wascorroborated using the protein sequence analysis and classification resource InterPro (Finn et al. 2017). The locus_taq identification name "Foxg_02666" and "Foxg_02662", for pepm and ppd genes respectively, from the National Center for Biotechnology Information (NCBI), were used to locate the genes position in the $F$. oxysporum genome. Gene sequences immediately before and after the pepm gene locus were retrieved and searched in UniProt (European Bioinformatics Institute, EMBL-EBI) to obtain the predicted protein function. The protein domains were identified using InterPro and the gene product function was predicted based on the Gene Ontology (GO) consortium (The Gene Ontology Consortium 2015).

Candidate phosphonatebiosynthesis-related protein sequences were retrieved and aligned against homologs from other fungal species and phosphonates producers using Clustal Omega (Sievers et al. 2011). Protein residues characterization were done based onJia et al. (1999)for pepm protein and on Zhang et al. (2003)for ppd protein. Percentage of amino acids identity and similarity between $F$. oxysporum proteins and others were obtained after a pairwise sequence alignment [EMBOSS Needle (Rice et al. 2000)] using EBLOSUM62 as matrix, gap penalty of 10 and extended penalty of 0.5 .

F. oxysporum pepm protein structure was predicted using as template the reviewed pepm protein from M. edulis(Liu et al. 2004). The modelling was done in the Swiss-Model workspace (Biasini et al. 2014). 


\subsection{Gene expression of phosphonate-related genes in $F$. oxysporum}

\subsubsection{Experiment using different bacteria}

In order to determine whether gram-negative or positive bacteria could influence the expression of the main gene related with phosphonates biosynthesis: pepm, the expression of the gene was evaluated after $24 \mathrm{~h}$ of $F$. oxysporum culturated with different bacteria, i.e. E. coli DH5a, P. syringae GSPB1142, X. carotae GSPB1792 and B. brevis. The experiment was carried out as follows: spores $\left(10^{3}\right)$ of $F$. oxysporum DSM62291 were cultivated on $10 \mathrm{ml}$ of liquid phosphonates induction medium (Takeuchi et al. 1989) and incubated at $180 \mathrm{rpm}$ and $28^{\circ} \mathrm{C}$. After $12-14$ days, $5 \mathrm{ml}$ of bacteria growing on liquid LB [lysogeny broth (Bertani 1951)] (for E. coli, P. syringae and B. brevis) or on PS (peptonesucrose) medium (Lelliott and Stead 1987) (for X. carotae) for 5 days were added into the fungal cultures. Three mycelium samples (biological replicates) from each treatment were collected before the addition of the bacteria $(0 \mathrm{~h})$ and after $24 \mathrm{~h}$.

\subsubsection{Experiment using only $X$. carotae}

A following gene expression experiment was performed in which $F$. oxysporum was cultivated only with $X$. carotae. The same protocol as described before was used however, in this case, samples were collected at several time points: $0 \mathrm{~h}$ (before addition of bacteria) and $2,4,8,12,16,24,36,48,72 \mathrm{~h}$ after the addition of the bacteria. Three samples were also collected at the same time points from control samples in which only PS liquid medium without bacteria was added to the fungal liquid cultures.

\subsubsection{RNA extraction and cDNA synthesis}

Collected mycelium from each treatment, was vacuum filtered, washed with demineralized water during filtering, and grinded immediately using liquid nitrogen. RNA was extracted based on (Stead et al. 2012)modified as follows: $600 \mu$ l of RNA extraction solution [95\% deionized formamide (RNAse free, Carl Roth $\mathrm{GmbH}$, Karlsruhe, Germany), $18 \mathrm{mM}$ EDTA, $0.025 \%$ SDS, and 1\% 2-mercaptoethanol] was added to approximately $10 \mathrm{mg}$ of grinded mycelium, vortex vigorously and incubated $7 \mathrm{~min}$ at $95^{\circ} \mathrm{C}$. Cells debris were centrifuged at $16000 \mathrm{~g}$ for $5 \mathrm{~min}$ at room temperature. The supernatant (400 $\mu 1)$ was transferred into the RNA precipitation mixture composed of $800 \mu 1$ of isobutanol, $400 \mu 1$ of $5 \mathrm{M}$ guanidine thiocyanate and $5 \mu 1$ of Co-Precipitant Pink (New England Bioline, London, UK). The mixture was centrifuged at $16000 \mathrm{~g}$ for $5 \mathrm{~min}$ at room temperature and the pellet was washed once using $75 \%$ ethanol. After drying for 8 minutes, the pellet was dissolved 
in $50 \mu \mathrm{l}$ of DEPC-treated water. Dissolved pellet was treated with $1 \mathrm{U}$ of DNase I (Thermo Scientific, Massachusetts, US) according to the company instructions and immediately frozen at $-80^{\circ} \mathrm{C}$. RNA (60-80 ng, 260/280>2) was reversed transcribed into cDNA in $10 \mu \mathrm{l}$ reaction mixture containing $1 \mathrm{x}$ reaction buffer, $10 \mu \mathrm{M}$ random hexamer primers, $10 \mathrm{U}$ of RiboLock RNase inhibitor, $1 \mathrm{mM}$ of dNTPs and $100 \mathrm{U}$ of RevertAid Reverse Transcriptase (all of them from Thermo Scientific, Massachusetts, US), the mixture was incubated at $25^{\circ} \mathrm{C}$ for $10 \mathrm{~min}, 42^{\circ} \mathrm{C}$ for $60 \mathrm{~min}$ and at $70^{\circ} \mathrm{C}$ for $10 \mathrm{~min}$ and stored at $-20^{\circ} \mathrm{C}$ until the analysis. cDNA was diluted 1 to 10 times, and employed as template to perform qRT-PCR using a CFX384 (Bio-Rad, California, US) thermocycler in $4 \mu 1$ of reaction mixture containing $1 \mathrm{x}$ reaction buffer [20 mM Tris- $\mathrm{HCl}, 10 \mathrm{mM}\left(\mathrm{NH}_{4}\right)_{2} \mathrm{SO}_{4}, 10 \mathrm{mM} \mathrm{KCl}$, $2 \mathrm{mM} \mathrm{MgSO}_{4}, 0.1 \%$ Triton $\left.\mathrm{X}-100, \mathrm{pH} 8.8\right], 4.5 \mathrm{mM}$ of $\mathrm{MgCl}_{2}, 100 \mu \mathrm{M}$ of dNTP, $0.3 \mu \mathrm{M}$ specific primers for phosphonates-related-genes in F. oxysporum (primers 1 to 12 in supplementary table 1), 0.1x of SyBr Green I (Molecular Probes, Eugene, Oregon, US), 0.1 $\mathrm{U}$ of taq polymerase (New England Bioline, London, UK) and $1 \mu \mathrm{l}$ of cDNA as a template. Reactions were performed on 384 well plates (Kisker Biotech GmbH, Steinfurt, Germany). PCR conditions were as follows: $95^{\circ} \mathrm{C}$ for $2 \mathrm{~min}, 35$ cycles of $94^{\circ} \mathrm{C}$ for $30 \mathrm{~s}, 60^{\circ} \mathrm{C}$ for $30 \mathrm{~s}$ and $68^{\circ} \mathrm{C}$ for $30 \mathrm{~s}$, with a final extension of $68^{\circ} \mathrm{C}$ for $15 \mathrm{~min}$ followed by melting curve analysis beginning at $95^{\circ} \mathrm{C}$ with decrement of $0.5^{\circ} \mathrm{C}$ to $55^{\circ} \mathrm{C}$.

\subsection{4. $\mathrm{qRT}$-PCR data analysis}

GAPDH (glyceraldehyde 3-phosphate dehydrogenase) and EFIA (elongation factor 1alpha) were used as reference genes using the primers 13 to 16 described in supplementary table 1. Baseline correction and threshold setting were done using the automatic calculation of the CFX Manager Software (Bio-Rad). The specificity of each primer was confirmed by the melting curves and by gel electrophoresis compared to positive and negative controls. Calibration curves were done for each gene based on (Pfaffl 2001) in duplicates: a set of five-fold dilutions of pooled cDNA were used. The PCR efficiency $\left(E=10^{(-1 / \text { slope })}-1\right)$ and correlation coefficient $\left(\mathrm{R}^{2}\right)$ values for each primer are shown in supplementary table 1 . The relative expression ratio of a target gene was calculated based Pfaffl (2001) equation 1, using the previously calculated efficiency for each gene and the $\mathrm{Cq}$ values of three biological and two technical replicates, as well as, the $\mathrm{Cq}$ average values of the two reference genes using either 0 hours (in the experiment with different bacteria) or the sample without bacteria (in the experiment with only $X$. carotae) as controls. The standard error of the mean for each relative gene expression ratio was calculated as a measure of 
data variation. The essential information described in the MIQE [Minimum Information for publication of qRT-PCR experiments (Bustin et al. 2009)] guide was all revised and included.

\subsection{Heterologous pepm protein expression in $E$. coli}

\subsubsection{DNA and RNA extraction and cDNA synthesis}

DNA was extracted from $F$. oxysporum DSM62291 using the CTAB method described by(Brandfass and Karlovsky 2008). Total RNA was extracted from the same organismusing one step guanidinium thiocyanate-phenol-chloroform method combined with $\mathrm{LiCl}$ precipitation (Chomczynski and Sacchi 2006). The RNA was reversed transcribed into cDNA as described in section 2.2.3.

\subsubsection{Vector construction (pET21_pepm) and $E$. coli transformation}

DNA or cDNA were used as templates to amplify pepm gene by means of PCR using a Peqlab thermocycler (Peqlab Biotechnologie $\mathrm{GmbH}$, Erlangen, Germany) in $25 \mu \mathrm{l}$ of reaction mixture containing $1 \mathrm{x}$ reaction buffer, $0.4 \mu \mathrm{M}$ of forward (A_F) and reverse (D_R) primers (supplementary table 2), $0.4 \mathrm{U}$ of PCRBio HiFi polymerase (PCRBiosystems, London, UK) and $1 \mu \mathrm{l}(50-100 \mathrm{ng})$ of DNA as a template. PCR conditions were as follows: $94^{\circ} \mathrm{C}$ for $1 \mathrm{~min}, 30$ cycles of $94^{\circ} \mathrm{C}$ for $20 \mathrm{~s}, 64^{\circ} \mathrm{C}$ for $30 \mathrm{~s}$ and $72^{\circ} \mathrm{C}$ for $45 \mathrm{~s}$. Primers were designed in a way that stop codon of the gene was removed to include the his taq from pET21a at the end of the protein.Amplified pepm gene was inserted between HindIII and XhoI sites of pET21a expression vector (Novagen, Merck, Darmstadt, Germany)as follows: amplified gene and pET21a were double digested (HindIII and XhoI, Thermo Scientific, Massachusetts, US) for 2 hours at $37^{\circ} \mathrm{C}$ followed by inactivation at $80^{\circ} \mathrm{C}$ for $20 \mathrm{~min}$. Digested products were ligated using T4 ligase (Thermo Scientific, Massachusetts, US) following the company instructions overnight at $17^{\circ} \mathrm{C}$ using a 4:1 (pepm:vector)ratio. Bacteria transformation was performed immediately by means of heat shock using competent $E$. coli DH5 $\alpha$ cells and $2 \mu 1$ of the ligation product (90 ng of vector DNA) as follows: E. coli $\mathrm{DH} 5 \alpha$ stock in $-60^{\circ} \mathrm{C}$ was thawed for $30 \mathrm{~min}$ on ice, $100 \mu \mathrm{l}$ of thawed bacteria was added to $2 \mu 1$ of the ligation product previously suspended in $5 \mu 1$ of double distilled water. The mixture was incubated on ice for another $30 \mathrm{~min}$. Heat shock was performed at $42^{\circ} \mathrm{C}$ for 60 seconds followed by incubation for $45 \mathrm{~min}$ in Super Optimal Broth with Catabolite repression (SOC) medium(Hanahan 1983) in a rotary shaker. 
Bacteria were platted out $(200 \mu \mathrm{l})$ in LBmedium supplemented with ampicillin (100 $\mu \mathrm{g} / \mathrm{ml})$. Plates were incubated overnight at $37^{\circ} \mathrm{C}$. Random colonies were chosen and the positive ones,carrying the right pET21_pepm, were detected by means of colony PCR using T7 promoter and terminator primers. Positive colonies were cloned overnight in LB medium with $100 \mu \mathrm{g} / \mathrm{mlof}$ ampicillin and the vector (pET21_pepm) was extracted using alkaline lysis. PCR, using primers T7, was repeated and products were sent for sequencing to verify the sequence. Vectors containing the right sequences were used to transform competent E. coli BL21 (DE3) or BL21 (DE3) rossetta 2 cells. Transformation was performed as explained before for DH5 $\alpha$ and only positive colonies (BL21 carrying the vector pET21_pepm) after colony PCR were used for protein expression. E.coli BL21 carrying the vector pET21 without insert was used as control during protein expression experiments.

\subsubsection{Expression of pepm protein in E. coli BL21}

A single colony of BL21 carrying the vector pET21_pepm was incubated overnight at $37^{\circ} \mathrm{C}$ and $250 \mathrm{rpm}$ in LB medium with $100 \mu \mathrm{g} / \mathrm{ml}$ ampicillin. Bacteria $(400 \mu \mathrm{l})$ were added into $40 \mathrm{ml}$ of Terrific Broth (TB)medium with ampicillin until $\mathrm{OD}_{600}=0.5-0.8$. Pepm protein was induced using $0.5 \mathrm{mM}$ of IPTG (isopropyl $\beta-\mathrm{D}-1$-thiogalactopyranoside) at $25^{\circ} \mathrm{C}$ and $100 \mathrm{rpm}$ for $16 \mathrm{~h}$. Extraction of proteins was performed as follows: cells were harvested by centrifugation at room temperature and $2 \mathrm{ml}$ of $50 \mathrm{mM}$ sodium phosphate equilibration buffer with $150 \mathrm{mM} \mathrm{NaCl} \mathrm{pH} 7.8$ was added. Leupeptin $(10 \mathrm{mg} / \mathrm{ml})$, pepstatin A $(1 \mathrm{mg} / \mathrm{ml})$ and lysozyme $(1 \mathrm{mg} / \mathrm{ml})$ were added to the vortex cells and the mixture was incubated for $20 \mathrm{~min}$ at room temperature. Cells were placed directly on ice and sonication was performed also on ice for 3 rounds of 30 secs (power output of 3) (Bandelin Sonoplus GM2200, Berlin, Germany). After sonication, proteins were separated from cell residues at $600 \mathrm{xg}, 30 \mathrm{~min}, 4^{\circ} \mathrm{C}$. Supernatant, containing the soluble proteins, was used for SDSPAGE (sodium dodecyl sulfate polyacrylamide gel electrophoresis) to detect the right protein by size using a gradient from 12 to $19 \%$ acrylamide in $7.5 \mathrm{~mm}$ for $4 \mathrm{~mm}$ gels chamber (SE275, Hoefer, Massachusetts, US).Twenty microliters of soluble proteins in 2xsample buffer (10\% SDS, 10\% 2-mercaptoethanol, 50\% glycerol, $0.1 \mathrm{M}$ Tris buffer pH8, 2mM EDTA pH 7.6 and $0.25 \%$ bromophenolblue) were load into each well. Samples were run for 1 hour, 100 Volts and 10mA. Gels were stained with Coomassie Blue solution (0.2\% Coomassie Brilliant Blue R250, 48\% MeOH, $10 \%$ acetic acid) for 1 hour and distained overnight using a solution of $10 \% \mathrm{MeOH} /$ acetic acid. A single colony of BL21 
carrying the pET21 with no pepm gene inserted (empty vector), was expressed in the same way and used as control.

\subsubsection{Pepm protein purification}

The putative pepm protein was purified using Talon ${ }^{\circledR}$ Metal affinity resin (Takara Bio, Japan)charged with cobalt ions following the company instructions. Protein was eluted using a gradient of imidazole $(0-300 \mathrm{mM})$ in $50 \mathrm{mM}$ sodium phosphate elution buffer supplemented with $150 \mathrm{mM} \mathrm{NaCl} \mathrm{pH} \mathrm{7.0.} \mathrm{Eluted} \mathrm{proteins} \mathrm{were} \mathrm{concentrated} \mathrm{five} \mathrm{times} \mathrm{and}$ exchanged with 50 mM Hepes buffer (Carl Roth GmbH, Karlsruhe, Germany)pH 8.0.

\subsubsection{GFP_pepm fusion protein expression and activity}

GFP (Green Fluorescent Protein) gene was amplified from pGFPuv vector (Takara Bio, Japan) using the primers GFP_F and GFP_R (Supplementary table 2). A sequence which codifies for the linker GSA GSA AGS GEF and Factor Xa cleavage site were added to the primer GFP_R sequence in order to include them in the final protein. The PCR product (GFP_linker_Factor Xa) was inserted between NheI and HindIII sites in the previously constructed pET21_pepm (pepm gene amplified from the DNA of $F$. oxysporum) to produce the vector pET21_GFP_pepm. The vector thus constructed was transformed into E. coli BL21(DE3) as explained before in section 2.3.2. Fusion protein was expressed and extracted as explain before in section 2.3.3 however in this case $0.1 \mathrm{mM}$ of IPTG was used and incubation was done for 4 or $16 \mathrm{~h}$.

The solubility of the GFP_pepm fusion protein was determined based on GFP fluorescence as follows: GFP_pepm protein was induced as described before in BL21 (DE3) but in this case using LB or TB medium with $0.1 \mathrm{mM}$ of IPTG at $20^{\circ} \mathrm{C}$ and $100 \mathrm{rpm}$ for $0,1,3,4,5,6$ and $22 \mathrm{~h}$. Extraction of proteins was performed as described before and the supernatant, containing the soluble proteins, was used for SDS-PAGE to detect the right protein and for fluorescence measurement with a Spectro fluorometer (Jasco, FP-6200, Japan) using $1 \mathrm{ml}$ of soluble protein, an excitation wavelength of $395 \mathrm{~nm}$, emission of $507 \mathrm{~nm}$ and bandwidth of $10 \mathrm{~nm}$.Pepm protein was purified using Talon ${ }^{\circledR}$ Metal affinity resin charged with cobalt as described before in section 2.3.4.

GFP_pepm fusion protein activity was done as follows: the soluble fusion protein was induced and extracted as described before, however in this case LB medium with $0.1 \mathrm{mM}$ of IPTG at $20{ }^{\circ} \mathrm{C}, 100 \mathrm{rpm}$ for $6 \mathrm{~h}$ were used. Eluates from Talon resin showing the right 
size on SDS-PAGE were concentrated five times, exchanged with $50 \mathrm{mM}$ Hepes buffer $\mathrm{pH} 8.0$ and then used directly for the protein activity assay.

Spectrophotometric protein activity assay was performed as described by Bowman et al. (1990) and Kim and Dunaway-Mariano (1996) monitoring the formation of PEP from PnPy though a couple assay (piruvate kinase and lactate dehydrogenase) in which the reduction of absorbance at $340 \mathrm{~nm}$ due to NADH oxidation was measured using an Epoch microplatespectrophotometer (BioTek, Vermont, US) (for details see Supplementary figure 1). A positive control was employed in which PEP was added to the reaction. The negative control consisted of the addition of Hepes buffer $\mathrm{pH} 8$ instead of the enzyme.

\section{Results}

\subsection{Identification of the putatively phosphonate genomic cluster in F.oxysporum}

\subsection{1. pepm and ppdgenes and their encoding proteins in fungi}

The most important genes related with phosphonates biosynthesis are pepm, encoding the C-P bond formation-related enzyme, and $p p d$, which encoding enzyme decarboxylates the substrate and moves the reaction forward. Both genes were found in $F$. oxysporum(chromosome 8 ) and $F$. avenaceum genomes,both species already described as phosphonate producers by Takeuchi et al. (1989). The whole-genome information of the other two fungal species described as phosphonate producers by the same authors $(F$. tricinctum and Talaromyces flavus) has not been generated so far. However, a highly similar pepmsequence is present in T. islandicusgenome.

Many fungal species have also genes that likely encode for pepm and ppd proteins, a few are listed in table 1.Among fungi, the most similar ones to $F$. oxysporum are in $F$. fujikuroi and $F$. proliferatum, while the least similar are present in Aspergillus nomius. Interestingly, some of them have the pepm protein-encoding-sequence but not theppd, i.e. $F$. graminearum and $F$. poae, suggesting that another biosynthetic step from PnPy, different from the most common one, could occur in these two fungi.

Apart from pepm and ppd proteins of fungal origin, from which a high homology within the same protein is expected, the highest identity/similarity of $F$. oxysporum protein 
sequences were with the already revised pepm sequence of $M$. edulis $(25 / 40 \%)$ and ppd sequence of $B$. fragilis (34/53\%) (Table 1).

Table 1. Comparison of $F$. oxysporum pepm and ppd protein sequences against homologues from other species.

\begin{tabular}{|c|c|c|c|c|c|}
\hline Organism & Organism description & Phosphonate & $\begin{array}{c}\text { Number } \\
\text { of } \mathbf{A A}\end{array}$ & $\begin{array}{c}\% \text { AA } \\
\text { ident } / \text { sim }^{3}\end{array}$ & $\begin{array}{c}\text { Protein acc. } \\
\text { number }^{1}\end{array}$ \\
\hline \multicolumn{6}{|c|}{ pepm (acc. number ${ }^{1}$ : KNA98284) } \\
\hline F. fujikuroi & Ascomycete & unknown & 404 & $97 / 98$ & KLO94689 \\
\hline F. proliferatum & Ascomycete & unknown & 404 & $97 / 98$ & CZR42889 \\
\hline F. avenaceum & Ascomycete & unknown & 402 & $82 / 89$ & KIL92284 \\
\hline T. islandicus & Ascomycete & unknown & 397 & $68 / 78$ & CRG87786 \\
\hline F. graminearum & Ascomycete & unknown & 381 & $51 / 66$ & CEF78892 \\
\hline F. poae & Ascomycete & unknown & 381 & $51 / 66$ & OBS25306 \\
\hline A. nomius & Ascomycete & unknown & 395 & $45 / 63$ & KNG85760 \\
\hline M. edulis ${ }^{2}$ & Marine mollusc & AEP & 295 & $25 / 40$ & P56839 \\
\hline T. pyriformis $^{2}$ & Ciliated protozoa & AEP & 300 & $23 / 36$ & P33182 \\
\hline S. hygroscopicus ${ }^{2}$ & Gram-positive bacteria & Phosphinothricin & 313 & $22 / 31$ & P29247 \\
\hline S.viridochromogenes $^{2}$ & Gram-positive bacteria & Phosphinothricin & 313 & $22 / 33$ & O86937 \\
\hline \multicolumn{6}{|c|}{ ppd (acc. number ${ }^{1}$ : KNA98279) } \\
\hline F. fujikuroi & Ascomycete & unknown & 400 & $93 / 97$ & СCT70701 \\
\hline F. proliferatum & Ascomycete & unknown & 400 & 93/97 & CZR42893 \\
\hline F. verticillioides & Ascomycete & unknown & 400 & $93 / 96$ & KYG13815 \\
\hline F. avenaceum & Ascomycete & unknown & 399 & $86 / 92$ & KIL92280 \\
\hline T. islandicus & Ascomycete & unknown & 406 & $72 / 83$ & CRG87785 \\
\hline A. nomius & Ascomycete & unknown & 399 & $52 / 67$ & KNG85754 \\
\hline B. fragilis $^{2}$ & Gram-negative bacteria & AEP & 378 & $34 / 53$ & EXZ28912 \\
\hline S. hygroscopicus ${ }^{2}$ & Gram-positive bacteria & Phosphinothricin & 401 & $30 / 43$ & Q54271 \\
\hline S.viridochromogenes $^{2}$ & Gram-positive bacteria & Phosphinothricin & 397 & $29 / 43$ & O86938 \\
\hline
\end{tabular}

${ }^{1}$ Accession number from UniProt consortium. ${ }^{2}$ Known phosphonates producers: revised pepm and ppd proteins

${ }^{3}$ ident=AA identity in which only the same residues are considered. Sim=AA similarity in which synonymous substitutions are considered (Rost 1999).

Pepm and ppdprotein sequencesin $F$. oxysporum, $F$. fujikuroi and $F$. proliferatum share most of the invariant residues within the already revised protein sequences from other phosphonates producers (Figure 2A and 3). Moreover, pepm and ppd active sites are highly conserved in theseFusarium speciesand in other organisms, i.e. Streptomyces sp., M. edulis and $T$. pyriformis, suggesting that the interaction with the cofactors could be similar in the same enzyme from different sources.

In the case of the pepm protein, the highly conserved catalytic motif: EDKXXXXXNS is present also in the pepm proteins from the three Fusarium species (Figure 2A). Moreover, in $F$. oxysporum, the predicted quaternary structure of this protein fits with that one from 
M. edulis, suggesting a similar protein conformation in which the accessibility to the active sites may occurs like in other pepm proteins (Figure 2B and C).
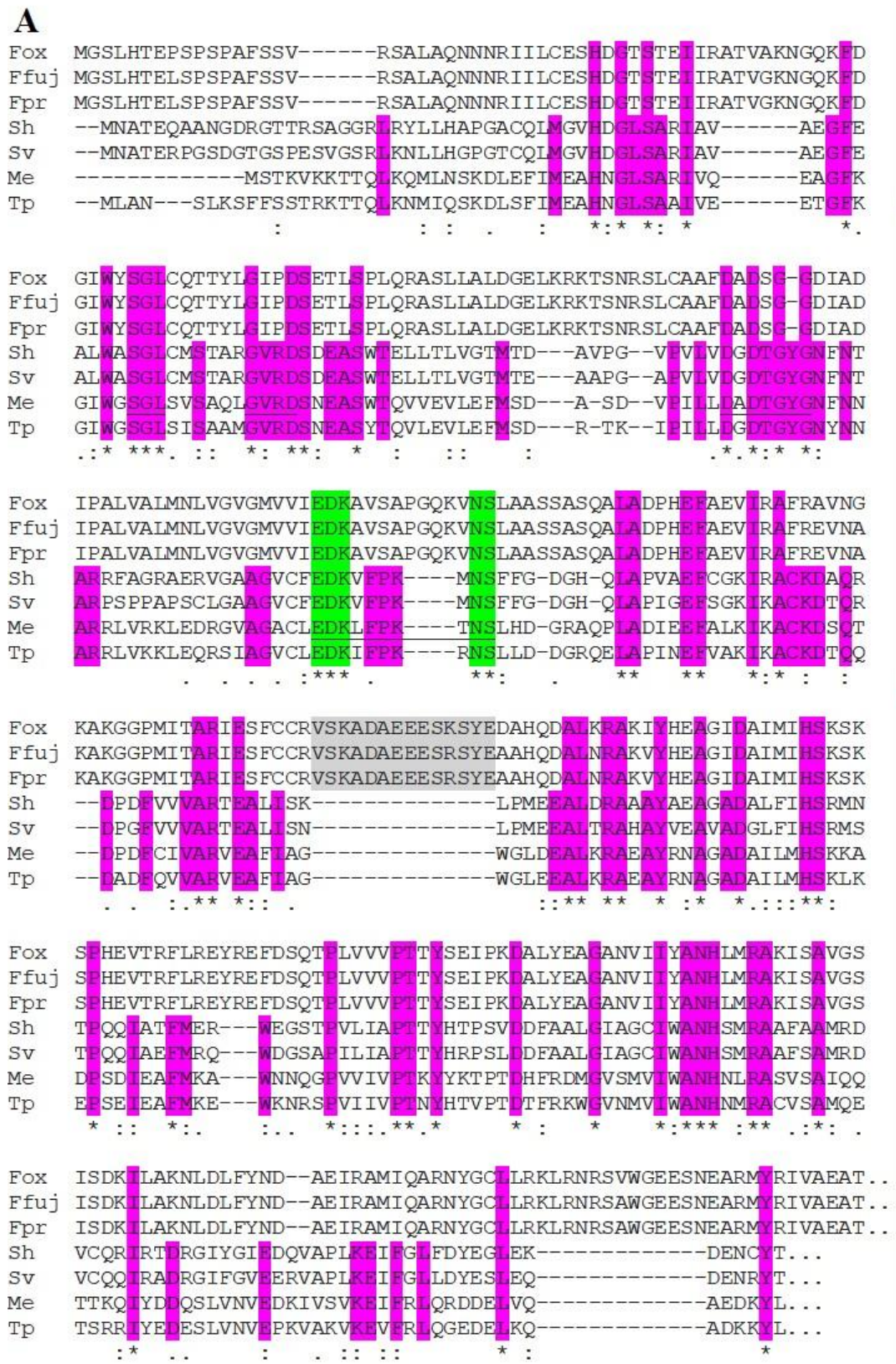

Figure 2. Multiple protein sequence alignment of Fusarium spp. pepm sequences (Fox: $F$. oxysporum, Ffuj: F. fujikuroi, Fpr: F. proliferatum) and the already revised pepm proteins from Sh: S. hygroscopicus, Sv: S. viridochromogenes, Me: Mytilus edulis and Tp: Tetrahymena pyriformis(A). Alignment was done using Clustal Omega (1.2.4) with default settings. Conserved residues among the already revised pepm protein sequences (magenta), M. edulis pepm active sites (underlined), highly conserved pepm catalytic motif EDKXXXXXNS [green: motif used to distinguish this protein from other members of the isocitrate lyase superfamily (Chen et al. 2006)], predicted intron in Fusarium spp. (gray). Predicted protein structures from $F$. oxysporum $(\mathbf{B})$ and $M$. edulis $(\mathbf{C})$ : the green small circle in the middle of both structures represents the $\mathrm{Mg}^{+2}$ atoms.
B pepm protein $F$. oxysporum

C

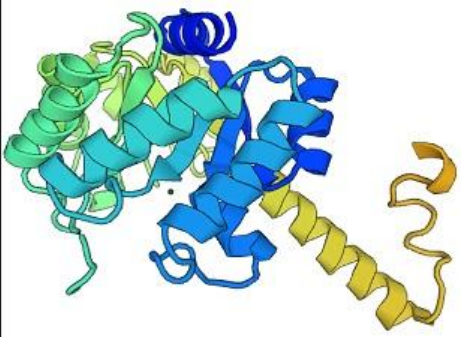



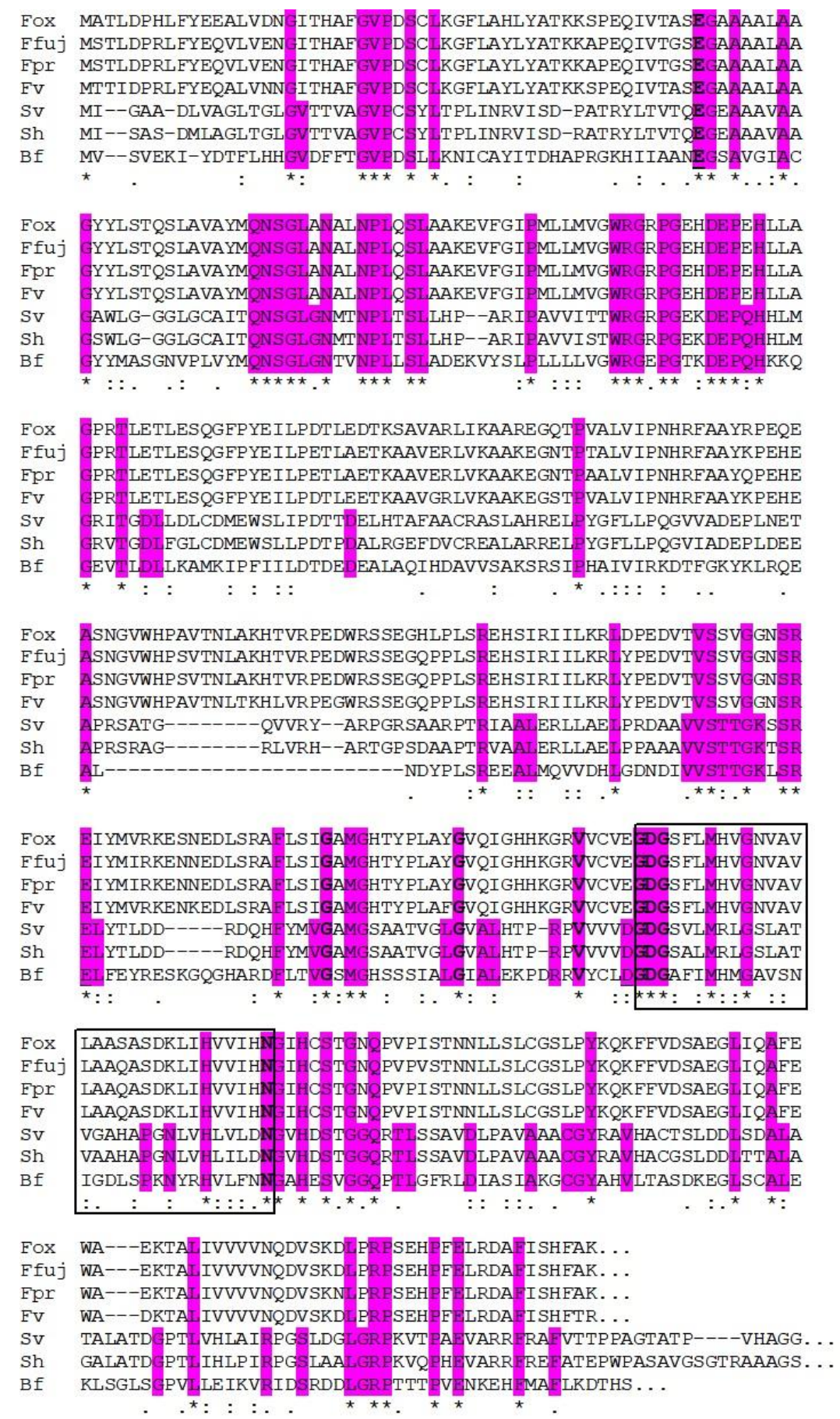

Figure 3. Multiple protein sequence alignment of Fusarium ppd sequences (Fox: $F$. oxysporum, Ffuj: F. fujikuroi, Fpr: F. proliferatum, Fv: F. verticillioides) and the already revised ppd proteins from Sv: S. viridochromogenes, Sh: S. hygroscopicus, Bf: B. fragilis. Alignment was done using Clustal Omega (1.2.4) with default settings. Conserved residues among the already revised ppd protein (magenta) and decarboxylases family of proteins (bold), B. fragilis ppd active site-polar residue interacting directly with $\mathrm{Mg}^{+2}$ or thiamine pyrophosphate (TPP) (underlined) and TPP signature motif (box) 


\subsubsection{Enzymes likely involved in the biosynthesis of fosfonochlorin in $F$. oxysporum}

The putative first two steps during phosphonates biosynthesis in $F$. oxysporum resemble that one's from phosphonate-producer-organisms. The unfavorable reaction from PEP is predicted to be carried out by the enzyme pepm (gene accession number: Foxg_02666) to produce PnPy, followed by a decarboxylation of PnPy to produce PnAA by the enzyme ppd (gene accession number: Foxg_02662). Based on the conserved status of these first reactions and the identification of the genes in Fusarium spp. genomes, both steps are likely to occur during fosfonochlorin biosynthesis in F. oxysporum as well. However, the followingreactions from PnAA are highly diverse in organisms, and this could be the case also in fungi.

To have an idea about the possible route for fosfonochlorin, the expected protein sequences from the genes located near pepm and ppdin F. oxysporum genome were retrieved and compared to that ones from phosphonates producers. In this way, the more likely steps for fosfonochlorin pathway from PnAA were deduced based on protein homology (Figure 4). Each step is explained in detail below.

Looking at the genes near the pepm and ppd locus in F. oxysporum, the presence of a gene sequence predicted to encode an aldo-keto reductase NADP dependent oxidoreductase (Foxg_02661, gene 3 in Figure 4), suggest that, in this fungus, the next step from PnAA could be a reduction of the aldehyde to produce a similar compound to 2-HEP in bacteria. This compound is already demonstrated to be the product of the reduction of PnAA in Streptomyces spp. carried out by a group III iron-dependent alcohol dehydrogenase that needs NADPH as cofactor (Blodgett et al. 2005; Woodyer et al. 2006; Shao et al. 2008). However, the identity and similarity of the revised enzyme from S. viridochromogenes (phpC, accession:D9XF45) with the predicted one in $F$. oxysporum is low and the codifying enzyme in $F$. oxysporum does not have the same iron metal binding site. This suggest that in the fungus, either the enzyme uses a different mechanism for the aldehyde reduction or another enzyme is responsible for this step. 


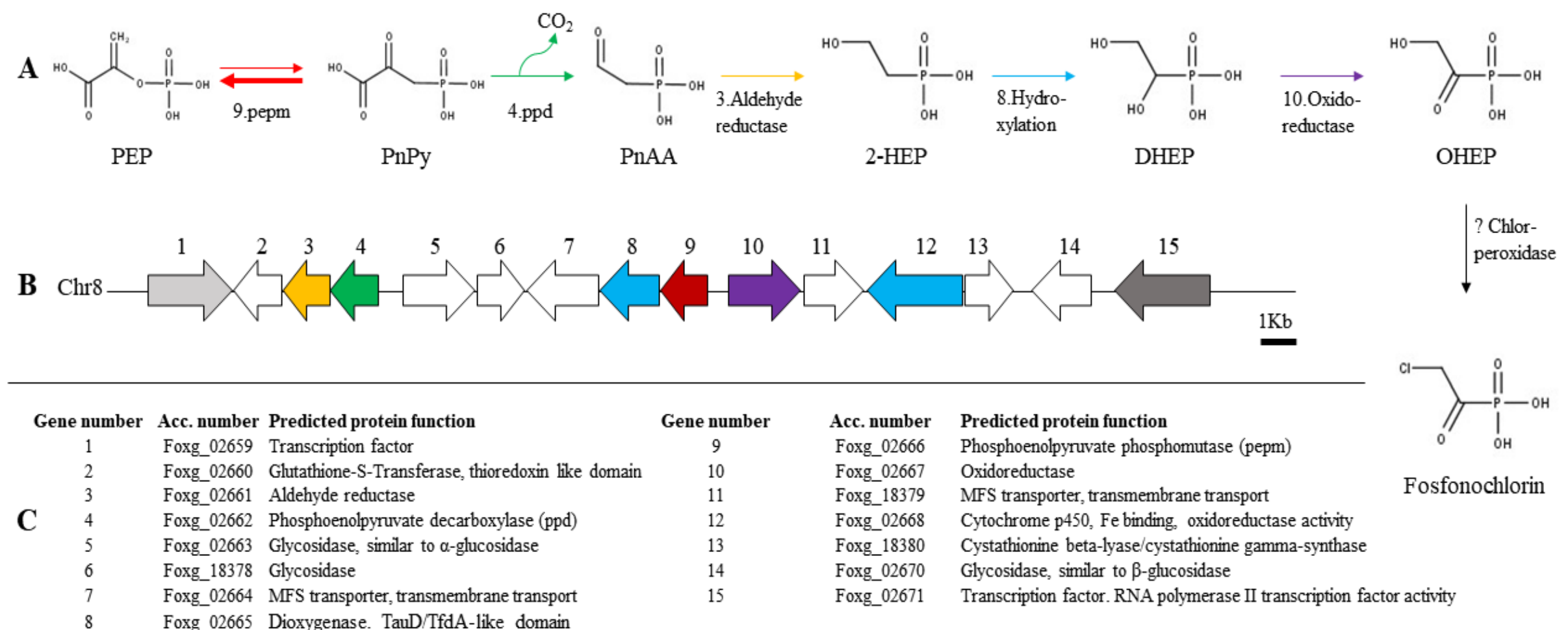

Figure 4. Proposed fosfonochlorin biosynthetic pathway in F. oxysporum(A), its possible genomic cluster (B) and predicted protein function of the genes related with the biosynthesis $(\mathbf{C})$. 
The conversion of 2-HEP into DHEP occurs through a 2-ketoglutarate-dependent dioxygenase in $S$. luridus during the production of the phosphonate dehydrophos (Circello et al. 2010)by the enzyme DhpA (UniProt accession number: D7PC13) in which a hydroxyl group is added at $\mathrm{C} 1$ in 2-HEP. In F. oxysporum, a similar dioxygenase encoded by gene 8 (Foxg_02665, figure 4) is clustered together with pepm and ppd. In the fungus, the encoding enzyme is predicted to have an oxidoreductase activity and a TauD/TfdAlike domain (taurine catabolism dioxygenase), similar to the bacterial one. The identity and similarity of this protein with the bacterial one is 18.2 and $30.8 \%$ respectively.

However, this hydroxylation could be also done by another enzyme codified by one of the longest genes in the cluster (Foxg_02668, gene 12 in figure 4). By prediction,its endoding enzyme has a monooxygenase activity with an iron binding domain and, according to GO terms,is an integral part of membranes. The protein belongs to the superfamily of haemcontaining monooxygenases cytochrome $\mathrm{p} 450$, thus maybe involved in the hydroxylation of the phosphonates in the fungus; though, a variety of reactions could be also catalyzed by this family of enzymes.

The following step from DHEP could be an oxidation of the molecule in $\mathrm{C} 1$ to produce 1oxo-2-hydroxyethylphosphonate (OHEP) by an oxidoreductase enzyme encoded by gene Foxg_02667 (gene 10 in figure 4). This gene is also clustered together in F. oxysporum genome with the last genes already described including pepm and ppd. The encoding enzyme is predicted to have an oxidoreductase activity, with a flavine-adenine dinucleotide binding site acting on $\mathrm{CH}-\mathrm{OH}$ group of donors. A similar mechanism occurs in $S$. luridus during the production of the phosphonate dehydrophos. In this specific case, the oxidoreductase DhpC produces 1-oxo-2-phosphorylethylphosphonate (OP-EP) through the oxidation of 1-hydroxy-2- phosphorylethylphosphonate (HP-EP) (Circello et al. 2010).

The last possible enzymatic step during the biosynthesis of fosfonochlorin should be a chlorination of OHEP carried out by a chloroperoxidase. Some genes in F. oxysporum f.sp lycopersici 4287 genome are predicted to encode heme-haloperoxidases. However, and different from the last predicted phosphonate-related genes, the haloperoxidases- 
encodinggenes are not near the putatively phosphonate cluster, they are located in the chromosomes 11 and 12 (Foxg_09703, Foxg_09717, Foxg_13077, Foxg_13304).

Two transcription factors (encoded by gene 1 and 15 in figure 4) are present at the beginning and at the end of the putative phosphonates cluster in $F$. oxysporum. Both are predicted to encodeRNA polymerase II transcription factors with DNA and zinc ion binding domains, thus likely belongs to the $\mathrm{Zn}(\mathrm{II})_{2}-\mathrm{Cys}_{6}$ fungal-type DNA-binding proteins which $\mathrm{N}$-terminal contains a cysteine-rich motif involved in zinc-dependent DNA binding.

\subsubsection{Other genes clustered together with the predicted fosfonochlorin-related genes}

Near pepm and ppd in $F$. oxysporum genome other genes possible related with phosphonates biosynthesis in the fungus are present. Two integral transmembrane components are predicted from the genes Foxg_02664 and Foxg_18379 (gene 7 and 11 respectively in figure 4). The predicted enzymes have a Mayor Facilitator Superfamily (MFS) domain which could be involved in the transport of a variety of substrates across cytoplasmic or internal membranes. Our comparison with other similar proteins from fungi, suggest that they are monocarboxylate transporters. A carboxylate group $\left(-\mathrm{COO}^{-}\right)$is present in OHEP and fosfonochlorin molecules (Figure 4) suggesting that Foxg_02664 and/or Foxg_18379 encoding enzymes could be involved in the transport of this molecules outside the fungal cells.

Other genes in the predicted cluster have functions which are barely related to phosphonates metabolism in F. oxysporum. For example, the gene Foxg_02660 is predicted to encode an enzyme belonging to glutathione-S-transferase family which is usually related with detoxification and tolerance to oxidative stress in fungi. Some other genes in the cluster are predicted to be involved in carbohydrates catabolism. For instance, genes Foxg_02663 and Foxg_02670, are predicted to encode, based on homology with fungal sequences, an $\alpha$-glucosidase and a $\beta$-lactamase respectively. In a similar way, the gene Foxg_18378 is predicted to belong to the glycoside hydrolase family of enzymes that hydrolyze glycosidic bonds between two or more carbohydrates. Finally, the sequence of 
the small gene Foxg_18380 shows $47 \%$ identity against the cystathionine $\beta$ lyase/cystathionine $\gamma$-synthase, related with amino acid transport and metabolism in Pelagirhabdus alkalitolerans (Bacillaceae).

\subsection{Gene expression of phosphonate-related genes in $F$. oxysporum}

Based on the already demonstrated antibiotic activity of fosfonochlorin (Takeuchi et al. 1989) we presumed that the genes related with phosphonates biosynthesis should be upregulated in $F$. oxysporum when the fungusis in the presence of bacteria. Therefore, experiments in which $F$. oxysporum was cultivated with this microorganism were carried out. During the first experiment, the fungus was cultivated together with gram-negative bacteria (E. coli, P. syringae or X. carotae)and one gram-positive bacterium (B. brevis) for 24 hours. The most important gene for phosphonates biosynthesis, i.e. pepm, was strongly up-regulated after $24 \mathrm{~h}$ of $F$. oxysporum-bacterium (E. coli, P. syringae, X. carotae or $B$. brevis) co-culture. The highest ratio of expression was obtained when fungi was cultivated with $E$. coli followed by $X$. carotae, $P$ syringae and B. brevis (Figure 5).

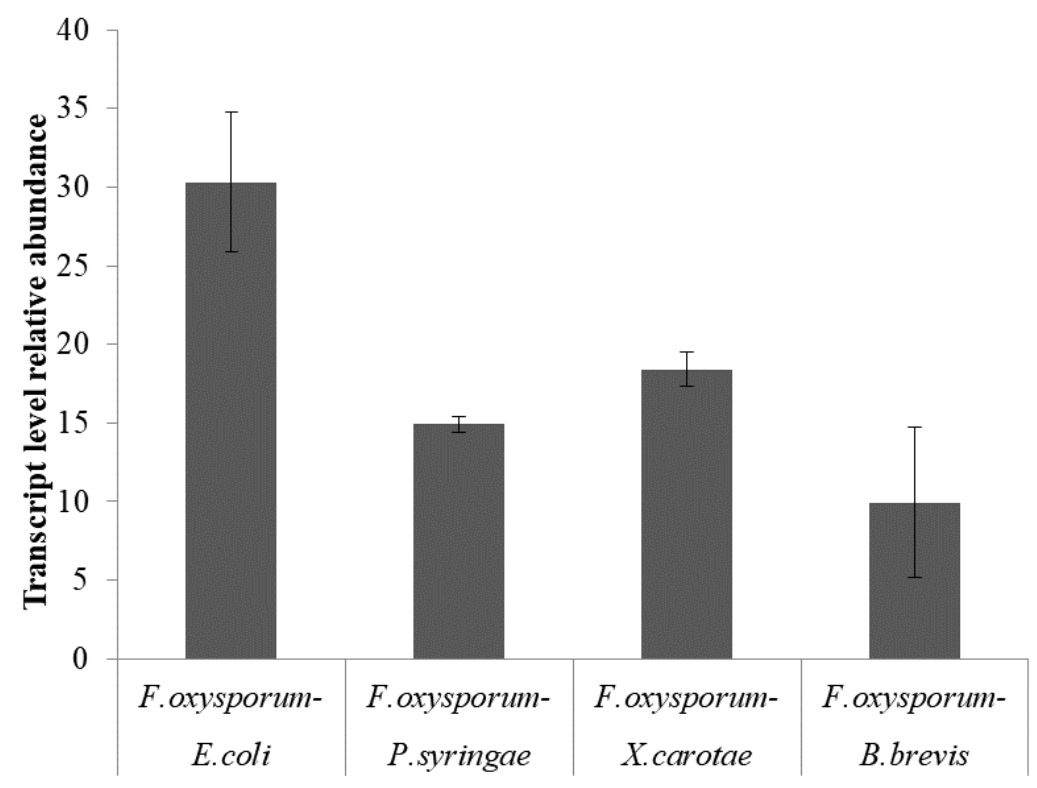

Figure 5. F. oxysporum relative pepm gene expression after $24 \mathrm{~h}$ of fungi-bacteria cocultivation. The relative expression ratio of pepm gene was calculated based on (Pfaffl 2001) equation 1, on three biological and two technical replicates, using GAPDH and EFIA as reference genes and 0 hours as control. The standard error for each relative gene expression ratio was calculated as a measure of data variation.

Also, other genes, possibly related with phosphonates biosynthesis in F. oxysporum (for gene details see figure 4C) were up-regulated after fungi-X. carotae co-cultivation (Figure 
6). The genes were divided into two groups, one group expressed earlier, after $2-4 \mathrm{~h}$ of fungi-bacteria culture (Figure 6A) and, another group expressed only after $24 \mathrm{~h}$ of cocultivation (Figure 6B). Within the first group, are the two most important genes related with phosphonates biosynthesis ( and a putative transcription factor (gene 15). The last two genes (genes 12 and15) and ppd showed a ratio of more than 2 after two hours of fungi-bacteria co-cultivation, while a similar ratio of expression was observed in pepm gene but only after four hours of cocultivation.

Interestingly, within the first group, the genes were down-regulated after 8, 12 and 16 hours and up-regulated again after $24 \mathrm{~h}$ (Figure 6A). The transcription factor encoded by gene 15 and pepm gene were still up-regulated after 36 and $48 \mathrm{~h}$ while the others not. None of them were up-regulated anymore at 72 hours. Within the second group (Figure $6 \mathrm{~B})$, the transcription factor encoded by gene 1 and the gene encoding an oxidoreductase (gene 10) were only up-regulated after 24 hours of fungi-bacterium cultivation. The oxidoreductase-encoding gene was even up-regulated at 72 hours.

Other genes inside the putative phosphonate cluster were not analyzed, however the gene 3 encoding an aldehyde reductase and the gene 8 could be good candidates for future analysis since they are likely related with phosphonates biosynthesis in the fungus as demonstratedbefore. 

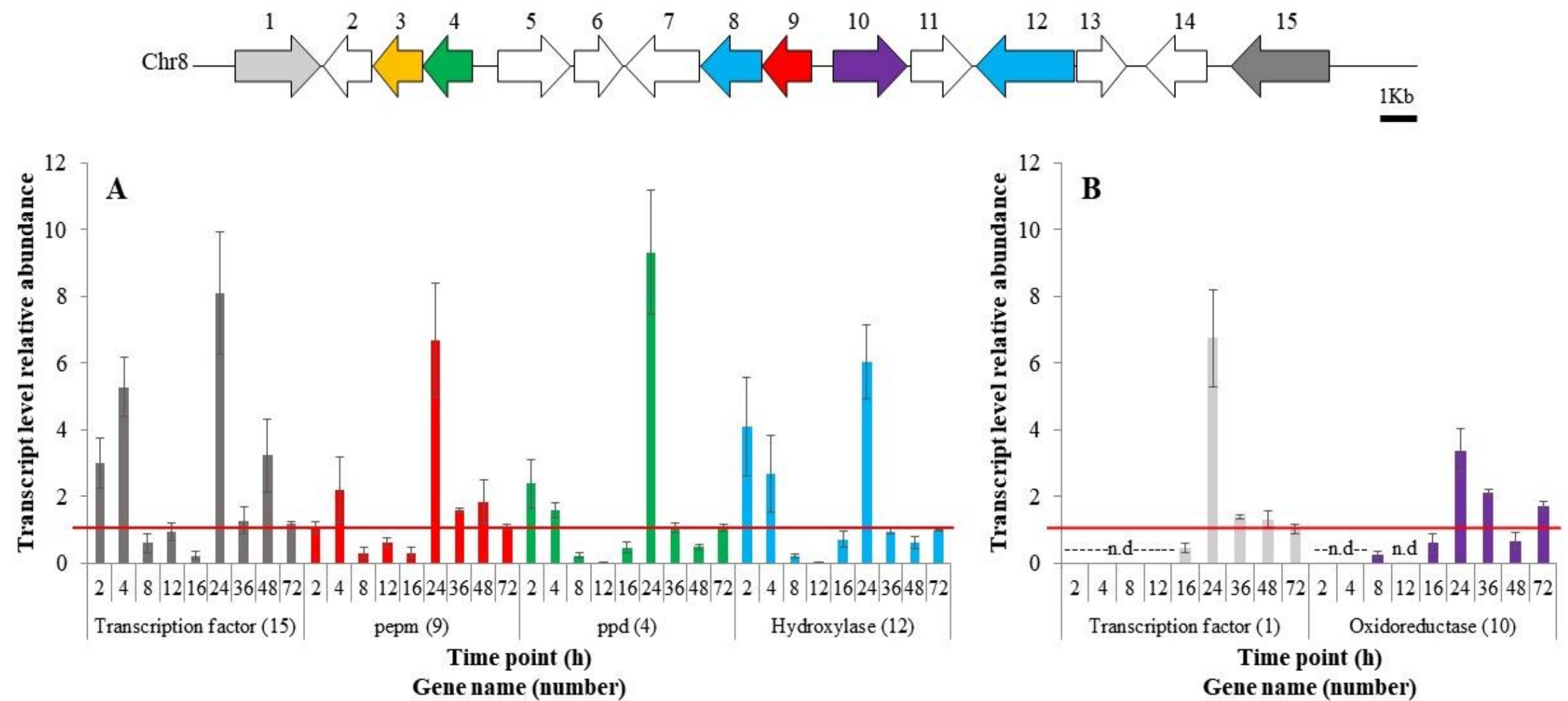

Figure 6. $F$. oxysporum relative genes expression after $2,4,8,12,16,24,36,48$ and 72 hours of fungi-X. carotae co-cultivation. Genes expressed early (A) or only after $24 \mathrm{~h}$ (B). The relative expression ratio of each targetgene was calculated based on (Pfaffl 2001) equation 1, on three biological and two technical replicates, using GAPDH and EFIA as reference genes and bacteria-untreated fungal sample as control. The standard error for each relative gene expression ratio was calculated as a measure of data variation. n.d = not detected product after qRT-PCR. Red line indicates a ratio of expression of 1 . 


\subsection{Heterologous pepm protein expression in E. coli}

To further confirm that the pepm-encoding gene is functional, we conducted an experiment in which pepm was heterologous expressed and extracted from E. coli, and the protein activity was further evaluated.

Pepm protein expressed in E.coli BL21 (DE3) or BL21 (DE3) Rosetta 2 using DNA or cDNA from $F$. oxysporum was always observed as a possible truncated protein on SDSPAGE. The expected molecular weight of the protein in $F$. oxysporum is $47 \mathrm{kDa}$ however in SDS-PAGE the new protein produced after induction with IPTG, was always observed, based on the marker, at around $29 \mathrm{kDa}$ (Figure 7A), which means that a part of around 18 $\mathrm{kDa}$ of the protein was not there. Based on the fact that the protein could not be purified using the Talon resin, we assumed that the last part of the protein, including the histidine tag, was missing. The truncated protein was produced even when IPTG was not added
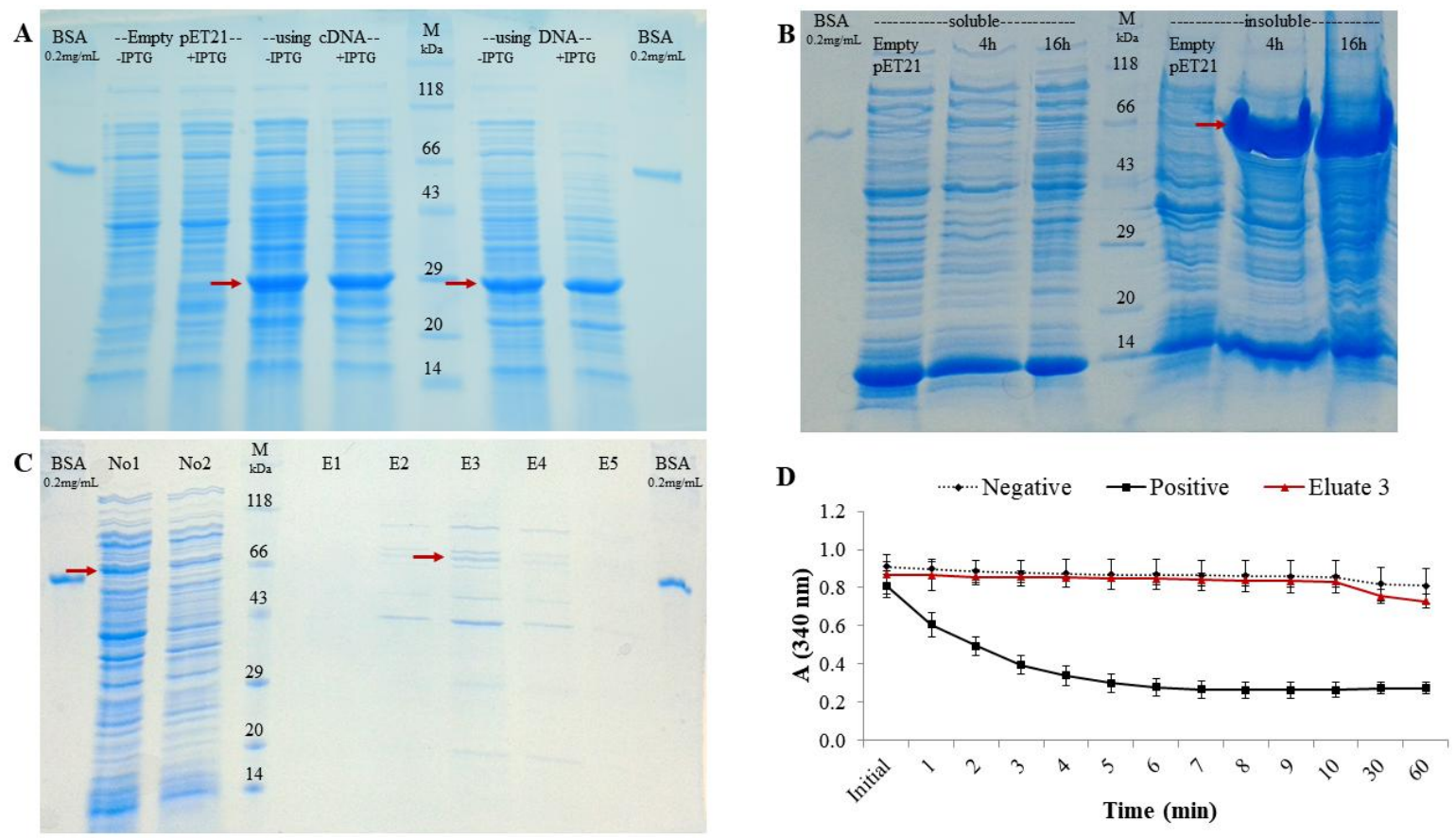

Figure 7. SDS-PAGE of proteins extracted from E. coli. A) Insoluble proteins extracted from BL21(DE3) Rosetta2 carrying the vector pET21_pepm with the gene obtained from cDNA or DNA of $F$. oxysporum after $16 \mathrm{~h}$ of induction using $0.5 \mathrm{mM}$ IPTG (+IPTG) or without IPTG (-IPTG). B) soluble and insoluble proteins extracted from BL21(DE3) carrying the vector pET21_GFP_pepm after $4 \mathrm{~h}$ or $16 \mathrm{~h}$ of protein induction using $0.1 \mathrm{mM}$ IPTG. C) Eluted proteins after talon resin extracted from BL21(DE3) carrying the vector pET21_GFP_pepm after 6h of induction using LB medium with $0.1 \mathrm{mM}$ IPTG; No1: soluble proteins before purification, No2: soluble proteins after passing No1 through the resin, E1 to E5 are the eluates from the resin using imidazole gradient (E1: $0 \mathrm{mM}$, E2: $50 \mathrm{mM}$, E3: $100 \mathrm{mM}, \mathrm{E} 4: 200 \mathrm{mM}, \mathrm{E} 5: 300 \mathrm{Mm})$. D) result of the enzymatic activity assay using the eluate 3 observed in panel C. Empty: BL21 carrying the vector pET21 without insert. Red arrows indicate the possible protein. M: marker Roti ${ }^{\circledR}$-Mark standard (Carl Roth GmbH, Karlsruhe, Germany). BSA (Bovine Serum Albumin: 66.5 kDa). 
GFP_pepm fusion protein, on the other hand was produced showing the expected size (72.6 kDa), however the protein was not soluble (Figure 7B). An experiment based on GFP fluorescence was performed in order to determine the best conditions for protein expression and solubility. The intensity of emission of GFP protein was similar when the protein was induced in LB or TB medium and the maximum emission in both were after 4 , 5 and 6 hours of induction (supplementary figure 2). After 22 hours the emission was very low indicating a decrease in GFP solubility. The conditions obtained from this experiment were used to induce the fusion protein again and to further purified the protein from the rest of the soluble proteins. After purification several proteins were observed from the eluate 3 using 100 mMimidazole (Figure 7C). One of the proteins with molecular size slightly higher than $66 \mathrm{kDa}$ was expected to be the GFP_pepm fusion protein. Therefore, this eluate was used for the enzymatic assays. Protein activity was evaluated using a spectrophotometric assay in which the oxidation of NADH (at $340 \mathrm{~nm}$ )was monitored as an indicator of the formation of pyruvate from the initial substrate PnPy. The absorbance at $340 \mathrm{~nm}$ read every minute for $10 \mathrm{~min}$ and then after 30 and 60 minutes did not change when the eluate 3 was used, indicating no enzyme activity when compared to the positive control (Figure 7D).

\section{Discussion}

The genes involved, the genomic cluster location, and the biosynthetic pathway of some phosphonates are already known in some organisms (Peck and van der Donk 2013; Horsman and Zechel 2017) but not in fungi. The key enzyme responsible for the C-P bond formation (pepm) has been well characterized in M. edulis(Jia et al. 1999) and a highly conserved regions in this protein can be used to predict natural phosphonate producers $(\mathrm{Yu}$ et al. 2013; Ju et al. 2015). From our gene and protein-based survey we have identified some fungal species that harbor the conserved sites within pepm and thus, probably can synthetize phosphonates, including $F$. oxysporum, $F$. fujikuroi and $F$. proliferatum. Moreover, looking at the pepm neighbors in some of the fungal species, we found the second most common gene related with phosphonates biosynthesis, i.e. ppd, which is essential to move the reaction forward from PnPy (Zhang et al. 2003). From our survey we also found that many other fungal species can probably produce the pepm protein as well (not all results are shown). Based on this, is likely that other unknown fungal origin phosphonates exist. Accordingly, recent evidence suggested that the presence of 
phosphonate producers in nature has been probably underestimated (Yu et al. 2013; Ju et al. 2014; Horsman and Zechel 2017).

In the case of $F$. oxysporum, the first steps of the biosynthetic pathwayfor fosfonochlorin proposed in the present study resembles that one from bacteria-phosphonate producers. For instance, the isomerization of PEP to PnPy and the decarboxylation of PnPy to produce PnAA carried out by pepm and ppd enzymes respectively, are likely to occur in the fungus. F. oxysporum pepm and ppd enzyme showed high identity (22-34\%) with the bacterial ones, including most of the conserved residues and the active site. This percentage of identity is enough to predict more than $70 \%$ of secondary structure identity (Sander and Schneider 1991). The step carried out by these enzymes happens in most of the phosphonate biosynthetic pathways from other organisms (Peck and van der Donk 2013; Horsman and Zechel 2017). Moreover, we have demonstrated that both genes, pepm and $p p d$, are up-regulated during $F$. oxysporum-bacteria interaction supporting our hypothesis that the genes are active and thus, the fungus can indeed produce phosphonates.

Besides that, not only the most important phosphonate-related genes were found in $F$. oxysporum genome, also the presence of a gene encoding an aldehyde reductase (gene 3), made us suppose that the reduction of the acetaldehyde PnAA occurs during the first step of fosfonochlorin biosynthesis, as it happens during the biosynthesis of other phosphonates such as dehydrophos, phosphinothricin and fosfomycin (in Streptomyces spp.) (Blodgett et al. 2005; Woodyer et al. 2006; Shao et al. 2008). The expression of this gene was not evaluated in our analysis however, it is an important one to consider for future studies. Other genes in the proposed fungal phosphonates cluster, were up-regulated (genes 12 and 10) together with pepm and ppdduring bacteria-fungal interaction, thus they could be also implicated in fosfonochlorin biosynthesis similar to what happens in bacteria, i.e. the hydroxylation of HEP and the further DHEP oxidation as in S. luridus during dehydrophos production (Circello et al. 2010).

The early up-regulation of one of the transcription factors inside the proposed phosphonate biosynthetic cluster in $F$. oxysporum support in fact that the genes are located in an active genomic cluster. Although two transcription factors are present, only the transcription factor encoded by gene 15 is likely to be involved in phosphonates biosynthesis since it was expressed earlier than the transcription factor encoded by gene 1. Both transcription 
factorsare members of the zinc cluster protein family of enzymes consisting of six cysteine residues bound to two zinc atoms $\left[\mathrm{Zn}(\mathrm{II})_{2}-\mathrm{Cys}_{6}\right]$. These pathway specific transcription factors are exclusively found in fungi and are related with both primary and secondary metabolism (MacPherson et al. 2006; Yin and Keller 2011). For instance, they are involved in the biosynthesis of aflatoxins (Woloshuk et al. 1994), fumonisins (Brown et al. 2007) and aurofusarin (Kim et al. 2006). Zinc cluster proteins can act as activatorsbut also as repressors (MacPherson et al. 2006). Perhaps, in the case of the transcription factor codified by gene 1 in $F$. oxysporum, the encoded enzyme has a repressor activity, or it could be involved in another pathway.

To further confirm that the biosynthesis of fosfonochlorin is possible, we investigate the presence of haloperoxidases in F. oxysporum genome. Indeed, some genes in the genome are predicted to codified heme-haloperoxidases, but they are not near the putative cluster. In this regard, biosynthetic pathways of halogenated compounds in fungi and other organisms are already known however, in most cases, the halogenation-responsible gene is located in the same cluster. For instance, the chloroperoxidase-encoding gene is located inside the ochratoxin A cluster in Penicillum(Geisen et al. 2006)and in the merochlorin cluster in Streptomyces sp. (Kaysser et al. 2012).

The presence of the pepm gene in Fusarium genome, the protein similarity with that one from phosphonates-producers and the up-regulation of some putative phosphonatesrelated genes during bacteria-fungus interaction suggest that $F$. oxysporum can produce phosphonates. On the other hand, it was not possible to demonstrate the pepm protein activity when it was heterologously produced in E. coli. The recombinant pepm protein was, at first, observed as a truncated protein on the SDS-PAGE gels even when cDNA, thus including no introns, was used for protein expression. In this case, it is possible that the eukaryotic protein was degraded in E. coli by endogenous proteases during the expression as it happens when the protein is misfolded (Georgiou and Segatori 2005). On the other hand, the fusion GFP_pepm recombinant proteindid not showed any activity in our experiments, even when the right molecular weight was observed on SDS-PAGE. This could happen when the protein is incomplete folded (Rosano and Ceccarelli 2014) or when the protein is wrongly processed in E. coli. For instance, E. coli being a prokaryotic system, cannot process rare codons or made protein post-translational modifications which are essential for protein activity(Terpe 2006; Rosano and Ceccarelli 2014).The protocol 
used in the present study for the protein activity is based on a pepm protein extracted directly from a eukaryotic organism (the protozoa T. pyriformis) (Bowman et al. 1990; Kim and Dunaway-Mariano 1996). Therefore, we suspect that in our case the protein was wrongly processed in E. coli with the consequently loss of activity. As solution, we recommend another expression system for the heterologous expression of Fusarium pepm protein. In this respect, yeast or insects are alternative host for eukaryotic proteins expression (Rai and Padh 2001; Demain and Vaishnav 2009).

The evidence presented in this chapter support ourhypothesis that $F$. oxysporumand maybe many other fungal species have the genetic potential tobiosynthesize phosphonates. Moreover, the expression of the genes presumably related with their biosynthesis were upregulated during bacteria-fungal interaction indicating that the genes are active and suggesting that one biological function for fungal phosphonates could be the defense against bacteria.

\section{References}

Bai G, Shaner G (1996) Variation in Fusarium graminearum and cultivar resistance to wheat scab. Plant Dis 80:975-979

Bauer A, Luetjohann J, Rohn S, et al (2017) Determination of fosetyl and phosphonic acid at $0.010 \mathrm{mg} / \mathrm{kg}$ level by ion chromatography tandem mass spectrometry (IC-MS/MS). J Agric Food Chem 66:346-350

Bertani G (1951) Studies on lysogenesis. I. The mode of phage liberation by lysogenic Escherichia coli. J Bacteriol 62:293-300

Biasini M, Bienert S, Waterhouse A, et al (2014) SWISS-MODEL: modelling protein tertiary and quaternary structure using evolutionary information. Nucleic Acids Res 42:W252-W258

Black DM, Thompson DE, Bauer DC, et al (2000) Fracture risk reduction with alendronate in women with osteoporosis: the Fracture intervention trial. J Clin Endocrinol Metab $85: 4118-4124$

Blodgett JA, Zhang JK, Yu X, Metcalf WW (2016) Conserved biosynthetic pathways for phosalacine, bialaphos and newly discovered phosphonic acid natural products. J Antibiot (Tokyo) 69:15-25 
Blodgett JA V, Zhang JK, Metcalf WW (2005) Molecular cloning, sequence analysis, and heterologous expression of the phosphinothricin tripeptide biosynthetic gene cluster from Streptomyces viridochromogenes DSM 40736. Antimicrob Agents Chemother 49:230-40

Borisova SA, Circello BT, Zhang JK, et al (2010) Biosynthesis of rhizocticins, antifungal phosphonate oligopeptides produced by Bacillus subtilis ATCC6633. Chem Biol 17:28-37

Bowman E, McQueney M, Barry RJ, Dunaway-Mariano D (1988) Catalysis and thermodynamics of the phosphoenolpyruvate/phosphonopyruvate rearrangement. Entry into the phosphonate class of naturally occurring organophosphorus compounds. J Am Chem Soc 110:5575-5576

Bowman ED, McQueney MS, Scholten JD, Dunaway-Mariano D (1990) Purification and characterization of the Tetrahymena pyriformis P-C bond forming enzyme phosphoenolpyruvate phosphomutase. Biochemistry 29:7059-7063

Brandfass C, Karlovsky P (2008) Upscaled CTAB-based DNA extraction and real-time PCR assays for Fusarium culmorum and $F$. graminearum DNA in plant material with reduced sampling error. Int J Mol Sci 9:2306-2321

Brown DW, Butchko RAE, Busman M, Proctor RH (2007) The Fusarium verticillioides FUM gene cluster encodes a $\mathrm{Zn}(\mathrm{II}) 2 \mathrm{Cys} 6$ protein that affects FUM gene expression and fumonisin production. Eukaryot Cell 6:1210-8

Bustin SA, Benes V, Garson JA, et al (2009) The MIQE guidelines: minimum information for publication of quantitative real-time PCR experiments. Clin Chem 55:611-22

Buszewski B, Noga S (2012) Hydrophilic interaction liquid chromatography (HILIC)-a powerful separation technique. Anal Bioanal Chem 402:231-247

Cech NB, Enke CG (2001) Practical implications of some recent studies in electrospray ionization fundamentals. Mass Spectrom Rev 20:362-387

Chen CCH, Han Y, Niu W, et al (2006) Structure and kinetics of phosphonopyruvate hydrolase from Voriovorax sp. Pal2: new insight into the divergence of catalysis within the PEP mutase/isocitrate lyase superfamily. Biochemistry 45:11491-11504

Chomczynski P, Sacchi N (2006) The single-step method of RNA isolation by acid guanidinium thiocyanate-phenol-chloroform extraction: twenty-something years on. 
Nat Protoc 1:581-585

Cioni JP, Doroghazi JR, Ju K-S, et al (2014) Cyanohydrin phosphonate natural product from Streptomyces regensis. J Nat Prod 77:243-249

Circello BT, Eliot AC, Lee J-H, et al (2010) Molecular cloning and heterologous expression of the dehydrophos biosynthetic gene cluster. Chem Biol 17:402-411

Covert SF, Kapoor P, Lee M, et al (2001) Agrobacterium tumefaciens-mediated transformation of Fusarium circinatum. Mycol Res 105:259-264

Creamer JR, Bostock RM (1986) Characterization and biological activity of Phytophthora infestans phospholipids in the hypersensitive response of potato tuber. Physiol Mol Plant Pathol 28:215-225

Cubbon S, Antonio C, Wilson J, Thomas-Oates J (2010) Metabolomic applications of HILIC-LC-MS. Mass Spectrom Rev 29:671-684

de Groot MJA, Bundock P, Hooykaas PJ., Beijersbergen AGM (1998) Agrobacterium tumefaciens-mediated transformation of filamentous fungi. Nat Biotechnol 16:839842

Demain AL, Vaishnav P (2009) Production of recombinant proteins by microbes and higher organisms. Biotechnol Adv 27:297-306

Duyvesteijn RGE, Van Wijk R, Boer Y, et al (2005) Frp1 is a Fusarium oxysporum F-box protein required for pathogenicity on tomato. Mol Microbiol 57:1051-1063

Eliot AC, Griffin BM, Thomas PM, et al (2008) Cloning, expression, and biochemical characterization of Streptomyces rubellomurinus genes required for biosynthesis of antimalarial compound FR900098. Chem Biol 15:765-770

Evans BS, Zhao C, Gao J, et al (2013) Discovery of the antibiotic phosacetamycin via a new mass spectrometry-based method for phosphonic acid detection. ACS Chem Biol 8:908-913

Ferguson CG, Gorin BI, Thatcher GRJ (2000) Design of novel derivatives of phosphonoformate (Foscarnet) as prodrugs and antiviral agents. J Org Chem 65:12181221

Finn RD, Attwood TK, Babbitt PC, et al (2017) InterPro in 2017-beyond protein family and domain annotations. Nucleic Acids Res 45:D190-D199 
Fox EM, Mendz GL (2006) Phosphonate degradation in microorganisms. Enzyme Microb Technol 40:145-150

Frandsen RJN (2011) A guide to binary vectors and strategies for targeted genome modification in fungi using Agrobacterium tumefaciens-mediated transformation. $\mathrm{J}$ Microbiol Methods 87:247-262

Gao J, Ju K-S, Yu X, et al (2014) Use of a phosphonate methyltransferase in the identification of the fosfazinomycin biosynthetic gene cluster. Angew Chemie Int Ed $53: 1334-1337$

Geisen R, Schmidt-Heydt M, Karolewiez A (2006) A gene cluster of the ochratoxin A biosynthetic genes in Penicillium. Mycotoxin Res 22:134-141

Georgiou G, Segatori L (2005) Preparative expression of secreted proteins in bacteria: status report and future prospects. Curr Opin Biotechnol 16:538-545

Gioumouxouzis CI, Kouskoura MG, Markopoulou CK (2015) Negative electrospray ionization mode in mass spectrometry: A new perspective via modeling. $\mathrm{J}$ Chromatogr B 998-999:97-105

Glish GL, Vachet RW (2003) The basics of mass spectrometry in the twenty-first century. Nat Rev Drug Discov 2:140-150

Greco G, Letzel T (2013) Main interactions and influences of the chromatographic parameters in HILIC separations. J Chromatogr Sci 51:684-693

Gribble GW (2004) Natural organohalogens. Science Dossiers, Brussels, Belgium

Gunji S, Arima K, Beppu T (1983) Screening of antifungal antibiotics according to activities inducing morphological abnormalities. Agric Biol Chem 47:2061-2069

Guo Z, Döll K, Dastjerdi R, et al (2014) Effect of fungal colonization of wheat grains with Fusarium spp. on food choice, weight gain and mortality of meal beetle larvae (Tenebrio molitor). PLoS One 9:e100112

Hanahan D (1983) Studies on transformation of Escherichia coli with plasmids. J Mol Biol $166: 557-580$

Hao Z, Xiao B, Weng N (2008) Impact of column temperature and mobile phase components on selectivity of hydrophilic interaction chromatography (HILIC). J Sep Sci 31:1449-1464 
Hemström P, Irgum K (2006) Hydrophilic interaction chromatography. J Sep Sci 29:17841821

Henriksen T, Juhler RK, Svensmark B, Cech NB (2005) The relative influences of acidity and polarity on responsiveness of small organic molecules to analysis with negative ion electrospray ionization mass spectrometry (ESI-MS). J Am Soc Mass Spectrom $16: 446-455$

Hidaka T, Mori M, Imai S, et al (1989) Studies on the biosynthesis of bialaphos (SF-1293).

9. Biochemical mechanism of C-P bond formation in bialaphos: Discovery of phosphoenolpyruvate phosphomutase which catalyzes the formation of phosphonopyruvate from phosphoenolpyruvete. J Antibiot (Tokyo) 42:491-494

Horiguchi M, Kandatstu M (1959) Isolation of 2-aminoethane phosphonic acid from rumen protozoa. Nature 184:901-902

Horsman GP, Zechel DL (2017) Phosphonate biochemistry. Chem Rev 117:5704-5783

Hothorn T, Bretz F, Westfall P (2008) Simultaneous inference in general parametric models. Biometrical J 50:346-363

Hove-Jensen B, Zechel DL, Jochimsen B (2014) Utilization of glyphosate as phosphate source: biochemistry and genetics of bacterial carbon-phosphorus lyase. Microbiol Mol Biol Rev 78:176-97

Huang Z, Wang K-KA, Lee J, van der Donk WA (2015) Biosynthesis of fosfazinomycin is a convergent process. Chem Sci 6:1282-1287

Jia Y, Lu Z, Huang K, et al (1999) Insight into the mechanism of phosphoenolpyruvate mutase catalysis derived from site-directed mutagenesis studies of active site residues. Biochemistry 38:14165-14173

Ju K-S, Doroghazi JR, Metcalf WW (2014) Genomics-enabled discovery of phosphonate natural products and their biosynthetic pathways. J Ind Microbiol Biotechnol 41:345356

Ju K-S, Gao J, Doroghazi JR, et al (2015) Discovery of phosphonic acid natural products by mining the genomes of 10,000 actinomycetes. Proc Natl Acad Sci U S A 112:12175-80

Kamat SS, Raushel FM (2013) The enzymatic conversion of phosphonates to phosphate by bacteria. Curr Opin Chem Biol 17:589-596 
Katayama N, Tsubotani S, Nosaki Y, et al (1990) Fosfadecin and fosfocytocin, new nucleotide antibiotics produced by bacteria. J Antibiot (Tokyo) 43:238-246

Kaysser L, Bernhardt P, Nam S-J, et al (2012) Merochlorins A-D, cyclic meroterpenoid antibiotics biosynthesized in divergent pathways with vanadium-dependent chloroperoxidases. J Am Chem Soc 134:11988-11991

Kennedy K, Thompson G (1970) Phosphonolipids: localization in surface membranes of Tetrahymena. Science (80- ) 168:989-991

Kim A, Kim J, Martin BM, Dunaway-Mariano D (1998) Isolation and characterization of the carbon-phosphorus bond-forming enzyme phosphoenolpyruvate mutase from the mollusk Mytilus edulis. J Biol Chem 273:4443-8

Kim AD, Baker AS, Dunaway-Mariano D, et al (2002) The 2-aminoethylphosphonatespecific transaminase of the 2-aminoethylphosphonate degradation pathway. $\mathbf{J}$ Bacteriol 184:4134-40

Kim J-E, Jin J, Kim H, et al (2006) GIP2, a putative transcription factor that regulates the aurofusarin biosynthetic gene cluster in Gibberella zeae. Appl Environ Microbiol $72: 1645-52$

Kim J, Dunaway-Mariano D (1996) Phosphoenolpyruvate mutase catalysis of phosphoryl transfer in phosphoenolpyruvate: kinetics and mechanism of phosphorus-carbon bond formation. Biochemistry 35:4628-4635

Kim SY, Ju K-S, Metcalf WW, et al (2012) Different biosynthetic pathways to fosfomycin in Pseudomonas syringae and Streptomyces species. Antimicrob Agents Chemother $56: 4175-83$

Kittredge JS, Roberts E (1969) A carbon-phosphorus bond in nature. Science (80- ) $164: 37-42$

Kleinboelting N, Huep G, Appelhagen I, et al (2015) The structural features of thousands of T-DNA insertion sites are consistent with a double- strand break repair-based insertion mechanism. Mol Plant 8:1651-1664

Kononova S V., Nesmeyanova MA (2002) Phosphonates and their degradation by microorganisms. Biochem 67:184-195

Koukol O, Novák F, Hrabal R (2008) Composition of the organic phosphorus fraction in basidiocarps of saprotrophic and mycorrhizal fungi. Soil Biol Biochem 40:2464-2467 
Koukol O, Novák F, Hrabal R, Vosátka M (2006) Saprotrophic fungi transform organic phosphorus from spruce needle litter. Soil Biol Biochem 38:3372-3379

La Nauze JM, Coggins JR, Dixon HB (1977) Aldolase-like imine formation in the mechanism of action of phosphonoacetaldehyde hydrolase. Biochem J 165:409-11

La Nauze JM, Rosenberg H, Shaw DC (1970) The enzymic cleavage of the carbonphosphorus bond: Purification and properties of phosphonatase. Biochim Biophys Acta - Enzymol 212:332-350

Lea P, Joy K, Ramos J, Guerrero M (1984) The action of 2-amino-4-(methylphosphinyl)butanoic acid (phosphinothricin) and its 2-oxo-derivative on the metabolism of cyanobacteria and higher plants. Phytochemistry 23:1-6

Lee KS, Metcalf WW, Wanner BL (1992) Evidence for two phosphonate degradative pathways in Enterobacter aerogenes. J Bacteriol 174:2501-10

Lelliott RA, Stead DE (1987) Methods for the diagnosis of bacterial diseases of plants. Blackwell Scientific Publications, Oxford, UK

Liang C-R, Rosenberg H (1968) On the distribution and biosynthesis of 2aminoethylphosphonate in two terrestrial molluscs. Comp Biochem Physiol 25:673681

Liu S, Lu Z, Han Y, et al (2004) Conformational flexibility of PEP mutase. Biochemistry $43: 4447-4453$

Liu S, Lu Z, Jia Y, et al (2002) Dissociative phosphoryl transfer in PEP mutase catalysis: structure of the enzyme/sulfopyruvate complex and kinetic properties of mutants. Biochemistry 41:10270-10276

Lutz MP, Feichtinger G, Défago G, Duffy B (2003) Mycotoxigenic Fusarium and deoxynivalenol production repress chitinase gene expression in the biocontrol agent Trichoderma atroviride P1. Appl Environ Microbiol 69:3077-84

Maciejczyk E, Wieczorek D, Zwyrzykowska A, et al (2015) Phosphorus profile of basidiomycetes. Phosphorus Sulfur Silicon Relat Elem 190:763-768

MacPherson S, Larochelle M, Turcotte B (2006) A fungal family of transcriptional regulators: the zinc cluster proteins. Microbiol Mol Biol Rev 70:583-604

Maier F, Malz S, Losch A, et al (2005) Development of a highly efficient gene targeting 
system for using the disruption of a polyketide synthase gene as a visible marker. FEMS Yeast Res 5:653-662

Maile R, Fischesser G, Anderson M (1977) Thin-layer chromatographic separation of phosphonic acid derivatives. J Chromatogr 132:366-368

Marquardt JL, Brown ED, Lane WS, et al (1994) Kinetics, stoichiometry, and identification of the reactive thiolate in the inactivation of UDP-GlcNAc enolpyruvoyl transferase by the antibiotic fosfomycin. Biochemistry 33:10646-10651

Martinez A, Tyson GW, Delong EF (2010) Widespread known and novel phosphonate utilization pathways in marine bacteria revealed by functional screening and metagenomic analyses. Environ Microbiol 12:222-238

McGrath JW, Chin JP, Quinn JP (2013) Organophosphonates revealed: new insights into the microbial metabolism of ancient molecules. Nat Rev Microbiol 11:412-419

McSorley FR, Wyatt PB, Martinez A, et al (2012) PhnY and PhnZ comprise a new oxidative pathway for enzymatic cleavage of a carbon-phosphorus bond. J Am Chem Soc 134:8364-8367

Metcalf WW, van der Donk WA (2009) Biosynthesis of phosphonic and phosphinic acid natural products. Annu Rev Biochem 78:65-94

Meyer V (2008) Genetic engineering of filamentous fungi - Progress, obstacles and future trends. Biotechnol Adv 26:177-185

Michielse CB, Hooykaas PJJ, van den Hondel CAMJJ, Ram AFJ (2005) Agrobacteriummediated transformation as a tool for functional genomics in fungi. Curr Genet 48:117

Nakashita H, Watanabe K, Hara O, et al (1997) Studies on the biosynthesis of bialaphos. Biochemical mechanism of C-P bond formation: discovery of phosphonopyruvate decarboxylase which catalyzes the formation of phosphonoacetaldehyde from phosphonopyruvate. J Antibiot (Tokyo) 50:212-219

Nielsen ML, Pustinger J V., Strobel J (1964) Phosphorus-31 nuclear magnetic resonance chemical shifts of phosphorus compounds. J Chem Eng Data 9:167-170

Olsen DB, Hepburn TW, Lee S, et al (1992) Investigation of the substrate binding and catalytic groups of the P-C bond cleaving enzyme, phosphonoacetaldehyde hydrolase. Arch Biochem Biophys 296:144-151 
Omura S, Murata M, Hanaki H, et al (1984) Phosalacine, a new herbicidal antibiotic containing phosphinothricin. Fermentation, isolation, biological activity and mechanism of action. J Antibiot (Tokyo) 37:829-835

Onorato JM, Langish R, Bellamine A, Shipkova P (2010) Applications of HILIC for targeted and non-targeted LC/MS analyses in drug discovery. J Sep Sci 33:923-929

Pan Z, Raftery D (2007) Comparing and combining NMR spectroscopy and mass spectrometry in metabolomics. Anal Bioanal Chem 387:525-527

Park BK, Hirota A, Sakai H (1977) Studies on new antimetabolite produced by microorganism. III. Structure of plumbemycin A and B, antagonists of L-threonine from Streptomyces plumbeus. Agric Biol Chem 41:573-579

Peck SC, van der Donk WA (2013) Phosphonate biosynthesis and catabolism: a treasure trove of unusual enzymology. Curr Opin Chem Biol 17:580-588

Pfaffl MW (2001) A new mathematical model for relative quantification in real-time RTPCR. Nucleic Acids Res 29:45e-45

Punt PJ, Dingemanse MA, Kuyvenhoven A, et al (1990) Functional elements in the promoter region of the Aspergillus nidulans gpdA gene encoding glyceraldehyde-3phosphate dehydrogenase. Gene 93:101-109

R Core Team (2017) R: A language and environment for statistical computing. R Found. Stat. Comput.

Rai M, Padh H (2001) Expression systems for production of heterologous proteins. Curr Sci 80:1121-1128

Rao RN, Allen NE, Hobbs JN, et al (1983) Genetic and enzymatic basis of hygromycin B resistance in Escherichia coli. Antimicrob Agents Chemother 24:689-95

Reeves DS (1994) Fosfomycin trometamol. J Antimicrob Chemother 34:853-858

Rice P, Longden I, Bleasby A (2000) EMBOSS: the European molecular biology open software suite. Trends Genet 16:276-277

Rosano GL, Ceccarelli EA (2014) Recombinant protein expression in Escherichia coli: advances and challenges. Front Microbiol 5:172

Roseberg H, La Nauze JM (1967) The metabolism of phosphanates by microorganisms. The transport of aminoethylphosphonic acid in Basillus cereus. Biochim Biophys 
Acta 141:79-90

Rost B (1999) Twilight zone of protein sequence alignments. Protein Eng Des Sel 12:8594

Sander C, Schneider R (1991) Database of homology-derived protein structures and the structural meaning of sequence alignment. Proteins Struct Funct Genet 9:56-68

Sarkar M, Hamilton CJ, Fairlamb AH (2003) Properties of phosphoenolpyruvate mutase, the first enzyme in the aminoethylphosphonate biosynthetic pathway in Trypanosoma cruzi. J Biol Chem 278:22703-8

Schiesel S, Lämmerhofer M, Lindner W (2010) Multitarget quantitative metabolic profiling of hydrophilic metabolites in fermentation broths of $\beta$-lactam antibiotics production by HILIC-ESI-MS/MS. Anal Bioanal Chem 396:1655-1679

Schowanek D, Verstraete W (1990) Phosphonate utilization by bacterial cultures and enrichments from environmental samples. Appl Environ Microbiol 56:895-903

Seidel HM, Freeman S, Seto H, Knowles JR (1988) Phosphonate biosynthesis: isolation of the enzyme responsible for the formation of a carbon-phosphorus bond. Nature $335: 457-458$

Seidel HM, Pompliano DL, Knowles JR (1992) Phosphonate biosynthesis: molecular cloning of the gene for phosphoenolpyruvate mutase from Tetrahymena pyriformis and overexpression of the gene product in Escherichia coli. Biochemistry 31:25982608

Seto H, Imai S, Tsuruoka T, et al (1982) Studies on the biosynthesis of bialaphos (SF1293) 1. Incorporation of $13 \mathrm{C}$ - and $2 \mathrm{H}$-labeled precursors into bialaphos. J Antibiot (Tokyo) 35:1719-1721

Seto H, Kuzuyama T, Seto H, Kuzuyama T (1999) Bioactive natural products with carbonphosphorus bonds and their biosynthesis. Nat Prod Rep 16:589-596

Seweryn P, Van LB, Kjeldgaard M, et al (2015) Structural insights into the bacterial carbon-phosphorus lyase machinery. Nature 525:68-72

Shao Z, Blodgett JA V, Circello BT, et al (2008) Biosynthesis of 2hydroxyethylphosphonate, an unexpected intermediate common to multiple phosphonate biosynthetic pathways. J Biol Chem 283:23161-8 
Sievers F, Wilm A, Dineen D, et al (2011) Fast, scalable generation of high-quality protein multiple sequence alignments using Clustal Omega. Mol Syst Biol 7:539

Sosa OA, Repeta DJ, Ferrón S, et al (2017) Isolation and characterization of bacteria that degrade phosphonates in marine dissolved organic matter. Front Microbiol 8:1786

Stead MB, Agrawal A, Bowden KE, et al (2012) RNAsnap : a rapid, quantitative and inexpensive, method for isolating total RNA from bacteria. Nucleic Acids Res 40:e156-e156

Stutter MI, Shand CA, George TS, et al (2015) Land use and soil factors affecting accumulation of phosphorus species in temperate soils. Geoderma 257-258:29-39

Suchfort R (2016) Biological detoxification of enniatins. Georg-August-Universität Göttingen

Sugui JA, Chang YC, Kwon-Chung KJ (2005) Agrobacterium tumefaciens-mediated transformation of Aspergillus fumigatus: an efficient tool for insertional mutagenesis and targeted gene disruption. Appl Environ Microbiol 71:1798-802

Takahashi E, Kimura T, Nakamura K, et al (1995) Phosphonothrixin, a novel herbicidal antibiotic produced by Saccharothrix sp. ST-888. I. Taxonomy, fermentation, isolation and biological Properties. J Antibiot (Tokyo) 48:1124-1129

Takeuchi M, Nakajima M, Ogita T, et al (1989) Fosfonochlorin, a new antibiotic with spheroplast forming activity. J Antibiot (Tokyo) 42:198-205

Tate KR, Newman RH (1982) Phosphorus fractions of a climosequence of soils in New Zealand tussock grassland. Soil Biol Biochem 14:191-196

Terpe K (2006) Overview of bacterial expression systems for heterologous protein production: from molecular and biochemical fundamentals to commercial systems. Appl Microbiol Biotechnol 72:211-222

The Gene Ontology Consortium (2015) Gene Ontology Consortium: going forward. Nucleic Acids Res 43:D1049-D1056

Turner BL, Baxter R, Mahieu N, et al (2004) Phosphorus compounds in subarctic Fennoscandian soils at the mountain birch (Betula pubescens)-tundra ecotone. Soil Biol Biochem 36:815-823

Utermark J, Karlovsky P (2007) Role of zearalenone lactonase in protection of 
Gliocladium roseum from fungitoxic effects of the mycotoxin zearalenone. Appl Environ Microbiol 73:637-42

Vary PS, Biedendieck R, Fuerch T, et al (2007) Bacillus megaterium-from simple soil bacterium to industrial protein production host. Appl Microbiol Biotechnol 76:957967

Wackett LP, Shames SL, Venditti CP, Walsh CT (1987) Bacterial carbon-phosphorus lyase: products, rates, and regulation of phosphonic and phosphinic acid metabolism. J Bacteriol 169:710-7

Wassef MK, Hendrix JW (1977) Ceramide aminoethylphosphonate in the fungus Pythium prolatum. Biochim Biophys Acta - Lipids Lipid Metab 486:172-178

Weld RJ, Plummer KM, Carpenter MA, Ridgway HJ (2006) Approaches to functional genomics in filamentous fungi. Cell Res 16:31-44

Wendler C, Barniske M, Wild A (1990) Effect of phosphinothricin (glufosinate) on photosynthesis and photorespiration of C3 and C4 plants. Photosynth Res 24:55-61

Woloshuk CP, Foutz KR, Brewer JF, et al (1994) Molecular characterization of aflR, a regulatory locus for aflatoxin biosynthesis. Appl Environ Microbiol 60:2408-14

Woo G, Tomlinson G, Nishikawa Y, et al (2010) Tenofovir and entecavir are the most effective antiviral agents for chronic hepatitis B: a systematic review and bayesian meta-analyses. Gastroenterology 139:1218-1229.e5

Woodyer RD, Li G, Zhao H, van der Donk WA (2007) New insight into the mechanism of methyl transfer during the biosynthesis of fosfomycin. Chem Commun 0:359-361

Woodyer RD, Shao Z, Thomas PM, et al (2006) Heterologous production of fosfomycin and identification of the minimal biosynthetic gene cluster. Chem Biol 13:1171-1182

Xu D, Guo H, Yun L, York DM (2005) Theoretical studies of dissociative phosphoryl transfer in interconversion of phosphoenolpyruvate to phosphonopyruvate: solvent effects, thio effects, and implications for enzymatic reactions. J Phys Chem B 109:13827-13834

Yin W, Keller NP (2011) Transcriptional regulatory elements in fungal secondary metabolism. J Microbiol 49:329-339

Yu X, Doroghazi JR, Janga SC, et al (2013) Diversity and abundance of phosphonate 
biosynthetic genes in nature. Proc Natl Acad Sci U S A 110:20759-64

Zechel DL (2016) PhnK: another piece of the carbon-phosphorus lyase puzzle. Structure 24:3-4

Zeleznick L, Myers T, Titchener E (1963) Growth of Escherichia coli on methyl-and ethylphosphonic acids. Biochim Biophys Acta 78:547-550

Zhang G, Dai J, Lu Z, Dunaway-Mariano D (2003) The phosphonopyruvate decarboxylase from Bacteroides fragilis.J Biol Chem 278:41302-8 


\section{Supplementary information}

\subsection{Tables}

Supplement Table 1. List of primers used in F. oxysporum gene expression analysis

\begin{tabular}{|c|c|c|c|c|c|}
\hline $\begin{array}{c}\text { Primer } \\
\text { number }\end{array}$ & $\begin{array}{c}\text { Primer } \\
\text { name }\end{array}$ & $\begin{array}{c}\text { Accession } \\
\text { number }\end{array}$ & $\begin{array}{c}\text { Efficiency/ } \\
\mathbf{R}^{2} \\
\end{array}$ & $\begin{array}{c}\text { Product size } \\
\text { (bp) }\end{array}$ & Sequence $\left(5^{\prime}-3^{\prime}\right)$ \\
\hline 1 & TF1_F & \multirow{2}{*}{$\begin{array}{c}\text { Foxg_02659 } \\
\text { TF1 gene }\end{array}$} & \multirow{2}{*}{$1.19 / 0.98$} & \multirow{2}{*}{116} & GCTAGACAACCCCAAGCTCT \\
\hline 2 & TF1_R & & & & GTGACCTCTTGGCAGCGATA \\
\hline 3 & ppdRT_F & \multirow{2}{*}{$\begin{array}{c}\text { Foxg_02662 } \\
\text { ppd gene }\end{array}$} & \multirow{2}{*}{$1.05 / 0.97$} & \multirow{2}{*}{113} & TTCTGATGGAGTGTTCCCGC \\
\hline 4 & ppdRT_R & & & & CAATGGTGTTTGGCACCCAG \\
\hline 5 & pepmC_F & \multirow{2}{*}{$\begin{array}{c}\text { Foxg_02666 } \\
\text { pepm gene }\end{array}$} & \multirow{2}{*}{$0.94 / 0.99$} & \multirow{2}{*}{184} & GAAGTTCGATGGCATCTGGT \\
\hline 6 & pepmC_R & & & & TGCGATATCACCACCACTGT \\
\hline 7 & oxred_F & \multirow{2}{*}{$\begin{array}{c}\text { Foxg_02667 } \\
\text { oxred gene }\end{array}$} & \multirow{2}{*}{$1.16 / 0.99$} & \multirow{2}{*}{179} & GATGTTCAACCGCCCTACCA \\
\hline 8 & oxred_R & & & & TCTCTGAGAAAGCGGCAGTG \\
\hline 9 & cyt450_F & \multirow{2}{*}{$\begin{array}{l}\text { Foxg_02668 } \\
\text { cyt450 gene }\end{array}$} & \multirow{2}{*}{$1.04 / 0.99$} & \multirow{2}{*}{107} & AGGGAACCTTACACATGCGA \\
\hline 10 & cyt450_R & & & & ACGCTCTGCCTTTAGCTCAG \\
\hline 11 & TF15_F & \multirow{2}{*}{$\begin{array}{l}\text { Foxg_02671 } \\
\text { TF15 gene }\end{array}$} & \multirow{2}{*}{$1.01 / 0.99$} & \multirow{2}{*}{226} & GCAAAGATGACCCCCAAGGA \\
\hline 12 & TF15_R & & & & TCGCTACACGCTGAGTCAAT \\
\hline 13 & GAPDH_F & \multirow{2}{*}{$\begin{array}{l}\text { Foxg_08006 } \\
\text { gapdh gene }\end{array}$} & \multirow{2}{*}{$0.83 / 0.98$} & \multirow{2}{*}{142} & CTACATGCTCAAGTACGACTCTTCC \\
\hline 14 & GAPDH_R & & & & GCCGGTCTCGGACCACTTG \\
\hline 15 & EFIA_F & \multirow{2}{*}{$\begin{array}{l}\text { Foxg_03515 } \\
\text { efia gene }\end{array}$} & \multirow{2}{*}{$1.04 / 0.98$} & \multirow{2}{*}{192} & AAAGACCCTCCTTGAGGCCATTGA \\
\hline 16 & EFIA_R & & & & ACTTCAGTGGTGACGTTGGAAGGA \\
\hline
\end{tabular}

Supplement Table 2. List of primers used for the heterologous expression of pepm protein in E. coli

\begin{tabular}{ll}
\hline $\begin{array}{l}\text { Primer } \\
\text { name }\end{array}$ & \multicolumn{1}{c}{ Sequence $\left(\mathbf{5}^{\prime}-\mathbf{3}^{\prime}\right.$ ) } \\
\hline A_F & AGAGAAAGCTTATGGGTTCCCTTCATACTGA \\
D_R & AGAGACTCGAGGTAAACTACTACCTGGGTGA \\
GFP_F & AGAGAGCTAGCatgagtaaaggagaagaactttcactggagt \\
GFP_R & AGAGAAAGCTTACGACCTTCGATGAATTCTCCGCTTCCTGCTGCGCTTCCTGCGCTTCCttgtagagctcatccatgccatgtg
\end{tabular}




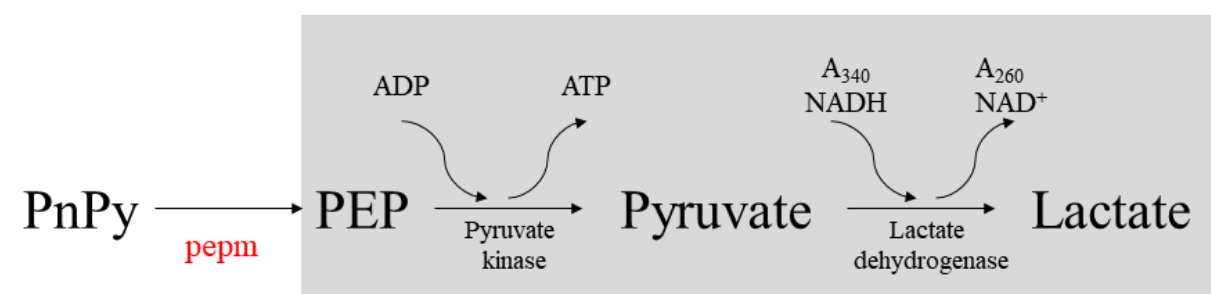

Supplement figure 1. Representation of the pepm enzymatic assayemployed in the present study in which PEP was not added into the reaction to determine the formation of PEP based on the reduction of absorbance at $340 \mathrm{~nm}$ due to NADH oxidation. Steps inside the gray box represents the reaction in the positive sample in which PEP was included.
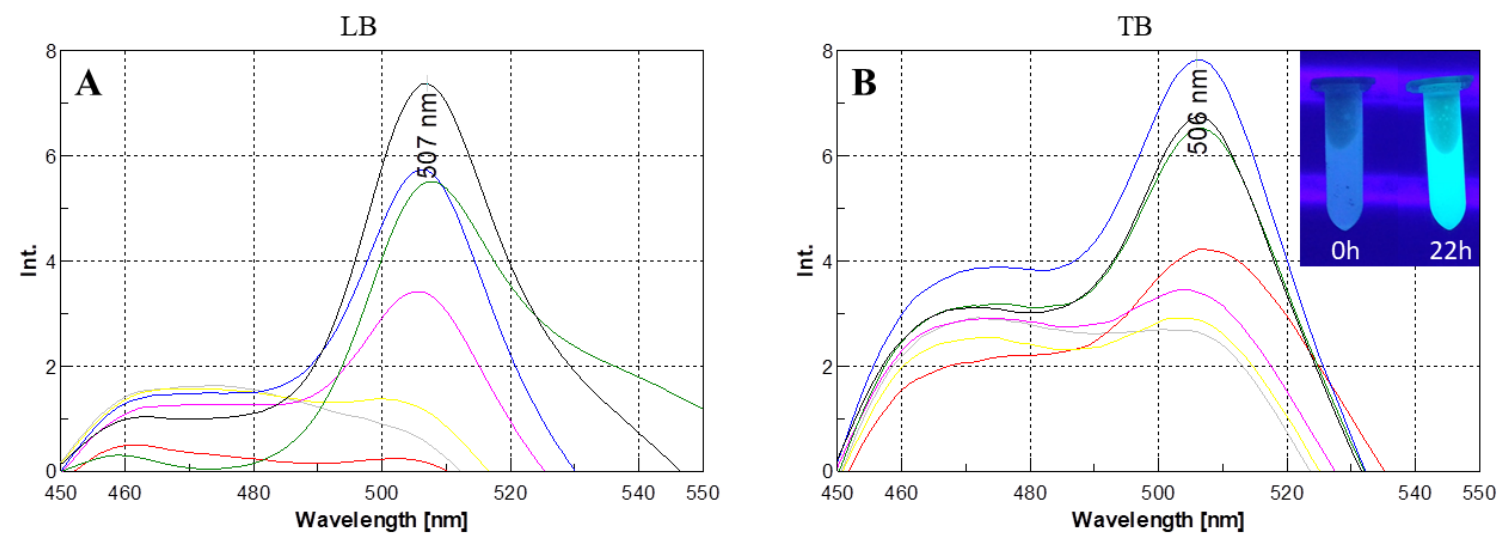

Oh

Supplement figure 2. Emission at $507 \mathrm{~nm}$ of soluble proteins extracted from E. coli BL21(DE3) carrying the vector pET21_GFP_pepm after 0h (gray), 1h (yellow), 3h (purple), 4h (blue), 5h (green), 6h (black) and 22h (red) of induction using LB (A) or TB (B) medium supplemented with 0.1 mM IPTG. 


\title{
CHAPTER 3. The biological function of phosphonates in F. oxysporum
}

\begin{abstract}
Natural phosphonates provide advantages to the producer organisms in competitive environments due to the stable $\mathrm{C}-\mathrm{P}$ bond. Some bacteria can synthetize bioactive phosphonates, while other organisms, such as marine invertebrates, mollusk and protozoa, produce a special kind of phosphonate [aminoethylphosphonate(AEP)], with a structural function in membranes. Only one phosphonate has been identified in fungi, called fosfonochlorin, which was described as an antibiotic compound produced by some Fusarium species. The interest in bioactive phosphonates relies in their plenty uses in medicine and agriculture; however, the biological function of these compounds has not been investigated so far. In the present study we disrupted phosphonates biosynthesis in $F$. oxysporumand we used the knockout mutants to clarify the biological role of $F$. oxysporum phosphonates against bacteria, mycoparasitic fungi and T. molitor larvae. Any strong effect of the phosphonates producer (wild type) on bacterial growth was observed when compared with the phosphonates-disrupted (knock-out) strains. Similarly, although the wild type inhibited the growth of mycoparasitic fungi while the knock-outs did not, this inhibition effect, expected from the ectopic strain (which can still produce phosphonates), was not observed. When T. molitor larvae were fed with wild type and knock-outs mycelium no effect on their fitness related with phosphonates was observed. However, interestingly, during food choice experiments, larvae preferred always the mycelium of the wild type and the ectopic strains instead of the knock-outs mycelium, suggesting that an unknown factor related with phosphonates could influence the feeding larvae behavior. The phosphonates-disrupted strains generated in the present study can be used for further research on Fusarium phosphonates.
\end{abstract}

Keywords: phosphonates, C-P compounds, Fusariumoxysporum, Agrobacterium tumefaciens-mediated transformation, knock-out, biological function. 


\section{Introduction}

Phosphonates contains a direct $\mathrm{C}-\mathrm{P}$ bond, whichis stable to thermal and chemical degradation, and enzymatic hydrolysis. Therefore, they provide competitive advantages to the producing organisms. Natural phosphonates are produced by several species of bacteria (Katayama et al. 1990; Takahashi et al. 1995; Zhang et al. 2003; Borisova et al. 2010; Kim et al. 2012), mainly belonging to the Streptomyces genus (Park et al. 1977; Seto et al. 1982; Blodgett et al. 2005; Woodyer et al. 2006; Eliot et al. 2008; Circello et al. 2010; Gao et al. 2014), but also by marine invertebrates, mollusks and protozoa (Liang and Rosenberg 1968; Kittredge and Roberts 1969; Sarkar et al. 2003; Martinez et al. 2010).

Some phosphonates of natural origin are bioactive molecules with antibiotic activity such as dehydrophos (Circello et al. 2010) and fosfomycin (Woodyer et al. 2006) or with antifungal activity such as fosfazinomycin (Gunji et al. 1983) and rhizocticins (Borisova et al. 2010). Another known phosphonate [aminoethylphosphonate(AEP)], on the other hand, has structural function (phosphonolipids, phosphonoglycans) in the membranes of certain organisms such as marine invertebrates, oomycetesandsome bacteria(Liang and Rosenberg 1968; Kittredge and Roberts 1969; Wassef and Hendrix 1977; Creamer and Bostock 1986; Kim et al. 2002; Zhang et al. 2003).

The biosynthetic pathways of some phosphonates are already known. The first steps share the same enzymes in most organisms. Phosphoenolpyruvate mutase (pepm) is the key enzyme and the responsible for the $\mathrm{C}-\mathrm{P}$ bond formation using always phosphoenolpyruvate (PEP) as a substrate to produce phosphonopyruvate (PnPy). From here the following steps vary depending on the organism; however, the decarboxylation of PnPy to produce phosphonoacetaldehyde (PnAA) is the most common reaction that moves the reaction forward (Hidaka et al. 1989; Nakashita et al. 1997; Seto et al. 1999; Zhang et al. 2003; Blodgett et al. 2005; Eliot et al. 2008; Ju et al. 2014).

Research onbioactive phosphonates has been focused mainly on its application in different areas for human interest, mainly medicine and agriculture. However, the biological function of these compounds is still unknown. One useful way to clarify the function of an unknown natural compound is by disrupting an essential gene for the biosynthesis, thus 
eliminating the production of the compound. Then, severalassaysare carry out where the disrupted strain (knock-out)and the wild type (wt) strain are assayed against other organisms to evaluate the effect on them. In fungi, one method to disrupt genes is through Agrobacterium tumefaciens -mediated transformation. This system has the advantage that allows the replacement of the target gene by homologous recombination (Weld et al. 2006), resulting in transformants which, most of the times, carry a single copy of the replaced-gene (Michielse et al. 2005).

Fosfonochlorin is the only fungal phosphonate described so far. In 1989, Takeuchi and collaborators demonstrated that Fusarium oxysporum, F. avenaceum, F. tricinctum and Talaromyces flavus can produce this compound which showed antibiotic activity against some gram-negative bacteria (Takeuchi et al. 1989). In the previous chapter we have demonstrated that the genome of some fungal species, including Fusarium spp., contain homologous phosphonates-related genes and that they are active under bacteria-fungal interaction. In the present chapter we tried to elucidate the biological function of these compounds in $F$. oxysporum using phosphonates-disrupted strains.

The objective of this chapter was to clarify the biological function of phosphonates in $F$. oxysporum. To accomplish this, first, $F$. oxysporum was genetically modified in order to disrupt phosphonates biosynthesis in the fungus. Thereafter, several biological assays were carried out in which the phosphonates-disrupted strains or knock-outs ( $\Delta p e p m)$ were used together with the wt to compare the effect of phosphonates on other organism's growth (bacteria, mycoparasitic fungi and T. molitor larvae).

\section{Materials and methods}

\subsection{Disruption of phosphonates biosynthesis in $F$. oxysporum}

Phosphonates biosynthesis was disrupted by replacement of the pepm gene by the hph (Hygromycin B phosphotransferase)-cassette in F. oxysporum DSM62291 genome though homologous recombination by means of A. tumefaciens-mediated transformation as follows: 


\subsubsection{Fungal spore production and DNA extraction}

F. oxysporum spores were cultivated on potato dextrose broth (PDB, Carl Roth $\mathrm{GmbH}$, Karlsruhe, Germany) medium supplemented with $7 \mathrm{~g} / \mathrm{L}$ of agar (PDA), for 5-7 days until enough mycelium was obtained to use it further for DNA extraction or for large scale spore production for fungal transformation purposes. For DNA extraction, a plug of the mycelium ( $5 \mathrm{~mm}$ diameter) was cultivated on PDB for 7-8 days at $120 \mathrm{rpm}$ and $25^{\circ} \mathrm{C}$. The mycelium was freeze dried and 50-100 mg was used for DNA extraction using the CTAB method described by Brandfass and Karlovsky (2008). Spores were produced cultivating a plug of mycelium (5 mm diameter) in liquid Mung Bean media (Bai and Shaner 1996) at $28{ }^{\circ} \mathrm{C}, 200 \mathrm{rpm}$ for 5 days. The spores thus obtained were stored at $-60{ }^{\circ} \mathrm{C}$ in $15 \%$ glycerol in sterilized tap water until the experiments.

\subsubsection{Sensitivity test of ygromycin on $F$. oxysporum}

The lowest concentration of hygromycin B that inhibits $F$. oxysporum DSM62291 growth was determined as follows: spores $\left(10^{6}\right)$ were cultivated on the center of a plate with PDA medium supplemented with $0,10,25$ and $50 \mu \mathrm{g} / \mathrm{ml}$ of Hygromycin B. After one week, the presence or absence of mycelium growth was recorded.

\subsubsection{Binary vector construction and $A$. tumefaciens transformation}

A modified binary vector pPK2 (Covert et al. 2001) carrying the pepm flanking regions (FL) inside the transfer-DNA (T-DNA) region was used for A. tumefaciens transformation. Pepmgene FL5' and FL3' (949 bp and 727 bp respectively) were amplified from the DNA of F. oxysporum DSM62291 by means of PCR using a Peqlab thermocycler (Peqlab Biotechnologie GmbH, Erlangen, Germany) in $15 \mu$ l of reaction mixture containing $1 \mathrm{x}$ reaction buffer, $0.4 \mu \mathrm{M}$ of forward (primer 1 and 3 ) and reverse (primers 2 and 4) primers (supplementary table 1), $0.4 \mathrm{U}$ of PCRBio $\mathrm{HiFi}$ polymerase (PCRBiosystems, London, UK) and $1 \mu \mathrm{l}(50-100 \mathrm{ng})$ of DNA as a template. PCR conditions were as follows: $94^{\circ} \mathrm{C}$ for $1 \mathrm{~min}, 30$ cycles of $94^{\circ} \mathrm{C}$ for $20 \mathrm{~s}, 60^{\circ} \mathrm{C}$ for $30 \mathrm{~s}$ and $72^{\circ} \mathrm{C}$ for $30 \mathrm{~s}$.

FLs of pepm gene were inserted downstream and upstream of the $h p h$-cassette in pPK2 to obtain pPK2_FL3+FL5. To construct this vector, first the FL3' was inserted between SbfI and HindIII sites of pPK2 and the vector thus produced (pPK2_FL3) was transformed into competent E. coli DH5 $\alpha$ by means of heat shock. Single colonies were cloned overnight and then purified using alkaline lysis. FL5' region was further inserted between KpnI and 
PacI sites of the previously constructed pPK2_FL3 vector to produce the final vector pPK2_FL3+FL5, which was cloned into E. coli DH5a and purified as previously described. Vector containing both FLs was transformed into competent A. tumefaciens AGL1 cells (provided by Dr. Susanne Frick, Leibniz Institute of Plant Biochemistry, Halle/Saale, Germany) by electroporation using $2 \mu \mathrm{l}$ of the vector (100 ng of vector DNA) and the following conditions: $1.8 \mathrm{kV}, 200 \Omega, 25 \mu \mathrm{F}$. Single colonies were obtained after $48 \mathrm{~h}$ at $28{ }^{\circ} \mathrm{C}$ on LB [Lysogeny Broth,(Bertani 1951)] plates supplemented with rifampicin $50 \mu \mathrm{g} / \mathrm{ml}$, carbenicillin $25 \mu \mathrm{g} / \mathrm{mL}$ and kanamycin $50 \mu \mathrm{g} / \mathrm{ml}$. Random colonies were selected to cloned overnight and store at $-60 \mathrm{C}$ in $15 \%$ glycerol in sterilized tap water to use them for further experiments. Colonies carrying the right constructed vector were always corroborated by colony PCR in $25 \mu 1$ reaction mixture containing $1 \mathrm{x}$ reaction buffer (20 $\mathrm{mM}$ Tris- $\mathrm{HCl}, 10 \mathrm{mM}\left(\mathrm{NH}_{4}\right)_{2} \mathrm{SO}_{4}, 10 \mathrm{mM} \mathrm{KCl}, 2 \mathrm{mM} \mathrm{MgSO} 4,0.1 \%$ Triton $\mathrm{X}-100, \mathrm{pH}$ 8.8), $4.5 \mathrm{mM}$ of $\mathrm{MgCl}_{2}, 100 \mu \mathrm{M}$ of dNTP, $0.3 \mu \mathrm{M}$ of specific primers to detect FL3' (primers 5 and 6, supplementary table 1) and FL5' (primers 3 and 4, supplementary table 1) insertions in pPK2, $0.6 \mathrm{U}$ of taq polymerase (New England Bioline, London, UK) and $10 \mu \mathrm{l}$ of a crushed single colony as a template. Colony PCR conditions were as follows: $95^{\circ} \mathrm{C}$ for $6 \mathrm{~min}, 35$ cycles of $94^{\circ} \mathrm{C}$ for $45 \mathrm{~s}, 54^{\circ} \mathrm{C}$ for $45 \mathrm{~s}$ and $68^{\circ} \mathrm{C}$ for $1 \mathrm{~min} 30 \mathrm{~s}$, with a final extension of $68^{\circ} \mathrm{C}$ for $4 \mathrm{~min}$.

\subsubsection{A. tumefaciens-mediated transformation of $F$. oxysporum}

Fungal transformation was performed according to Utermark and Karlovsky (2007) with some modifications. Briefly, T-DNA mobilization from a single AGL1 colony harboring the pPK2_FL3+FL5 vector was induced overnight at $200 \mathrm{rpm}$ and $28{ }^{\circ} \mathrm{C}$ using T-DNA induction medium (de Groot et al. 1998) supplemented with $200 \mu \mathrm{M}$ acetosyringone. Induced $\mathrm{T}-\mathrm{DNA}-$ bacteria cells $\left(\mathrm{OD}_{600}=0.3\right)$ were co-cultivated $(1: 1)$ with $F$. oxysporum spores $\left(1 \times 10^{5}\right.$ spores) on cellophane membranes (Prod.No 297/25, Folia Bringmann, Wendelstein, Germany) previously placed on induction medium agar plates supplemented with $200 \mu \mathrm{M}$ acetosyringone. After incubation for $48 \mathrm{~h}$ at $24{ }^{\circ} \mathrm{C}$, cellophane membranes were placed on selection PDA plates containing $200 \mu \mathrm{M}$ cefotaxime and $25 \mu \mathrm{g} / \mathrm{ml}$ of Hygromycin B. During the first 2-4 days, random single fungal colonies were chosen and placed on PDA plates containing $25 \mu \mathrm{g} / \mathrm{ml}$ of Hygromycin B. They were incubated for 5-6 days at $24{ }^{\circ} \mathrm{C}$ until DNA extraction. 


\subsubsection{Detection of $F$. oxysporumpepm knock-outs by means of PCR}

DNA was extracted from single fungal colonies growing on hygromycin-PDA plates using the CTAB method described by Brandfass and Karlovsky (2008). All PCRs were performed using a Peqlab thermocycler (Peqlab Biotechnologie GmbH, Erlangen, Germany) in $15 \mu \mathrm{l}$ of reaction mixture containing $1 \mathrm{x}$ reaction buffer $[20 \mathrm{mM}$ Tris $-\mathrm{HCl}(\mathrm{pH}$ 8.9), $1.8 \mathrm{mM} \mathrm{MgCl}_{2}, 22 \mathrm{mM} \mathrm{NH}_{4} \mathrm{Cl}, 22 \mathrm{mM} \mathrm{KCl}, 0.06 \%$ IGEPAL CA-630, 0.05\% Tween 20], $0.2 \mathrm{mM} \mathrm{MgCl} 2,200 \mu \mathrm{M}$ dNTPs, $0.2 \mu \mathrm{M}$ of forward and reverse primers, $0.75 \mathrm{U}$ of OneTaq hot start polymerase [optimized blend of Taq and Deep Vent ${ }^{\circledR}$ DNA polymerases (New England Bioline, London, UK)] and 1 $\mu 1$ (100-200 ng) of DNA as a template. PCR conditions were as follows: $94^{\circ} \mathrm{C}$ for $2 \mathrm{~min}, 30$ cycles of $94{ }^{\circ} \mathrm{C}$ for $30 \mathrm{~s}, 60{ }^{\circ} \mathrm{C}$ for $30 \mathrm{~s}$ and $68^{\circ} \mathrm{C}$ for 1 to $7 \mathrm{~min}$ (depending on the product length), and a final extension at $68{ }^{\circ} \mathrm{C}$ for 5 min. PCR products were run on $1.7 \%$ agarose (Biozym Scientific GmbH, Hessisch Oldendorf, Germany) gels at 60 Volts for $70 \mathrm{~min}$.

F. oxysporumpepm knock-outs ( $($ pepm), i.e. the disruptedphosphonates strains in which the pepmORF was replaced by the $h p h$-cassette in the genome, were detected using specific primers (figure 1 and described in supplementary table 1) as follows:

First, the presence or not of the pepm gene was determined using the primers 7 (pepm_F) and 8 (pepm_R) aligning at the beginning and at the end of pepm thus amplifying the whole gene. DNAs from colonies in which no pepm-gene PCR product was obtained, were used further to corroborate the right replacement of pepm ORF by the $h p h$-cassette. The primers 9 and 12 (aligning inside the $h p h$-cassette and outside FL5', expected product: 1493 bp only in knock-outs) and the primers 10 and 11 (aligning inside the $h p h$-cassette and outside FL3', expected product: 1261 bp only in knock-outs)were used to detect the right T-DNA insertion in $F$. oxysporum genome. For a final corroboration, the primers 11 and 12 (aligning outside FL5' and FL3', expected product in knock-outs: 6324 bp, expected product in wt: $2821 \mathrm{bp}$ ) were employed using only the DNA of the colonies that showed the right PCR products before.

Mycelium of the positive knock-out colonies was used to produce spores in liquid Mung Bean media at $28{ }^{\circ} \mathrm{C}$ and $200 \mathrm{rpm}$. After 5 days spores were collected, and the concentration was calculated using a counting chamber (Thoma, depth $0.1 \mathrm{~mm}$, Marienfeld, Germany). Spores were diluted using sterilized tap water and cultivated to have 30-50 spores per plate. After 2-3 days random single colonies were chosen for DNA extraction and corroboration of the correct pepm replacement in F. oxysporum genome was 
done by means of PCR as explained before. Only single colonies showing the right products after PCR, were further used for experiments.

Ectopic integration of the $h p h$-cassette, i.e. the random integration of the region in the genome, was detected in DNA samples showing the complete pepm gene product after PCR. The primers 13 and 14 were used to amplify a region inside the $h p h$-cassette (product: $521 \mathrm{bp}$ ) to confirm the ectopic integration in F. oxysporum genome. Two positive colonies were chosen to use them further as controls for experiments.

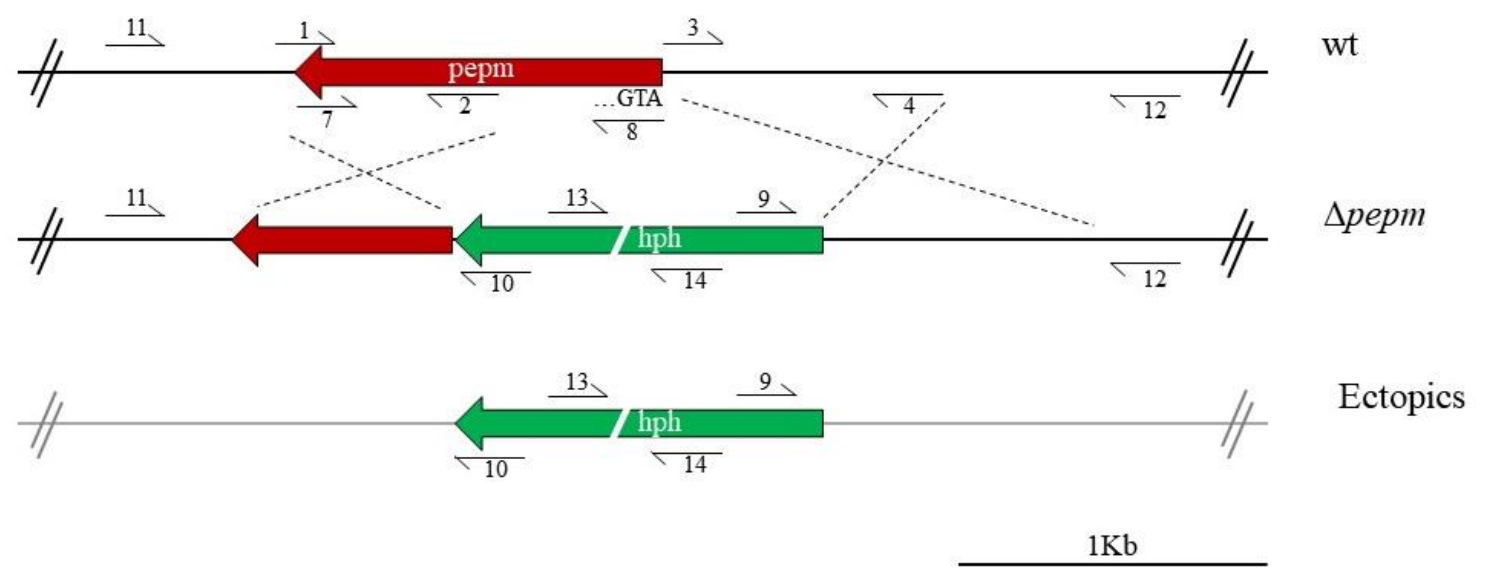

Figure 1. Diagram showing the primers used to differentiate the non-transformed strains (wt) from the target disrupted or knock-outs ( integrations in $F$. oxysporum. Primers sequences in supplementary table 1 .

\subsubsection{Phenotypic characteristics of $F$. oxysporum transformants compared to the wt}

Mycelium growth and color as well as spore germination were evaluated in the wt, the knock-outs and the ectopic integration strains. Mycelium growth, as colony diameter, was evaluated 1, 3, 7 and 9 days after cultivation of $10^{4} \mathrm{~F}$. oxysporum spores in the middle of a Petri dish $(90 \mathrm{~mm})$ containing PDA medium and incubated at $25{ }^{\circ} \mathrm{C}$ in dark conditions. Together with the evaluation of growth, also observations of color, and other phenotypic characteristics of the fungi were done. Three replicates were performed per treatment.

To evaluate the capacity of the fungal spores to form colonies, freshly spores of wt, knockouts and ectopic integrations were prepared following the same protocol described in section 2.1.1. Spores thus produced were collected and diluted using sterilized tap water to have 500 spores. $\mu 1^{-1} ; 100 \mu 1$ were spread on the surface of PDA plates and allowed to dry. The number of colonies in each plate was counted after 3 days incubation at $25^{\circ} \mathrm{C}$ in dark conditions. Three replicates were done per strain and two plates of each were plated out. 
The diameter change was calculated by substracting the current mycelium diameter value from the last evaluation value, while the cumulative growth indicates the current diameter value. Data were analyzed using $\mathrm{R}$ ( $\mathrm{R}$ Core Team 2017). The analysis of variance (ANOVA) was performed followed by Tukey's test [package "multcomp" (Hothorn et al. 2008)] when a difference between means was found (for mycelium diameter data) or followed by chi-square test in the case of binomial distributed data (for spores forming colonies data).

\subsection{Phosphonates function in $F$. oxysporum}

The pepm knock-outs previously generated were used to determine the effect of phosphonates on the growth of some organisms -gram negative and positive bacteria, mycoparasitic fungi and Tenebrio molitor larvae-

\subsubsection{Effect of phosphonates on bacteria growth}

The effect of phosphonates on bacterial growth was tested using the wt and one or more phosphonate knock-out strains ( used as control for some of the experiments. Fungi were cultivated together with E. coli DH5 $\alpha$, Xanthomonas carotae GSPB1792 (gram-negative bacteria) or Bacillus licheniformis [gram-positive bacterium K4 (Suchfort 2016)].

The experiment with E. coli was carried out as follows: $500 \mu 1$ of spores $\left(10^{6}\right.$ spores.ml $\left.{ }^{-1}\right)$ of each $F$. oxysporum strain (wt, $\Delta$ pepm35) were cultivated together with $500 \mu 1$ of bacteria (previously grown overnight at $37^{\circ} \mathrm{C}$ ) on $100 \mathrm{ml}$ of liquid phosphonate inducing medium (Takeuchi et al. 1989)and incubated at $180 \mathrm{rpm}$ and $28^{\circ} \mathrm{C}$. Only E. coli was used for the bacteria controls and only spores for the fungal controls. After 1, 3, 5, 7, 9 days, $100 \mu \mathrm{l}$ of each culture were taken and a series of dilutions using sterilized tap water were done until a dilution of $10^{4}$ times was reached. Each dilution $(80 \mu \mathrm{l})$ was plated out three times on LB plates $\mathrm{pH} 8.0$ and incubated overnight at $37^{\circ} \mathrm{C}$. Counting was done only on the plates with single colonies. To determine if there was an effect of the bacteria on the fungal growth, at the end of the experiment (after 9 days), mycelium was filtered using cheesecloth, washed with demineralized water to remove bacteria from the surface and freeze dried for three days. Dry weight of mycelium was determined immediately from fungi cultivated with and without bacteria. 
Experiments with $X$. carotae was carried out as follows: spores $\left(10^{4}\right)$ of each $F$. oxysporum strain (wt, knockouts and ectopics) were cultivated on $100 \mathrm{ml}$ of liquid phosphonate inducing medium (Takeuchi et al. 1989) and incubated at $180 \mathrm{rpm}$ and $28{ }^{\circ} \mathrm{C}$. After 10 days, the cultures were centrifuged at $4500 \mathrm{rpm}$ for $15 \mathrm{~min}$ at room temperature and $10 \mathrm{ml}$ of the supernatant was added into $10 \mathrm{ml}$ of bacteria cultures previously cultivated overnight at $180 \mathrm{rpm}$ and $28{ }^{\circ} \mathrm{C}$. Bacteria was incubated with the fungal supernatant at $180 \mathrm{rpm}$ and $28{ }^{\circ} \mathrm{C}$. After 1 and 2 days, $100 \mu \mathrm{l}$ of each culture were taken and a series of dilutions using sterilized tap water were done until a dilution of $10^{4}$ times was reached. Each dilution (50 $\mu \mathrm{l})$ was plated out on PSA plates $\mathrm{pH} 8.0$ and incubated overnight at $28^{\circ} \mathrm{C}$. Counting was done only on the plates with single colonies.

Experiments with $B$. licheniformis were carried out as follows: spores $\left(10^{3}\right)$ of the fungi (wt, knockouts and ectopics) were cultivated in $10 \mathrm{ml}$ of liquid phosphonate inducing medium (Takeuchi et al. 1989). After 12-14 days, $5 \mathrm{ml}$ of bacteria growing on liquid LB medium for 5 days at $28^{\circ} \mathrm{C}$ was added into the fungi cultures, as explained in chapter 2 for gene expression analysis. After 24 hours, the cultures were filtered using cheesecloth, washed with sterilized tap water to collect also bacteria from the surface and all cultures were adjusted to a final volume of $50 \mathrm{ml}$. After mixing, a sample of $1 \mathrm{ml}$ was taken and a series of dilutions using sterilized tap water were done until a dilution of $50^{3}$ times was reached. Each dilution $(100 \mu \mathrm{l})$ was plated out on LB plates $\mathrm{pH} 8.0$ and incubated overnight at $37^{\circ} \mathrm{C}$. Number of colonies on each plate was determined from the dilutions in which single colonies occurred.

Three biological replicates were done per treatment. The number of bacterial cells. $\mu 1^{-1}$ was analyzed using R (R Core Team 2017). The ANOVA was done followed by Tukey's test [package "multcomp" (Hothorn et al. 2008)] when a difference between means was found.

\subsubsection{Effect of phosphonates on mycoparasitic fungi growth}

To determine if phosphonates are involve in $F$. oxysporum interaction with mycoparasitic fungi species, a confrontation test was performed using one of the phosphonate knock-out strain (Lpepm35), the wt and one of the ectopic integration strain (ect116) against Gliocladium roseum DSMZ1165 and Trichoderma harzianum T12. A plug of mycelium (F. oxysporum and G. roseum or T. harzianum), previously cultivated for 5-6 days on PDA plates, was placed on opposite sides of a $90 \mathrm{~mm}$ Petri dish plate (at the same distance from the edge: $1.5 \mathrm{~cm}$ ) containing PDA or Czapek-Dox $(\mathrm{C}-\mathrm{dox})$ medium. They were maintained 
at $25^{\circ} \mathrm{C}$ for 9 days (in the case of $G$. roseum) and 6 days (in the case of $T$. harzianum). Fungal ratio was evaluated every day and three replicates per treatment were done.

\subsubsection{Effect of phosphonates on $T$. molitor larvae food preference and fitness}

\section{-Food preference}

Two F. oxysporum knock-outs ( and the wt growing for 10 days on liquid PDA medium were used to feed T. molitor larvae. Fresh mycelium ( $2 \mathrm{~g}$ ) of the wt was placed in one side of a Petri dish (90 cm diameter) and in the other side either one of the knock-out or the ectopic strain fresh mycelium. Six larvae were added in the middle of each Petri dish containing the fungal mycelium. The cultures were maintained in dark conditions at $17-18{ }^{\circ} \mathrm{C}$. Observations about the feeding behavior of the larvae were performed every half hour during the first $2.5 \mathrm{~h}$ and after 20 and 24h. Three replicates were done per treatment.

\section{-Fitness test}

Five $F$. oxysporum knock-outs (Apepm10, 23, 35, 67 and 101), one ectopic integrations (ect116) and the wt were used to test the effect of phosphonates on T. molitor larvae growth. A plug of each fungus (growing for 10 days on PDA plates) was cultivated in the middle of a Petri dish $(90 \mathrm{~mm}$ diameter) containing rice culture (sterilized $10 \mathrm{~g}$ of rice grains plus $10 \mathrm{ml}$ of tap water). Once mycelium covered the rice completely, approximately 10 days after culture, eight larvae were added into each Petri dish containing the contaminated rice. The same number of larvae was added in both controls empty Petri dish without any food and a Petri dish containing not contaminated rice-. The cultures were maintained in dark conditions at $17-18{ }^{\circ} \mathrm{C}$. After two weeks, larvae were collected, cleaned from the mycelium and alive larvae were weighed again. Dead larvae were considered in order to calculate the survival rate. Three replicates were done per treatment. Survival rate data were analyzed using R (R Core Team 2017); an ANOVA was performed followed by chi-square test. 


\section{Results}

\subsection{Disruption of phosphonates biosynthesis in F. oxysporum}

\subsubsection{A. tumefaciens-mediated transformation of $F$. oxysporumand detection of knock-outs by means of PCR}

Four A. tumefaciens-mediated transformations were performed in which spores of $F$. oxysporum were cultivated together with A. tumefaciens AGL1 cells (carrying the pPK2_FL3+FL5 vector) in order to disrupt phosphonates biosynthesis though replacement of the pepm gene by the $h p h$-cassette in the fungalgenome. Transformants were selected from plates containing $25 \mu \mathrm{g} / \mathrm{ml}$ of Hygromycin $\mathrm{B}$, the lowest concentration of the antibiotic that inhibited $F$. oxysporum DSM62291 growth, as determined in the present study.

From each transformation, a total of 40-50 colonies (transformants growing on $25 \mu \mathrm{g} / \mathrm{ml}$ of Hygromycin B) were randomly chosen to further extract DNA and to detect the right pepmORF replacement by PCR. In total, five $F$. oxysporumpepm knock-outs ( $\Delta$ pepm 10 , 23, 35, 67 and 101) were obtained in which any pepm gene product was observed after the PCR using the specific primers 7 and 8 (Figure 1) to amplify the whole gene (Figure 2A). One pepm knock-out was obtained from each of the first three transformations ( 23 and 35) and two pepm knock-outs (transformation. Knock-outs were further confirmed by several PCRs in which the same DNA was used. Using primers 9 and 12 (Figure 1) the right insertion of FL5' region was detected. In this case, the expected product of 1493 bp was obtained in the knock-outs and, as expected, no product was observed from the wt or the ectopic strains (Figure 2B). Similarly, the right insertion of the FL3' region was corroborated using primers 10 and 11 showing the right expected product of $1261 \mathrm{bp}$ in the knock-outs and not in the wt or the ectopic strains (Figure 2C). To finally corroborate the last results, the primers 11 and 12 (Figure 1), aligning outside FL5' and FL3' in the genome were used showing the expected large product in knock-outs of $6324 \mathrm{bp}$ and of $2821 \mathrm{bp}$ in the wt or the ectopic integration strains (Figure 2D). The integration of the $h p h$-cassette in the genome was confirmed in the knock-outs and the ectopics strains using the primers 13 and 14 (Figure 1), showing the right product of $521 \mathrm{bp}$ in all transformants but not in the wt as expected (Figure 2E). 

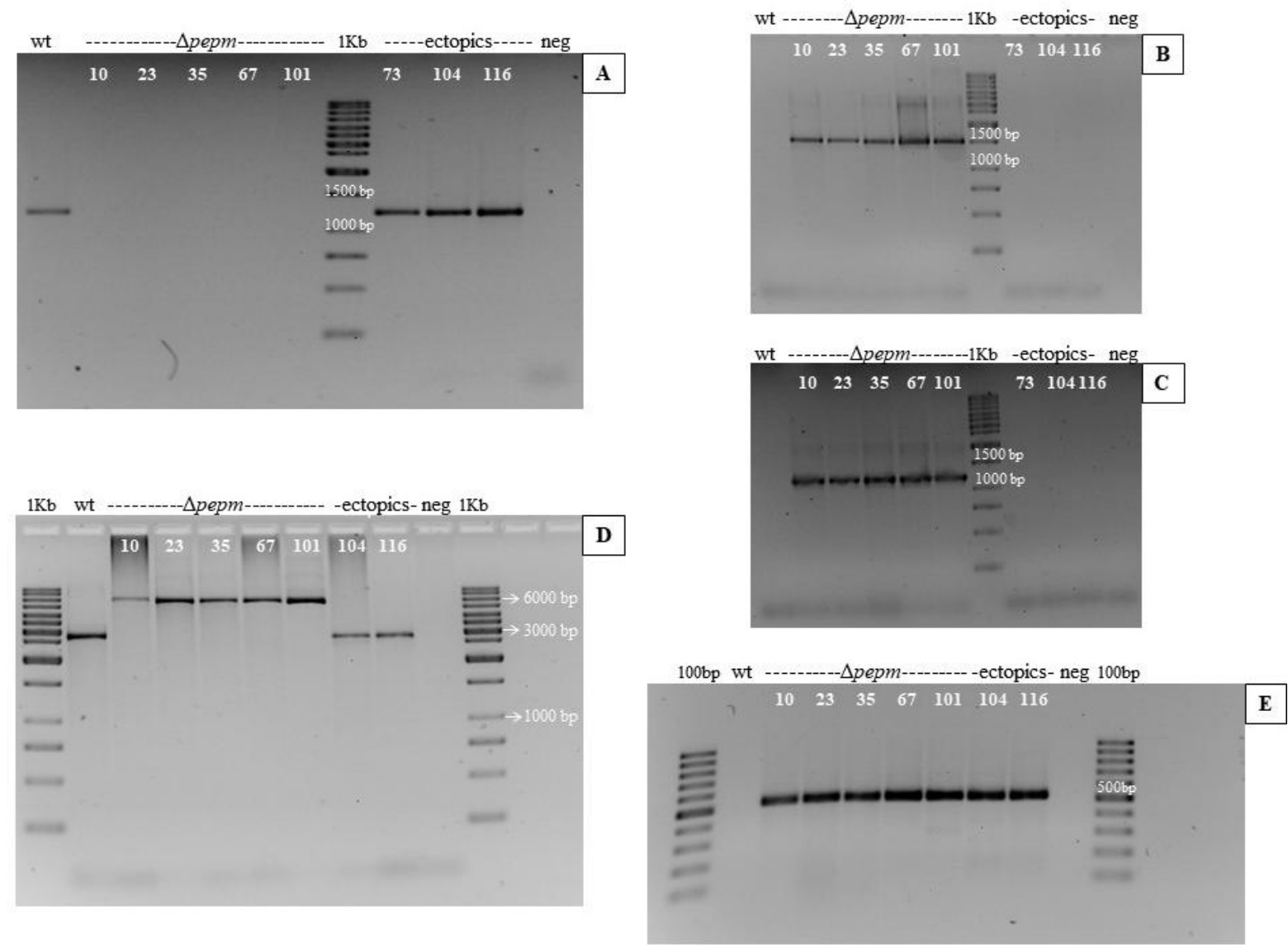

Figure 2. Agarose gels pictures showing the results of the PCR for pepm knock-outs identification using the DNA of the wt, the putative knock-outs ( $\Delta$ pepm 10, 23, 35, 67 and 101) and the putative $h p h$-cassette ectopic integrations (73, 104 and 116). Products were obtained after PCR using primers indicated in figure 1 and described in supplementary table 1: A) using primers 7 and 8 to amplify the complete pepm gene. B) using primers 9 and 12 aligning inside the $h p h$-cassette and outside pepm FL5'. C) using primers 10 and 11 aligning inside the $h p h$-cassette and outside pepm FL3'. D) using primers 11 and 12 aligning outside both pepm FLs. E) using primers 13 and 14 aligning both inside the $h p h-$ cassette. Samples were run on $1.7 \%$ (w/v) agarose gels at 60 Volts for 70 min. Marker: $1 \mathrm{~Kb}$ (Thermo Scientific, Massachusetts, US).

As a summary, most of the colonies growing on hygromycin showed the complete pepm gene product after the PCR and also the expected product from the $h p h$-cassette integration in the genome, thus a random T-DNA insertion happened in most of them but not the gene replacement by homologous recombination. The transformation efficiency was 0.04$0.05 \%$ : from $1 \times 10^{5} F$. oxysporum spores cultivated in the presence of A. tumefaciens cells, between 40-50 fungal colonies grew up on hygromycin plates, most of them carrying the $h p h$-resistance cassette, as detected by PCR. Five knock-outs were identified out of a total of around 200 transformed colonies growing on hygromycin, thus, the efficiency of the pepm replacement by homologous recombination in F. oxysporum was of $2.5 \%$. 


\subsubsection{Phenotypic characteristics of $F$. oxysporum transformants compared to} the wt

The change in colony diameter and the cumulative growth of the wt compared with some of the knock-outs (Apepm23, 35 and 101) and two ectopic strains (ect104 and 116) are shown in figure 3.

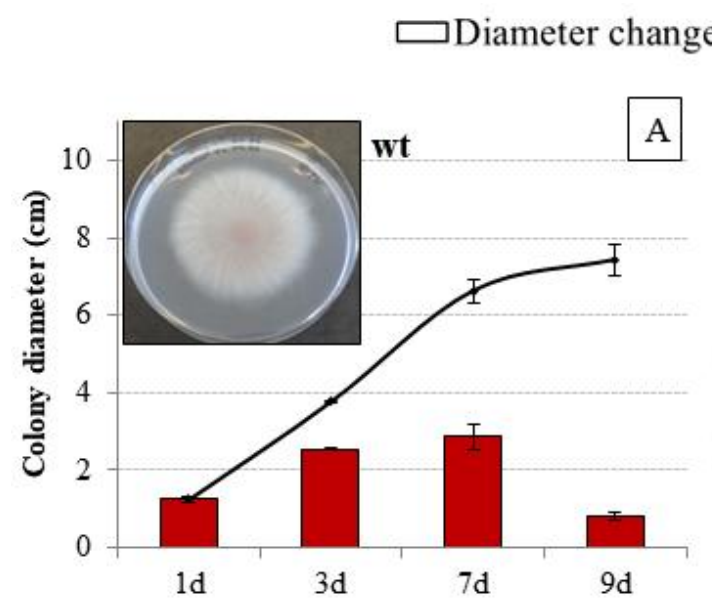

$\rightarrow$ Cumulative growth
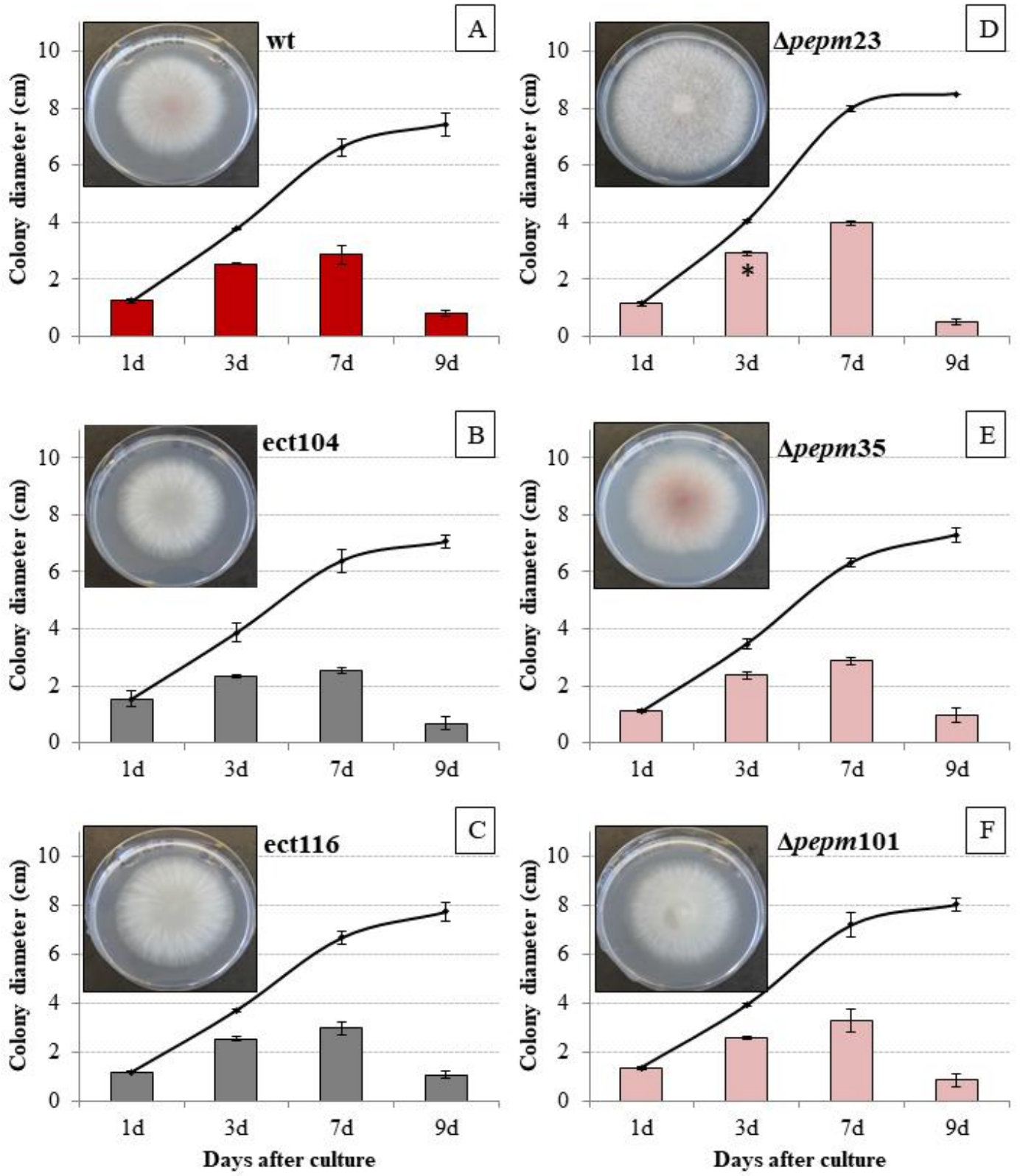

Figure 3. Mycelium diameter change and cumulative growth of $F$. oxysporum wt, knockouts (Apepm23, 35 and 101) and ectopics integration strains (ect104 and 116) after 1, 3, 7 and 9 days of culture on PDA medium at $25{ }^{\circ} \mathrm{C}$ in dark conditions. Wt (A), ect104 and 116 (B and Crespectively) and $\triangle p e p m 23,35$ and 101 (D, E and $\mathbf{F}$ respectively). Bars represent the $\pm \mathrm{SEM}$ for each treatment. Asterisks indicates a significant difference compared to the wt $(* \mathrm{p}<0.05)$. Pictures after 9 days of culture. 
During the whole period of culture all of them grew similar to the wt $(p>0.05)$ reaching a cumulative colony diameter of 7-8 cm after 9 days of culture(Figure $3 \mathrm{~A}-\mathrm{F}$ ). In the knockouts the cumulative colony diameter was between 8.0-8.5 cm, except in $\Delta$ pepm35 $(7.3$ $\mathrm{cm})$ which was similar to the wt $(7.4 \mathrm{~cm})$. Strains with the $h p h$-cassette ectopic integration showed, after 9 days, a diameter of $7.1 \mathrm{~cm}$ (in ect104) and of $7.7 \mathrm{~cm}$ (in ect116) (Figure 3 B and C). Only after 3 days of culture a difference between knock-out $\Delta$ pepm 23 and the wt was observed in which the diameter change between day 1 and day 3 was higher in the mutant $(2.9 \mathrm{~cm})$ than in the wt $(2.5 \mathrm{~cm})$ (Figure 3D). The largest increase in diameter between day 1 and 3 and between day 3 and 7 is the reason why this knock-out presented the larger colony diameter at the end, after 9 days.

The capacity of the spores to multiply and produce colonies was evaluated after 3 days on PDA plates. The percentage of spores forming colonies was similar in all knock-outs compared to the wt ( $>0.05)$, however in the ect104 the percentage was higher $(86 \%)$ and significantly different to the wt (63\%) (Table 1).

Table 1. Number and percentage of spores forming colonies per plate in $F$. oxysporum wt, knock-outs ( culture at $25^{\circ} \mathrm{C}$ in dark conditions. Asterisks indicates a significant difference compared to the wt $(* * * \mathrm{p}<0.001)$

\begin{tabular}{|c|c|c|}
\hline Strain & $\begin{array}{c}\text { spores forming } \\
\text { colonies/plate }\left( \pm \mathrm{SEM}^{1}\right)\end{array}$ & $\%$ \\
\hline wt & $32( \pm 1.3)$ & 63 \\
\hline Арерт 10 & $38( \pm 1.1)$ & 75 \\
\hline Арерт 23 & $37( \pm 1.7)$ & 75 \\
\hline Арерт35 & $33( \pm 1.2)$ & 65 \\
\hline Арерт67 & $37( \pm 2.4)$ & 75 \\
\hline ect104 & $43( \pm 0.8)$ & 86 \\
\hline
\end{tabular}

The wt and the $\Delta$ pepm35 strains showed the lowest values, both in colony diameter and in the number of spores forming colonies, also this knock-out exhibited, during the days of evaluation, a purple-color in the middle of the mycelium which was also observed in the wt but not in the rest of the transformants (see pictures in Figure 3). Despite this, the transformants did not lose the ability to produce the color since the pigment was again produce when theywere cultivated for longer periods ( $>15$ days). Mycelium appearance of 
the transformants was similar to the wt except in $\Delta$ pepm23, which showed a less dense, aerial mycelium showing no obvious radial growth. The rest of the transformants showed the common feature observed in Fusarium mycelia, i.e. an obvious radial growth attached to the medium.

\subsection{Phosphonates function in $F$. oxysporum}

\subsubsection{Effect of phosphonates on bacteria growth}

The pepm knock-outs were used to determine the effect of phosphonates on the growth of bacteria evaluated as the number of colonies appearing on plates after cultivation of bacterial dilutions. The phosphonate producer (wt) and the phosphonate-disrupted $(\Delta$ pepm35) strain reduced the bacteria growth almost the same level after 1, 3, 5 and 7 days of co-cultivation (Figure 4A). However, after 9 days more colonies were observed when bacteria were cultivated with the wt (Figure 4A), thus any negative effect of phosphonates on $E$. coli growth was observed in this case. There was an evident effect of the fungi on the bacteria growth, being that, when bacterium was cultivated alone, many more colonies were lately (after 3 and 5 days) observed on the plates (Figure 4A). After 7 days of cocultivation, the bacteria stopped their growth, or it was too low to generate colonies on the plates.
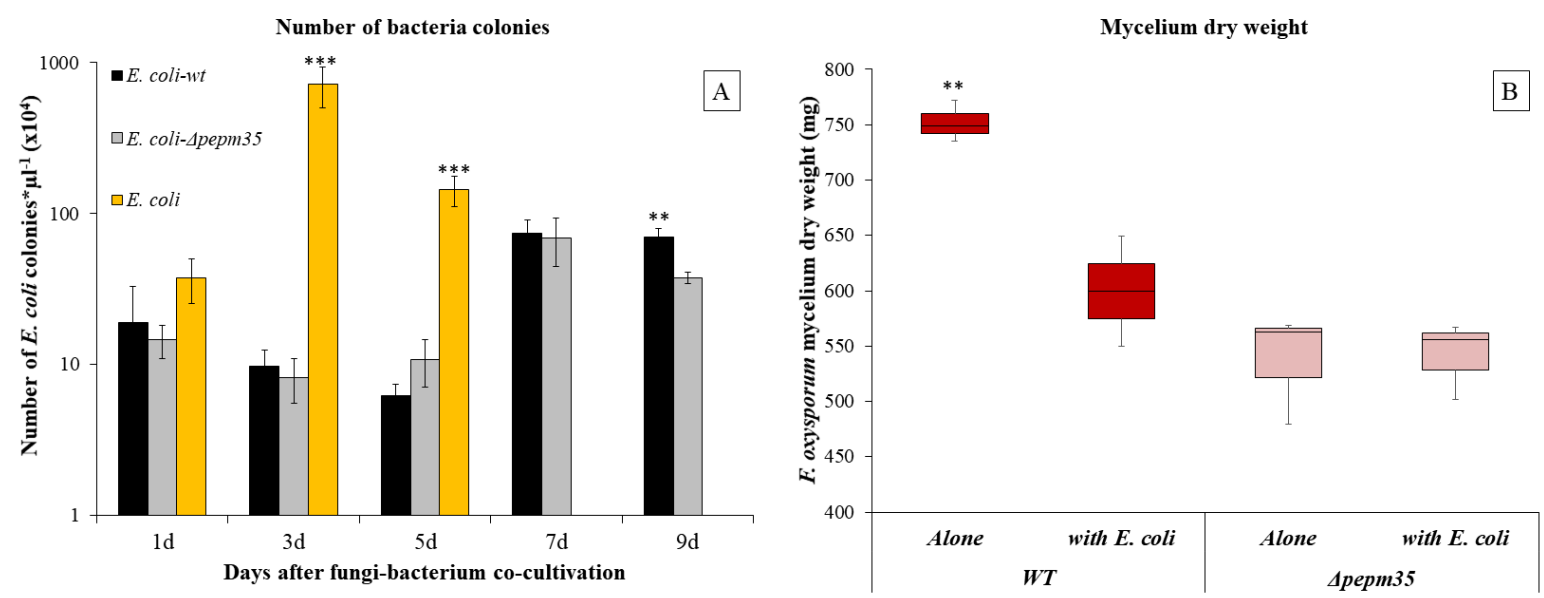

Figure 4. Number of bacteria colonies after E. coli-F. oxysporum (wt or $\Delta$ pepm35) cocultivation and bacterium alone for 1, 3, 5, 7 and 9 days (A). Mycelium dry weight after 9 days of E. coli-F. oxysporum (wt or $\Delta$ pepm35) co-cultivation and fungi alone (B). Bars represent the $\pm \mathrm{SEM}$ for each treatment. Asterisks indicates a significant difference between treatments $(* * * \mathrm{p}<0.001, * * \mathrm{p}<0.01)$. 
The effect of the bacteria on the fungal growth was also considered. After 9 days of fungal-bacteria co-cultivation, a reduction in the mycelium growth of the wt was observed when the fungus was cultivated with $E$. coli, however the growth of the mutant ( $\triangle$ pepm35) was not affected by the bacteria (Figure 4B). Additionally, the mycelium weight of this mutant was lower than the wt in the same conditions.

In the case of $X$. carotae, the number of colonies after 1 day was similar when the bacterium was cultivated either with the supernatant of the wt or with the supernatant of any of the two knock-outs ( $\Delta$ pepm35 or $\Delta$ pepm67) (Figure 5A). However, interestingly, after 2 days of culture, the number of bacteria colonies was higher when the supernatant of the phosphonates-disrupted strains was used. This experiment should be repeated again to increase the number of repetitions (more than 3) and to confirm the results by statistical differences.
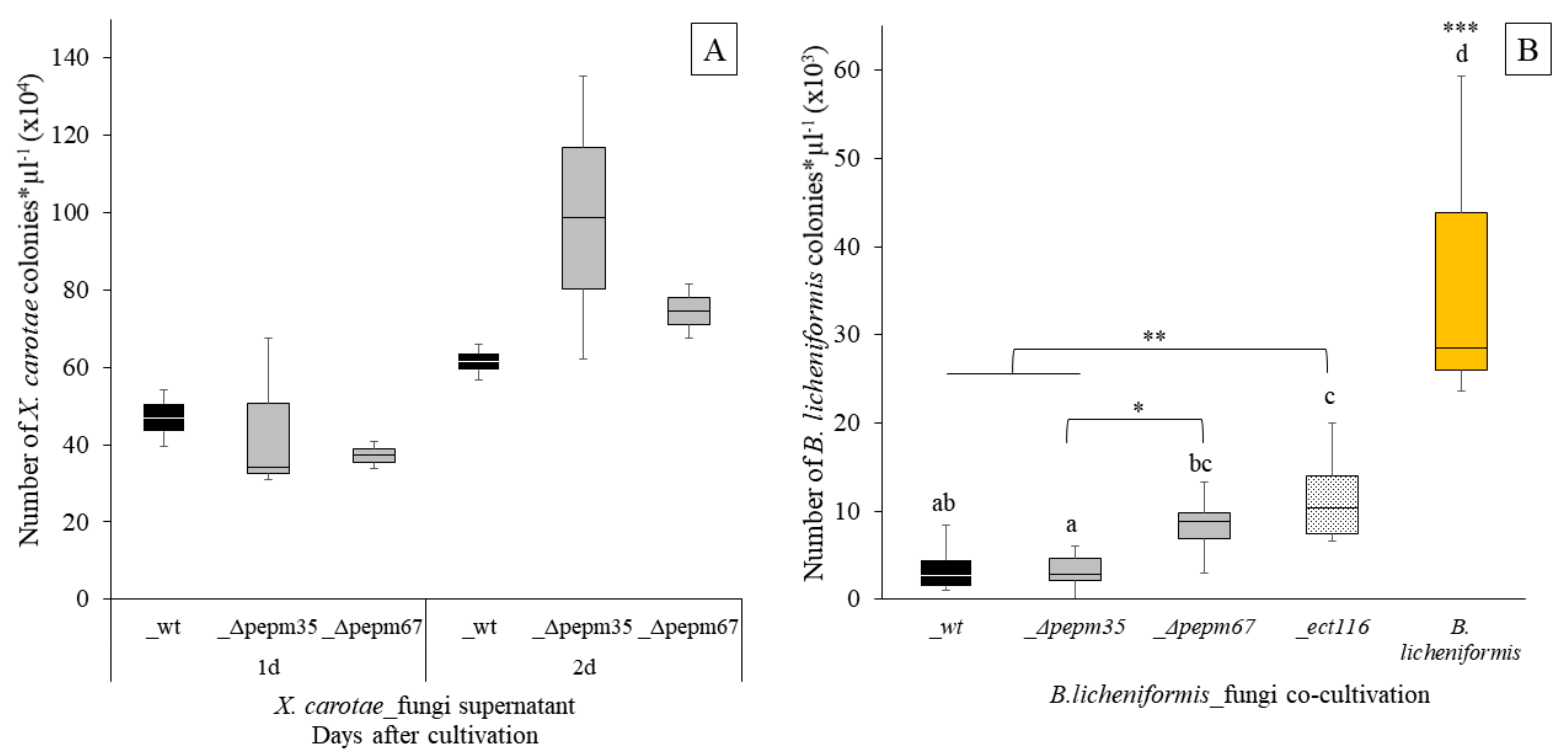

Figure 5. Number of bacteria colonies after bacterium $[X$. carotae (A) or B.licheniformis(B)] $-F$. oxysporum (wt, $\Delta$ pepm 35, $\Delta$ pepm67, or ect116) co-cultivation. $X$. carotae was cultivated with the fungal supernatant for 1 and 2 days while B. licheniformis was cultivated together with the fungal mycelium for 1 day. Bars represent the \pm SEM for each treatment. Significantly different means (one-way ANOVA, Tukey's test, $\mathrm{p}>0.001, \mathrm{n}$ $=8)$ are indicated with different letters. Asterisks indicates a significant difference between treatments $(* * * \mathrm{p}<0.001, * * \mathrm{p}<0.01, * \mathrm{p}<0.05)$.

The number of $B$. licheniformis (gram-positive bacteria) colonies was similar after oneday cultivation with the wt or the two knock-outs. However, more colonies were observed when the bacterium was cultivated with the ectopic strain than when it was cultivated with 
the wt or with the knock-out $\Delta$ pepm35 (Figure 5B). As in the case of E. coli,B. licheniformis growth was affected by the presence of the fungi, either the wt, the knockouts ( $\Delta$ pepm35 or $\Delta$ pepm67) or the ectopic (ect116) strain. After one day of bacteria-fungi co-cultivation, the number of bacteria colonies was significantly lower when compared to the bacterium cultivated alone (Figure 5B).

\subsubsection{Effect of phosphonates on mycoparasitic fungi}

A confrontation test was performed in which one of the $F$. oxysporum strains (wt, Аpepm35 or ect116) was confronted against either G. roseum or T. harzianum on PDA and c-dox media. After 9 days an inhibition zone was observed in both media between the $F$. oxysporum wt and G. roseum mycelia (Figure 6A and D). The same inhibition was not observed when the knock-out $\Delta$ pepm35 (Figure 6B and E) or the ectopic ect116 (Figure 6C and F) strains were used. Accordingly, G. roseum mycelium ratio was smaller when it was cultivated with the wt $(G$. roseum mycelium ratio of $1.8-1.9 \mathrm{~cm})$ than when it was cultivated with the knock-out (G. roseum mycelium ratio of $2.2-2.9 \mathrm{~cm}$ ) or with the ectopic strain (G. roseum mycelium ratio of 2.3-2.4 cm). The different effect of the wt and the ectopic strain on $G$. roseum growth suggest that the observed inhibition is not necessary related to phosphonates but to another unknown factor.

The same phenomenon was noticed when the confrontation between $F$. oxysporumand $T$. harzianumwas done. In this case, however, the effect was observed faster -after 6 days of culture- and the inhibition zone between the wt and the mycoparasitic fungi was more obvious (Figure 6G). T. harzianum mycelium grew much faster than G. roseum in PDA medium, being that $F$. oxysporum, either wt, knock-out or ectopic strain growth, was drastically reduced when they were cultivated with Trichoderma. The confrontation test with $T$. harzianum in c-dox medium was not carried out due to the non-growth of this mycoparasitic fungus in the medium. 

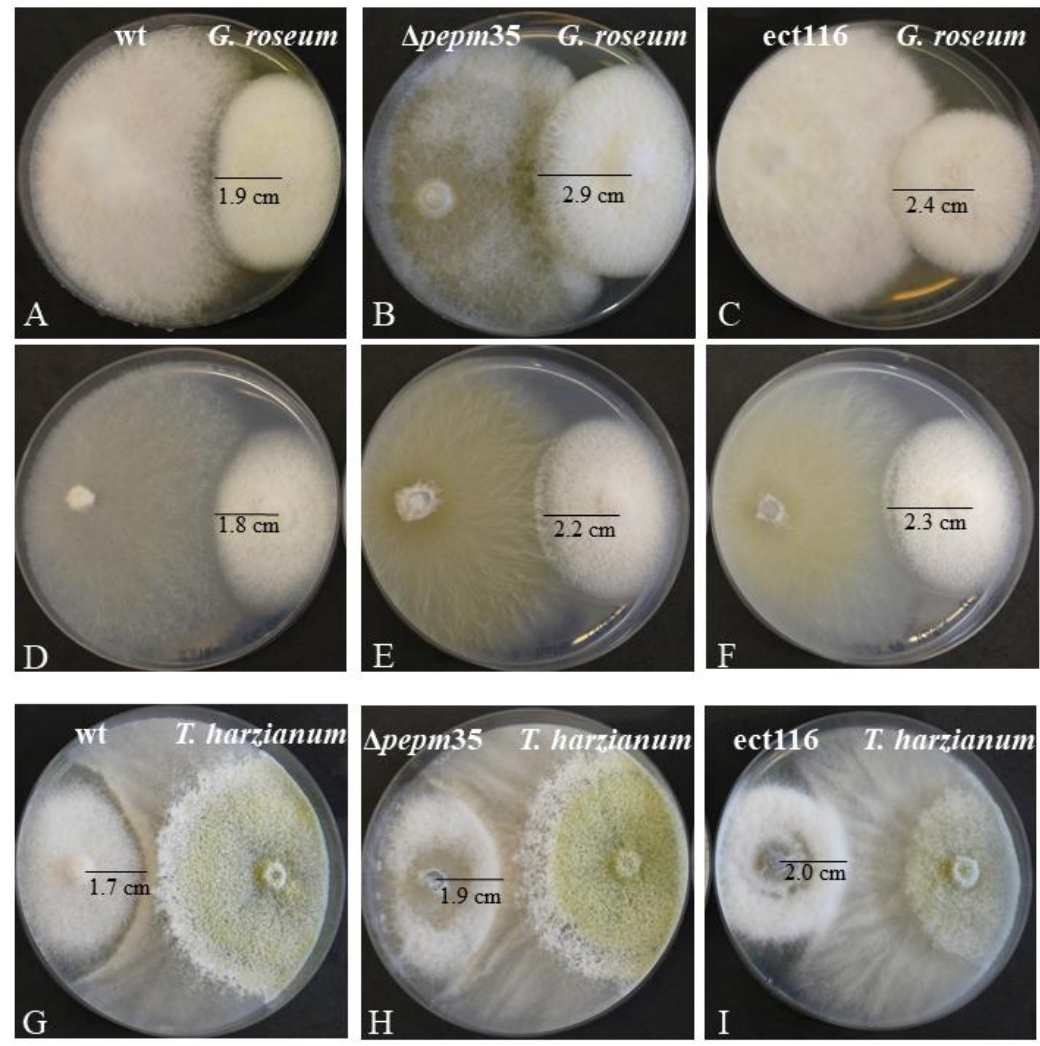

Figure 6. Confrontation assay of $F$. oxysporum (wt, $\Delta$ pepm 35 and ectopic116) against $G$. roseum(A to $\mathbf{F}$ ) or $T$. harzianum (G to I). Fungi were cultivated for 9 days (with $G$. roseum) or 6 days (with $T$. harzianum) in PDA (A to $\mathbf{C}$ and $\mathbf{G}$ to $\mathbf{I}$ ) and $\mathbf{C}$-dox medium (D to F). Note: T. harzianum did not growth in c-dox medium.

\subsubsection{Effect of phosphonates on $T$. molitor larvae (mealworm) food preference and fitness}

\section{-Food preference}

Six T. molitor larvae were placed in a Petri dish containing, on opposites sites, fresh mycelium of $F$. oxysporumwt and one knock-out or an ectopic strain, in a way that they were forced to choose one of the two options as a food source. An obvious preference of the larvae for the wt mycelium was observed during the first 2-2.5 hours compared to the knock-outs $\Delta$ pepm35 and $\Delta$ pepm67 (Figure 7A and B); interestingly, T. molitor larvae preferred the ectopic strain mycelium more than the wt (Figure 7C).

After 24 hours, the larvae finished most of the wt as well as the ectopic strain mycelium and, even when they visit the mycelium of the knock-outs strains, they did not feed on 
them. After 5 days they finished all the wt and the ectopic strain but not the knock-outs mycelium.
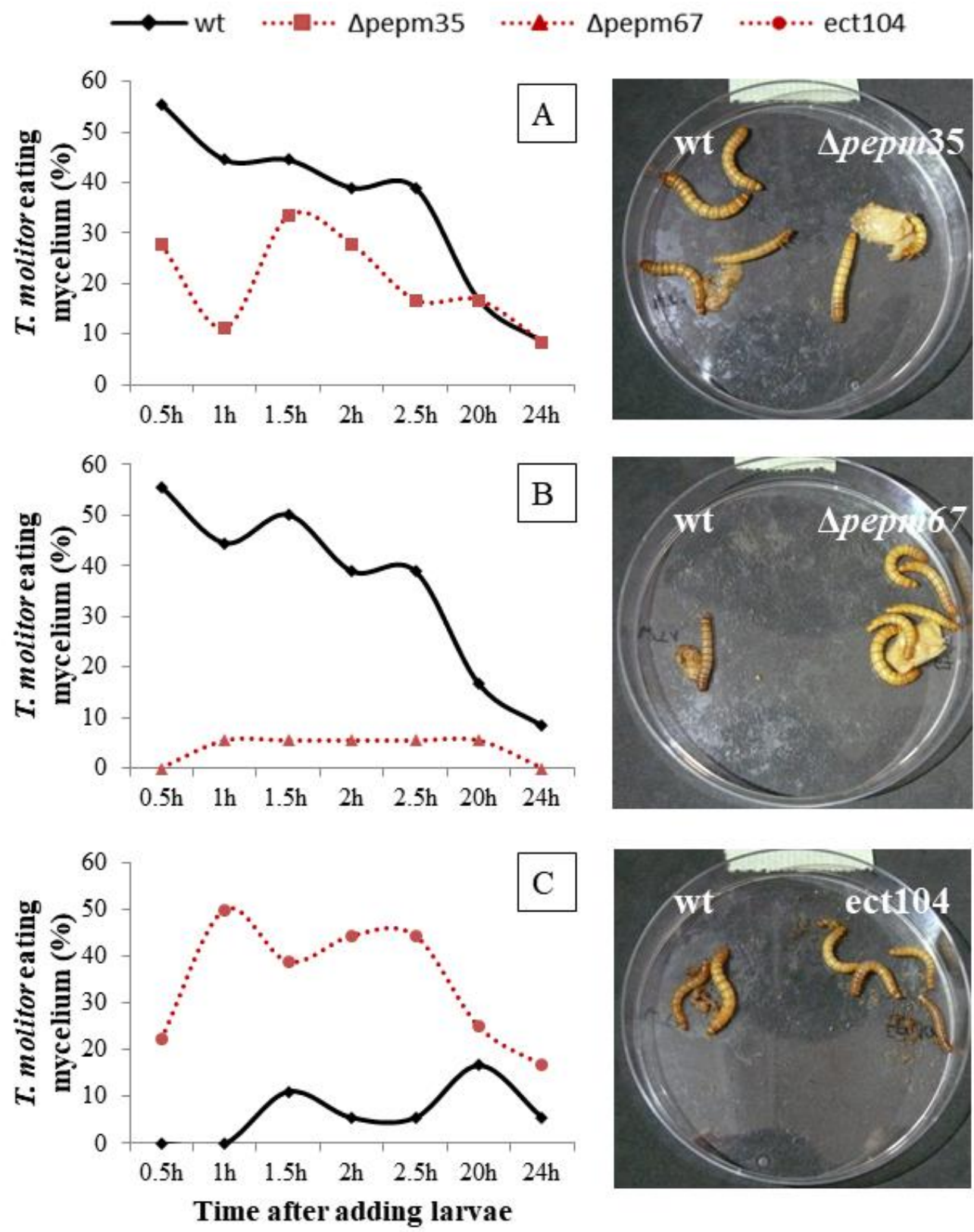

Figure 7. Percentage of T. molitor larvae eating mycelium after 0.5, 1, 1.5, 2, 2.5, 20 and 24hours fed with F. oxysporum [wt and $\Delta$ pepm35, 67 (A and B) or wt and ect104 (C)] fresh mycelium. Six larvae were used for each replicate $(n=3)$. Pictures were taken after five days.

\section{-Fitness test}


In order to evaluate the effect of the different fungal strains on T. molitor larvae growth and survival, eight mealworms were placed on plates filled with fungal-contaminated rice (wt, knock-outs and ectopics) and they were allowed to eat for two weeks. Any food (empty plates) and not-contaminated rice were used as controls. After two weeks, no differential effect on the larvae weight gain was observed when they were cultivated either with the wt, the knock-outs or the ectopic strains (Figure 8). The weight gain of T. molitor larvae was similar in all the contaminated rice samples; however, and interestingly, larvae gained less weight when they fed only on not-contaminated rice. As expected, the weight gain of the non-fed larvae, placed in empty plates for two weeks, was lower than the others.
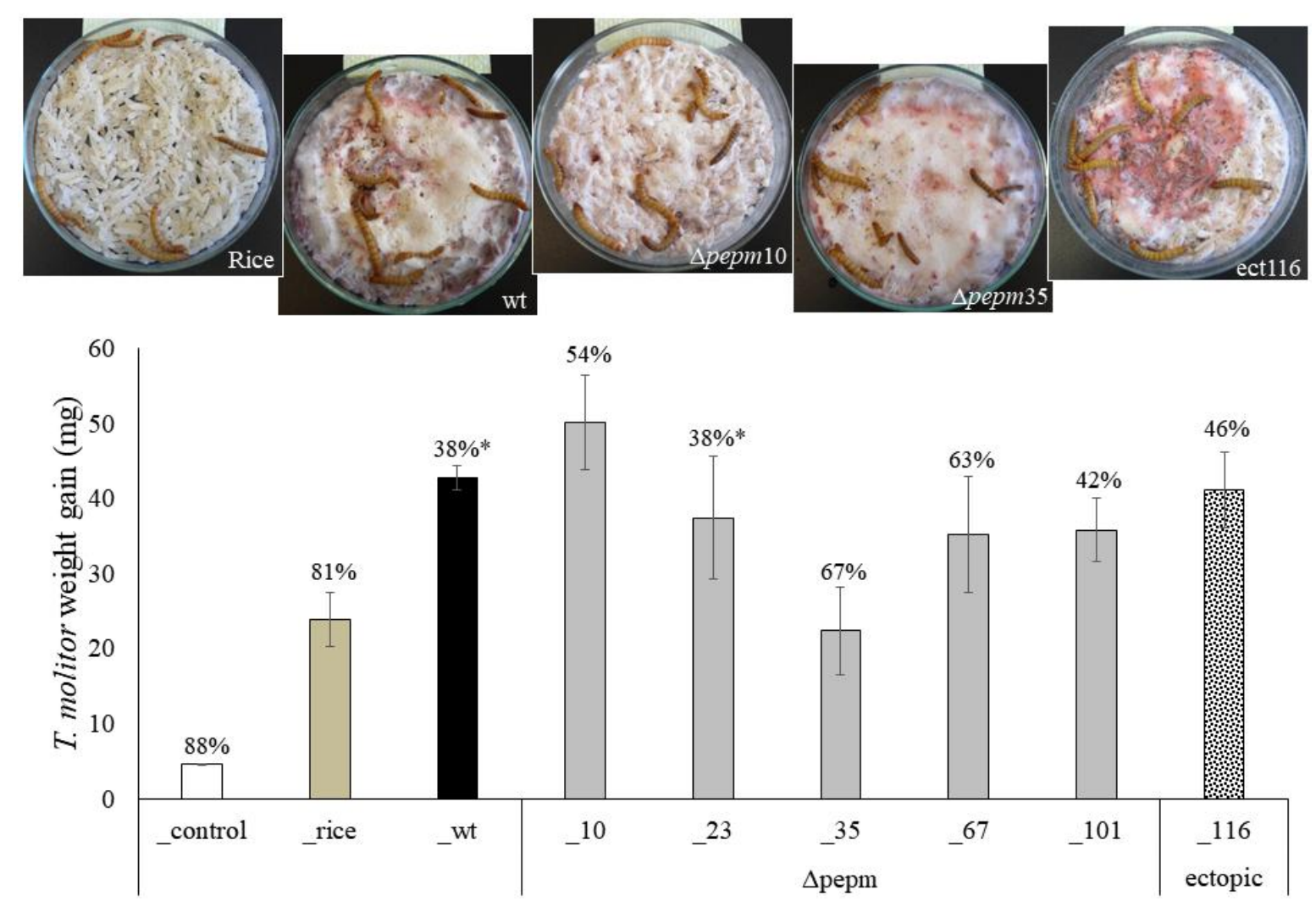

T. molitor_feeding fungi

Figure 8. T. molitor larvae weight gain after two weeks fed with only rice or with $F$. oxysporum (wt, spepm10, 23, 35, 67, 101 and ect104, 116) -contaminated rice. Larvae were also maintained in an empty Petri dish without food at the same time (_control). Percentage above each bar indicates the survival after two weeks. Bars represent the \pm SEM for each treatment. Asterisks indicates a significant difference in survival compared to the control $\left({ }^{*} \mathrm{p}<0.05\right)$. Pictures were taken after four days of feeding with contaminated and not-contaminated rice.

About 38-67\% of larvae survived when they fed on knock-outs contaminated rice while $38 \%$ of larvae survived after fed on the wt-contaminated rice for two weeks (Figure 8). 
Interestingly, the highest survival rate $(88 \%)$ was observed when larvae was maintained for two weeks without any food (_control), thus they were the ones who gained less weight but the ones that survived the most. Besides, the survival percentage was also high $(81 \%)$ in larvae fed with no-contaminated rice, suggesting a negatively effect of the fungi on the larvae.

Altogether, and considering that the influence of the wt and the knock-outs on T. molitor larvae weight gain was similar, the effect could not be attributed to phosphonates. Moreover, the preference of the mealworms for the wt and the ectopic strains mycelium (Figure $7 \mathrm{~A}$ and B) suggest that when these compounds are present, an unknown factor could influence the larvae feeding behavior.

\section{Discussion}

The most important gene for phosphonates biosynthesis, i.e. pepm, was successfully knock-out in $F$. oxysporum by A. tumefaciens-mediated transformation system using an already published protocol for other fungal species (Utermark and Karlovsky 2007) with some modifications. Fungal transformation efficiency was comparable or higher to other publications in which similar protocols for Fusarium sp. transformation were used. In our case, from $1 \times 10^{5}$ spores, 45-50 transformants were obtained, while (Covert et al. 2001) reported a similar efficiency: $300-400$ colonies from $1 \times 10^{6} F$. oxysporum spores. On the other hand,(de Groot et al. 1998)reported in F. venenatum a lower efficiency compared to our method: only 2.5 colonies from $1 \times 10^{6}$ spores.

A.tumefaciens-mediated transformation system is one of the most commonly used for fungi. Among others, this system has the advantage that, in most of the cases, a singlecopy of the T-DNA is inserted into the genome (Meyer 2008) allowing the replacement of a specific gene in the fungus by homologous recombination (Weld et al. 2006). In the present study, the efficiency of the pepm replacement by homologous recombination in $F$. oxysporum was of $2.5 \%$. In A. fumigatus, $95 \%$ of the transformants had the double crossover at the homologous site (Sugui et al. 2005), while one of the highest efficiency reported in F. oxysporum is $76 \%$ (Duyvesteijn et al. 2005). The reason of such differences is that the T-DNA integration depends on AT content and chromatin structure which makes some genome regions more susceptible than others to double strand breaks 
(Frandsen 2011). Besides, the length of the homologous recombination sequences, i.e. flanking regions, could play an important role in the gene targeting efficiency (Maier et al. 2005; Weld et al. 2006). Solutions to solve this problem includes the use of longer flanking regions (>1000bp) and the enhancement of the expression of the target gene (Weld et al. 2006).

Phenotypic characteristics of the transformants were, in most of the cases, similar to the wt strain. Only one of the mutants, the $\Delta$ pepm 23 , showed a different type of mycelium and grew faster than the wt. The purple pigmentation, the typical coloration of $F$. oxysporum mycelia, was present in all the five mutant's mycelia. However, in most of them, the color was observed later than in the wt, after 15 days of culture. Phenotypic changes could occur after an A. tumefaciens transformation procedure because, in some cases, the repair mechanism for T-DNA integration in the genomecauses deletions, duplications and inversions near the insertion site(Kleinboelting et al. 2015). This presumably affects the expression of phenotypic-related genes near the T-DNA insertion region. In our case, the similarity of the wt with most of the transformants suggest that little or nophenotypicrelated changes occurred in the genome of $F$. oxysporum after A. tumefaciens-mediated transformation.

Our results obtained from fungal-bacteria co-cultivation experiments using gram-negative and gram-positive bacteria indicates that, even when the genes are expressed during this interaction (for details see chapter 2), any strong differential effect of the wt or the knockouts on the bacterial growth was observed that could be attributed to phosphonates. One possible reason for this is that many bacteria have a catabolic mechanism for phosphonates. Therefore, is not surprising that the bacteria used in the present study also have a mechanism for phosphonate degradation. Three groups of enzymes have been already identified from bacteria that can degrade phosphonates (Kamat and Raushel 2013; Peck and van der Donk 2013): the phosphonates hydrolases (Chen et al. 2006), the C-P lyase (Kononova and Nesmeyanova 2002; Seweryn et al. 2015; Zechel 2016), and an especial hydrolase related with an oxidative process (McSorley et al. 2012). Among them, only the C-P lyase mechanism is known to have a broad substrate specificity. The complex C-P lyase in E. coli has been recently described in detail (Seweryn et al. 2015; Zechel 2016). C-P lyase pathway is present in many bacteria species (Hove-Jensen et al. 2014). 
For instance, we carried out a small survey in the databases to look for the proteins related with $\mathrm{C}-\mathrm{P}$ lyase pathway in bacteria and, indeed, we found that many species of Xanthomonas and Bacilluscan produce homologous proteins. This suggest that this catabolic process could have happened in our experiments during $F$. oxysporum-bacteria co-cultivation.

From the experiments using mycoparasitic fungi and mealworms to determine phosphonates function, interesting results were obtained however none of them suggest that phosphonates could plays a role in these interactions. In the case of mycoparasitic fungi, and inhibition zone was always observed between the wt and the mycoparasitic fungi, either G. roseum or T. harzianum, this was not observed when the knock-outswere used. However, the inhibition zone was also not observed between the ectopic integration strains and the mycoparasitic fungi, suggesting thatthe effect cannot be attributed to phosphonates. Moreover, the ectopic strain did not reduce $G$. roseumgrowth as wt strain did. Possibly the $h p h-$ resistance cassette reduces the ability of the transformed fungi to compete against other organisms. The substrate range of the hph enzyme is narrow due to its unique site for hygromycin B phosphorylation (Rao et al. 1983). Therefore, it is unlikely that this enzyme is responsible for any effect on the transformed fungi. However, the high transcription rate of the $h p h$ gene due to the strong constitutive promoter (Punt et al. 1990) could influence the fungal performance since an amount of the cell energy must be used for this purpose in detriment of other pathways needed, in this case, for the interaction with organisms. Certainly, the $h p h$-resistance cassette produces an effect on the fungi that should be considered.

Interesting results were obtained when the larvae of $T$. molitor were fed with the mycelium of the wt, the knock-outs and the ectopic $F$. oxysporumstrains. Larvae finished the mycelium of the wt and the ectopic strain within the first 24 hours however, even after 5 days, the larvae did not feed on the mycelium of the knock-outs. Undoubtedly, the deficiency of phosphonates in the knock-outs affects the larvae feeding behavior. However, in order to corroborate this result, more experiments should be done in which all phosphonates knock-outs and ectopics strains are used. 
When contaminated rice with wt, knock-outs or ectopic $F$. oxysporumstrains were offer to the larvae, no differential effect was observed on larvae weight gain among all treatments that could be attributed to phosphonates. Larvae survival was lower when they fed on contaminated rice than when they fed on not-contaminated rice or when they were not fed for two weeks (control). Possibly the fungi intake caused a negative effect on the larvae. In this regard, some secondary metabolites from Fusarium spp. have been already described as a defense compounds against T. molitor(Guo et al. 2014).

\section{References}

Bai G, Shaner G (1996) Variation in Fusarium graminearum and cultivar resistance to wheat scab. Plant Dis 80:975-979

Bauer A, Luetjohann J, Rohn S, et al (2017) Determination of fosetyl and phosphonic acid at $0.010 \mathrm{mg} / \mathrm{kg}$ level by ion chromatography tandem mass spectrometry (IC-MS/MS). J Agric Food Chem 66:346-350

Bertani G (1951) Studies on lysogenesis. I. The mode of phage liberation by lysogenic Escherichia coli. J Bacteriol 62:293-300

Biasini M, Bienert S, Waterhouse A, et al (2014) SWISS-MODEL: modelling protein tertiary and quaternary structure using evolutionary information. Nucleic Acids Res 42:W252-W258

Black DM, Thompson DE, Bauer DC, et al (2000) Fracture risk reduction with alendronate in women with osteoporosis: the Fracture intervention trial. J Clin Endocrinol Metab $85: 4118-4124$

Blodgett JA, Zhang JK, Yu X, Metcalf WW (2016) Conserved biosynthetic pathways for phosalacine, bialaphos and newly discovered phosphonic acid natural products. J Antibiot (Tokyo) 69:15-25

Blodgett JA V, Zhang JK, Metcalf WW (2005) Molecular cloning, sequence analysis, and heterologous expression of the phosphinothricin tripeptide biosynthetic gene cluster from Streptomyces viridochromogenes DSM 40736. Antimicrob Agents Chemother 49:230-40

Borisova SA, Circello BT, Zhang JK, et al (2010) Biosynthesis of rhizocticins, antifungal phosphonate oligopeptides produced by Bacillus subtilis ATCC6633. Chem Biol 
$17: 28-37$

Bowman E, McQueney M, Barry RJ, Dunaway-Mariano D (1988) Catalysis and thermodynamics of the phosphoenolpyruvate/phosphonopyruvate rearrangement. Entry into the phosphonate class of naturally occurring organophosphorus compounds. J Am Chem Soc 110:5575-5576

Bowman ED, McQueney MS, Scholten JD, Dunaway-Mariano D (1990) Purification and characterization of the Tetrahymena pyriformis P-C bond forming enzyme phosphoenolpyruvate phosphomutase. Biochemistry 29:7059-7063

Brandfass C, Karlovsky P (2008) Upscaled CTAB-based DNA extraction and real-time PCR assays for Fusarium culmorum and $F$. graminearum DNA in plant material with reduced sampling error. Int J Mol Sci 9:2306-2321

Brown DW, Butchko RAE, Busman M, Proctor RH (2007) The Fusarium verticillioides FUM gene cluster encodes a Zn(II)2Cys6 protein that affects FUM gene expression and fumonisin production. Eukaryot Cell 6:1210-8

Bustin SA, Benes V, Garson JA, et al (2009) The MIQE guidelines: minimum information for publication of quantitative real-time PCR experiments. Clin Chem 55:611-22

Buszewski B, Noga S (2012) Hydrophilic interaction liquid chromatography (HILIC)-a powerful separation technique. Anal Bioanal Chem 402:231-247

Cech NB, Enke CG (2001) Practical implications of some recent studies in electrospray ionization fundamentals. Mass Spectrom Rev 20:362-387

Chen CCH, Han Y, Niu W, et al (2006) Structure and kinetics of phosphonopyruvate hydrolase from Voriovorax sp. Pal2: new insight into the divergence of catalysis within the PEP mutase/isocitrate lyase superfamily. Biochemistry 45:11491-11504

Chomczynski P, Sacchi N (2006) The single-step method of RNA isolation by acid guanidinium thiocyanate-phenol-chloroform extraction: twenty-something years on. Nat Protoc 1:581-585

Cioni JP, Doroghazi JR, Ju K-S, et al (2014) Cyanohydrin phosphonate natural product from Streptomyces regensis. J Nat Prod 77:243-249

Circello BT, Eliot AC, Lee J-H, et al (2010) Molecular cloning and heterologous expression of the dehydrophos biosynthetic gene cluster. Chem Biol 17:402-411 
Covert SF, Kapoor P, Lee M, et al (2001) Agrobacterium tumefaciens-mediated transformation of Fusarium circinatum. Mycol Res 105:259-264

Creamer JR, Bostock RM (1986) Characterization and biological activity of Phytophthora infestans phospholipids in the hypersensitive response of potato tuber. Physiol Mol Plant Pathol 28:215-225

Cubbon S, Antonio C, Wilson J, Thomas-Oates J (2010) Metabolomic applications of HILIC-LC-MS. Mass Spectrom Rev 29:671-684

de Groot MJA, Bundock P, Hooykaas PJ., Beijersbergen AGM (1998) Agrobacteriumtumefaciens-mediated transformation of filamentous fungi. Nat Biotechnol 16:839-842

Demain AL, Vaishnav P (2009) Production of recombinant proteins by microbes and higher organisms. Biotechnol Adv 27:297-306

Duyvesteijn RGE, Van Wijk R, Boer Y, et al (2005) Frp1 is a Fusarium oxysporum F-box protein required for pathogenicity on tomato. Mol Microbiol 57:1051-1063

Eliot AC, Griffin BM, Thomas PM, et al (2008) Cloning, expression, and biochemical characterization of Streptomyces rubellomurinus genes required for biosynthesis of antimalarial compound FR900098. Chem Biol 15:765-770

Evans BS, Zhao C, Gao J, et al (2013) Discovery of the antibiotic phosacetamycin via a new mass spectrometry-based method for phosphonic acid detection. ACS Chem Biol 8:908-913

Ferguson CG, Gorin BI, Thatcher GRJ (2000) Design of novel derivatives of phosphonoformate (Foscarnet) as prodrugs and antiviral agents. J Org Chem 65:12181221

Finn RD, Attwood TK, Babbitt PC, et al (2017) InterPro in 2017-beyond protein family and domain annotations. Nucleic Acids Res 45:D190-D199

Fox EM, Mendz GL (2006) Phosphonate degradation in microorganisms. Enzyme Microb Technol 40:145-150

Frandsen RJN (2011) A guide to binary vectors and strategies for targeted genome modification in fungi using Agrobacterium tumefaciens-mediated transformation. J Microbiol Methods 87:247-262 
Gao J, Ju K-S, Yu X, et al (2014) Use of a phosphonate methyltransferase in the identification of the fosfazinomycin biosynthetic gene cluster. Angew Chemie Int Ed $53: 1334-1337$

Geisen R, Schmidt-Heydt M, Karolewiez A (2006) A gene cluster of the ochratoxin A biosynthetic genes in Penicillium. Mycotoxin Res 22:134-141

Georgiou G, Segatori L (2005) Preparative expression of secreted proteins in bacteria: status report and future prospects. Curr Opin Biotechnol 16:538-545

Gioumouxouzis CI, Kouskoura MG, Markopoulou CK (2015) Negative electrospray ionization mode in mass spectrometry: A new perspective via modeling. J Chromatogr B 998-999:97-105

Glish GL, Vachet RW (2003) The basics of mass spectrometry in the twenty-first century. Nat Rev Drug Discov 2:140-150

Greco G, Letzel T (2013) Main interactions and influences of the chromatographic parameters in HILIC separations. J Chromatogr Sci 51:684-693

Gribble GW (2004) Natural organohalogens. Science Dossiers, Brussels, Belgium

Gunji S, Arima K, Beppu T (1983) Screening of antifungal antibiotics according to activities inducing morphological abnormalities. Agric Biol Chem 47:2061-2069

Guo Z, Döll K, Dastjerdi R, et al (2014) Effect of fungal colonization of wheat grains with Fusarium spp. on food choice, weight gain and mortality of meal beetle larvae (Tenebrio molitor). PLoS One 9:e100112

Hanahan D (1983) Studies on transformation of Escherichia coli with plasmids. J Mol Biol $166: 557-580$

Hao Z, Xiao B, Weng N (2008) Impact of column temperature and mobile phase components on selectivity of hydrophilic interaction chromatography (HILIC). J Sep Sci 31:1449-1464

Hemström P, Irgum K (2006) Hydrophilic interaction chromatography. J Sep Sci 29:17841821

Henriksen T, Juhler RK, Svensmark B, Cech NB (2005) The relative influences of acidity and polarity on responsiveness of small organic molecules to analysis with negative ion electrospray ionization mass spectrometry (ESI-MS). J Am Soc Mass Spectrom 
$16: 446-455$

Hidaka T, Mori M, Imai S, et al (1989) Studies on the biosynthesis of bialaphos (SF-1293).

9. Biochemical mechanism of C-P bond formation in bialaphos: Discovery of phosphoenolpyruvate phosphomutase which catalyzes the formation of phosphonopyruvate from phosphoenolpyruvete. J Antibiot (Tokyo) 42:491-494

Horiguchi M, Kandatstu M (1959) Isolation of 2-aminoethane phosphonic acid from rumen protozoa. Nature 184:901-902

Horsman GP, Zechel DL (2017) Phosphonate biochemistry. Chem Rev 117:5704-5783

Hothorn T, Bretz F, Westfall P (2008) Simultaneous inference in general parametric models. Biometrical J 50:346-363

Hove-Jensen B, Zechel DL, Jochimsen B (2014) Utilization of glyphosate as phosphate source: biochemistry and genetics of bacterial carbon-phosphorus lyase. Microbiol Mol Biol Rev 78:176-97

Huang Z, Wang K-KA, Lee J, van der Donk WA (2015) Biosynthesis of fosfazinomycin is a convergent process. Chem Sci 6:1282-1287

Jia Y, Lu Z, Huang K, et al (1999) Insight into the mechanism of phosphoenolpyruvate mutase catalysis derived from site-directed mutagenesis studies of active site residues. Biochemistry 38:14165-14173

Ju K-S, Doroghazi JR, Metcalf WW (2014) Genomics-enabled discovery of phosphonate natural products and their biosynthetic pathways. J Ind Microbiol Biotechnol 41:345356

Ju K-S, Gao J, Doroghazi JR, et al (2015) Discovery of phosphonic acid natural products by mining the genomes of 10,000 actinomycetes. Proc Natl Acad Sci U S A 112:12175-80

Kamat SS, Raushel FM (2013) The enzymatic conversion of phosphonates to phosphate by bacteria. Curr Opin Chem Biol 17:589-596

Katayama N, Tsubotani S, Nosaki Y, et al (1990) Fosfadecin and fosfocytocin, new nucleotide antibiotics produced by bacteria. J Antibiot (Tokyo) 43:238-246

Kaysser L, Bernhardt P, Nam S-J, et al (2012) Merochlorins A-D, cyclic meroterpenoid antibiotics biosynthesized in divergent pathways with vanadium-dependent 
chloroperoxidases. J Am Chem Soc 134:11988-11991

Kennedy K, Thompson G (1970) Phosphonolipids: localization in surface membranes of Tetrahymena. Science (80- ) 168:989-991

Kim A, Kim J, Martin BM, Dunaway-Mariano D (1998) Isolation and characterization of the carbon-phosphorus bond-forming enzyme phosphoenolpyruvate mutase from the mollusk Mytilus edulis. J Biol Chem 273:4443-8

Kim AD, Baker AS, Dunaway-Mariano D, et al (2002) The 2-aminoethylphosphonatespecific transaminase of the 2-aminoethylphosphonate degradation pathway. $\mathrm{J}$ Bacteriol 184:4134-40

Kim J-E, Jin J, Kim H, et al (2006) GIP2, a putative transcription factor that regulates the aurofusarin biosynthetic gene cluster in Gibberella zeae. Appl Environ Microbiol $72: 1645-52$

Kim J, Dunaway-Mariano D (1996) Phosphoenolpyruvate mutase catalysis of phosphoryl transfer in phosphoenolpyruvate: kinetics and mechanism of phosphorus-carbon bond formation. Biochemistry 35:4628-4635

Kim SY, Ju K-S, Metcalf WW, et al (2012) Different biosynthetic pathways to fosfomycin in Pseudomonas syringae and Streptomyces species. Antimicrob Agents Chemother $56: 4175-83$

Kittredge JS, Roberts E (1969) A carbon-phosphorus bond in nature. Science (80- ) $164: 37-42$

Kleinboelting N, Huep G, Appelhagen I, et al (2015) The structural features of thousands of T-DNA insertion sites are consistent with a double- strand break repair-based insertion mechanism. Mol Plant 8:1651-1664

Kononova S V., Nesmeyanova MA (2002) Phosphonates and their degradation by microorganisms. Biochem 67:184-195

Koukol O, Novák F, Hrabal R (2008) Composition of the organic phosphorus fraction in basidiocarps of saprotrophic and mycorrhizal fungi. Soil Biol Biochem 40:2464-2467

Koukol O, Novák F, Hrabal R, Vosátka M (2006) Saprotrophic fungi transform organic phosphorus from spruce needle litter. Soil Biol Biochem 38:3372-3379

La Nauze JM, Coggins JR, Dixon HB (1977) Aldolase-like imine formation in the 
mechanism of action of phosphonoacetaldehyde hydrolase. Biochem J 165:409-11

La Nauze JM, Rosenberg H, Shaw DC (1970) The enzymic cleavage of the carbonphosphorus bond: Purification and properties of phosphonatase. Biochim Biophys Acta - Enzymol 212:332-350

Lea P, Joy K, Ramos J, Guerrero M (1984) The action of 2-amino-4-(methylphosphinyl)butanoic acid (phosphinothricin) and its 2-oxo-derivative on the metabolism of cyanobacteria and higher plants. Phytochemistry 23:1-6

Lee KS, Metcalf WW, Wanner BL (1992) Evidence for two phosphonate degradative pathways in Enterobacter aerogenes. J Bacteriol 174:2501-10

Lelliott RA, Stead DE (1987) Methods for the diagnosis of bacterial diseases of plants. Blackwell Scientific Publications, Oxford, UK

Liang C-R, Rosenberg H (1968) On the distribution and biosynthesis of 2aminoethylphosphonate in two terrestrial molluscs. Comp Biochem Physiol 25:673681

Liu S, Lu Z, Han Y, et al (2004) Conformational flexibility of PEP mutase. Biochemistry 43:4447-4453

Liu S, Lu Z, Jia Y, et al (2002) Dissociative phosphoryl transfer in PEP mutase catalysis: structure of the enzyme/sulfopyruvate complex and kinetic properties of mutants. Biochemistry 41:10270-10276

Lutz MP, Feichtinger G, Défago G, Duffy B (2003) Mycotoxigenic Fusarium and deoxynivalenol production repress chitinase gene expression in the biocontrol agent Trichoderma atroviride P1. Appl Environ Microbiol 69:3077-84

Maciejczyk E, Wieczorek D, Zwyrzykowska A, et al (2015) Phosphorus profile of basidiomycetes. Phosphorus Sulfur Silicon Relat Elem 190:763-768

MacPherson S, Larochelle M, Turcotte B (2006) A fungal family of transcriptional regulators: the zinc cluster proteins. Microbiol Mol Biol Rev 70:583-604

Maier F, Malz S, Losch A, et al (2005) Development of a highly efficient gene targeting system for using the disruption of a polyketide synthase gene as a visible marker. FEMS Yeast Res 5:653-662

Maile R, Fischesser G, Anderson M (1977) Thin-layer chromatographic separation of 
phosphonic acid derivatives. J Chromatogr 132:366-368

Marquardt JL, Brown ED, Lane WS, et al (1994) Kinetics, stoichiometry, and identification of the reactive thiolate in the inactivation of UDP-GlcNAc enolpyruvoyl transferase by the antibiotic fosfomycin. Biochemistry 33:10646-10651

Martinez A, Tyson GW, Delong EF (2010) Widespread known and novel phosphonate utilization pathways in marine bacteria revealed by functional screening and metagenomic analyses. Environ Microbiol 12:222-238

McGrath JW, Chin JP, Quinn JP (2013) Organophosphonates revealed: new insights into the microbial metabolism of ancient molecules. Nat Rev Microbiol 11:412-419

McSorley FR, Wyatt PB, Martinez A, et al (2012) PhnY and PhnZ comprise a new oxidative pathway for enzymatic cleavage of a carbon-phosphorus bond. J Am Chem Soc 134:8364-8367

Metcalf WW, van der Donk WA (2009) Biosynthesis of phosphonic and phosphinic acid natural products. Annu Rev Biochem 78:65-94

Meyer V (2008) Genetic engineering of filamentous fungi — Progress, obstacles and future trends. Biotechnol Adv 26:177-185

Michielse CB, Hooykaas PJJ, van den Hondel CAMJJ, Ram AFJ (2005) Agrobacteriummediated transformation as a tool for functional genomics in fungi. Curr Genet 48:117

Nakashita H, Watanabe K, Hara O, et al (1997) Studies on the biosynthesis of bialaphos. Biochemical mechanism of C-P bond formation: discovery of phosphonopyruvate decarboxylase which catalyzes the formation of phosphonoacetaldehyde from phosphonopyruvate. J Antibiot (Tokyo) 50:212-219

Nielsen ML, Pustinger J V., Strobel J (1964) Phosphorus-31 nuclear magnetic resonance chemical shifts of phosphorus compounds. J Chem Eng Data 9:167-170

Olsen DB, Hepburn TW, Lee S, et al (1992) Investigation of the substrate binding and catalytic groups of the P-C bond cleaving enzyme, phosphonoacetaldehyde hydrolase. Arch Biochem Biophys 296:144-151

Omura S, Murata M, Hanaki H, et al (1984) Phosalacine, a new herbicidal antibiotic containing phosphinothricin. Fermentation, isolation, biological activity and mechanism of action. J Antibiot (Tokyo) 37:829-835 
Onorato JM, Langish R, Bellamine A, Shipkova P (2010) Applications of HILIC for targeted and non-targeted LC/MS analyses in drug discovery. J Sep Sci 33:923-929

Pan Z, Raftery D (2007) Comparing and combining NMR spectroscopy and mass spectrometry in metabolomics. Anal Bioanal Chem 387:525-527

Park BK, Hirota A, Sakai H (1977) Studies on new antimetabolite produced by microorganism. III. Structure of plumbemycin A and B, antagonists of L-threonine from Streptomyces plumbeus. Agric Biol Chem 41:573-579

Peck SC, van der Donk WA (2013) Phosphonate biosynthesis and catabolism: a treasure trove of unusual enzymology. Curr Opin Chem Biol 17:580-588

Pfaffl MW (2001) A new mathematical model for relative quantification in real-time RTPCR. Nucleic Acids Res 29:45e-45

Punt PJ, Dingemanse MA, Kuyvenhoven A, et al (1990) Functional elements in the promoter region of the Aspergillus nidulans gpdA gene encoding glyceraldehyde-3phosphate dehydrogenase. Gene 93:101-109

R Core Team (2017) R: A language and environment for statistical computing. R Found. Stat. Comput.

Rai M, Padh H (2001) Expression systems for production of heterologous proteins. Curr Sci 80:1121-1128

Rao RN, Allen NE, Hobbs JN, et al (1983) Genetic and enzymatic basis of hygromycin B resistance in Escherichia coli. Antimicrob Agents Chemother 24:689-95

Reeves DS (1994) Fosfomycin trometamol. J Antimicrob Chemother 34:853-858

Rice P, Longden I, Bleasby A (2000) EMBOSS: the European molecular biology open software suite. Trends Genet 16:276-277

Rosano GL, Ceccarelli EA (2014) Recombinant protein expression in Escherichia coli: advances and challenges. Front Microbiol 5:172

Roseberg H, La Nauze JM (1967) The metabolism of phosphanates by microorganisms. The transport of aminoethylphosphonic acid in Basillus cereus. Biochim Biophys Acta 141:79-90

Rost B (1999) Twilight zone of protein sequence alignments. Protein Eng Des Sel 12:8594 
Sander C, Schneider R (1991) Database of homology-derived protein structures and the structural meaning of sequence alignment. Proteins Struct Funct Genet 9:56-68

Sarkar M, Hamilton CJ, Fairlamb AH (2003) Properties of phosphoenolpyruvate mutase, the first enzyme in the aminoethylphosphonate biosynthetic pathway in Trypanosoma cruzi. J Biol Chem 278:22703-8

Schiesel S, Lämmerhofer M, Lindner W (2010) Multitarget quantitative metabolic profiling of hydrophilic metabolites in fermentation broths of $\beta$-lactam antibiotics production by HILIC-ESI-MS/MS. Anal Bioanal Chem 396:1655-1679

Schowanek D, Verstraete W (1990) Phosphonate utilization by bacterial cultures and enrichments from environmental samples. Appl Environ Microbiol 56:895-903

Seidel HM, Freeman S, Seto H, Knowles JR (1988) Phosphonate biosynthesis: isolation of the enzyme responsible for the formation of a carbon-phosphorus bond. Nature $335: 457-458$

Seidel HM, Pompliano DL, Knowles JR (1992) Phosphonate biosynthesis: molecular cloning of the gene for phosphoenolpyruvate mutase from Tetrahymena pyriformis and overexpression of the gene product in Escherichia coli. Biochemistry 31:25982608

Seto H, Imai S, Tsuruoka T, et al (1982) Studies on the biosynthesis of bialaphos (SF1293) 1. Incorporation of $13 \mathrm{C}$ - and $2 \mathrm{H}$-labeled precursors into bialaphos. J Antibiot (Tokyo) 35:1719-1721

Seto H, Kuzuyama T, Seto H, Kuzuyama T (1999) Bioactive natural products with carbonphosphorus bonds and their biosynthesis. Nat Prod Rep 16:589-596

Seweryn P, Van LB, Kjeldgaard M, et al (2015) Structural insights into the bacterial carbon-phosphorus lyase machinery. Nature 525:68-72

Shao Z, Blodgett JA V, Circello BT, et al (2008) Biosynthesis of 2hydroxyethylphosphonate, an unexpected intermediate common to multiple phosphonate biosynthetic pathways. J Biol Chem 283:23161-8

Sievers F, Wilm A, Dineen D, et al (2011) Fast, scalable generation of high-quality protein multiple sequence alignments using Clustal Omega. Mol Syst Biol 7:539

Sosa OA, Repeta DJ, Ferrón S, et al (2017) Isolation and characterization of bacteria that degrade phosphonates in marine dissolved organic matter. Front Microbiol 8:1786 
Stead MB, Agrawal A, Bowden KE, et al (2012) RNAsnap : a rapid, quantitative and inexpensive, method for isolating total RNA from bacteria. Nucleic Acids Res 40:e156-e156

Stutter MI, Shand CA, George TS, et al (2015) Land use and soil factors affecting accumulation of phosphorus species in temperate soils. Geoderma 257-258:29-39

Suchfort R (2016) Biological detoxification of enniatins. Georg-August-Universität Göttingen

Sugui JA, Chang YC, Kwon-Chung KJ (2005) Agrobacterium tumefaciens-mediated transformation of Aspergillus fumigatus: an efficient tool for insertional mutagenesis and targeted gene disruption. Appl Environ Microbiol 71:1798-802

Takahashi E, Kimura T, Nakamura K, et al (1995) Phosphonothrixin, a novel herbicidal antibiotic produced by Saccharothrix sp. ST-888. I. Taxonomy, fermentation, isolation and biological Properties. J Antibiot (Tokyo) 48:1124-1129

Takeuchi M, Nakajima M, Ogita T, et al (1989) Fosfonochlorin, a new antibiotic with spheroplast forming activity. J Antibiot (Tokyo) 42:198-205

Tate KR, Newman RH (1982) Phosphorus fractions of a climosequence of soils in New Zealand tussock grassland. Soil Biol Biochem 14:191-196

Terpe K (2006) Overview of bacterial expression systems for heterologous protein production: from molecular and biochemical fundamentals to commercial systems. Appl Microbiol Biotechnol 72:211-222

The Gene Ontology Consortium (2015) Gene Ontology Consortium: going forward. Nucleic Acids Res 43:D1049-D1056

Turner BL, Baxter R, Mahieu N, et al (2004) Phosphorus compounds in subarctic Fennoscandian soils at the mountain birch (Betula pubescens)-tundra ecotone. Soil Biol Biochem 36:815-823

Utermark J, Karlovsky P (2007) Role of zearalenone lactonase in protection of Gliocladium roseum from fungitoxic effects of the mycotoxin zearalenone. Appl Environ Microbiol 73:637-42

Vary PS, Biedendieck R, Fuerch T, et al (2007) Bacillus megaterium-from simple soil bacterium to industrial protein production host. Appl Microbiol Biotechnol 76:957967 
Wackett LP, Shames SL, Venditti CP, Walsh CT (1987) Bacterial carbon-phosphorus lyase: products, rates, and regulation of phosphonic and phosphinic acid metabolism. J Bacteriol 169:710-7

Wassef MK, Hendrix JW (1977) Ceramide aminoethylphosphonate in the fungus Pythium prolatum. Biochim Biophys Acta - Lipids Lipid Metab 486:172-178

Weld RJ, Plummer KM, Carpenter MA, Ridgway HJ (2006) Approaches to functional genomics in filamentous fungi. Cell Res 16:31-44

Wendler C, Barniske M, Wild A (1990) Effect of phosphinothricin (glufosinate) on photosynthesis and photorespiration of C3 and C4 plants. Photosynth Res 24:55-61

Woloshuk CP, Foutz KR, Brewer JF, et al (1994) Molecular characterization of aflR, a regulatory locus for aflatoxin biosynthesis. Appl Environ Microbiol 60:2408-14

Woo G, Tomlinson G, Nishikawa Y, et al (2010) Tenofovir and entecavir are the most effective antiviral agents for chronic hepatitis B: a systematic review and bayesian meta-analyses. Gastroenterology 139:1218-1229.e5

Woodyer RD, Li G, Zhao H, van der Donk WA (2007) New insight into the mechanism of methyl transfer during the biosynthesis of fosfomycin. Chem Commun 0:359-361

Woodyer RD, Shao Z, Thomas PM, et al (2006) Heterologous production of fosfomycin and identification of the minimal biosynthetic gene cluster. Chem Biol 13:1171-1182

Xu D, Guo H, Yun L, York DM (2005) Theoretical studies of dissociative phosphoryl transfer in interconversion of phosphoenolpyruvate to phosphonopyruvate: solvent effects, thio effects, and implications for enzymatic reactions. J Phys Chem B 109:13827-13834

Yin W, Keller NP (2011) Transcriptional regulatory elements in fungal secondary metabolism. J Microbiol 49:329-339

Yu X, Doroghazi JR, Janga SC, et al (2013) Diversity and abundance of phosphonate biosynthetic genes in nature. Proc Natl Acad Sci U S A 110:20759-64

Zechel DL (2016) PhnK: another piece of the carbon-phosphorus lyase puzzle. Structure $24: 3-4$

Zeleznick L, Myers T, Titchener E (1963) Growth of Escherichia coli on methyl-and ethylphosphonic acids. Biochim Biophys Acta 78:547-550 
Zhang G, Dai J, Lu Z, Dunaway-Mariano D (2003) The phosphonopyruvate decarboxylase from Bacteroides fragilis. J Biol Chem 278:41302-8

\section{Supplementary information}

Supplementary table 1. List of primers used for the generation of $F$. oxysporum phosphonates- disrupted strains

\begin{tabular}{|c|c|c|c|}
\hline $\begin{array}{l}\text { Primer } \\
\text { number }\end{array}$ & $\begin{array}{l}\text { Primer } \\
\text { name }\end{array}$ & Product & Sequence $\left(5^{\prime}-3^{\prime}\right)$ \\
\hline 1 & pepm3'_F & \multirow{2}{*}{ 3' flanking region } & AGAGAAAGCTTGCTTAACCTAATCTAGTAAACATC \\
\hline 2 & pepm3’R & & AGAGACCTGCAGGTTTCAAGGCTGTCAATGCAAAGGC \\
\hline 3 & pepm5'_F & \multirow{2}{*}{5 ' flanking region } & AGAGAGGTACCTTAAGTGAGTAGAGGATTGTGGAC \\
\hline 4 & pepm5'_R & & AGAGATTAATTAATCATGATCTGAGCTTGGTCTCCCC \\
\hline 5 & pPK2_3F & \multirow{2}{*}{$\begin{array}{l}\text { To detect } 3^{\prime} \text { flanking } \\
\text { region insertion in pPK2 }\end{array}$} & GTCCTCGTGTACTGTGTAAGCGCCCACTCC \\
\hline 6 & pPK2_3R & & CGATTAAGTTGGGTAACGCCAGG \\
\hline 7 & pepm_F & \multirow{2}{*}{$\begin{array}{l}\text { Complete pepm gene } \\
\text { (Foxg_02666) }\end{array}$} & GTAAACATCTACCTGGGTGA \\
\hline 8 & pepm_R & & ATGGGTTCCCTTCATACTGA \\
\hline 9 & hph_F2 & \multirow{2}{*}{$\begin{array}{l}\text { For knock-outs } \\
\text { detection }\end{array}$} & CCAGTTCTTCTCGGCGTTCTGGA \\
\hline 10 & hph_R2 & & GTCCTCGTGTCCTGTGTAAGCGCCCACTCC \\
\hline 11 & Fox_F & \multirow{2}{*}{$\begin{array}{l}\text { pepm gene or T-DNA } \\
\text { outside flanking regions }\end{array}$} & CACACCTCCCATTGCCGATGA \\
\hline 12 & Fox_R & & ATCATCCGCAATAGTTCCTG \\
\hline 13 & hph_F & \multirow{2}{*}{$h p h$ gene } & AAGGTTCTTGGATGGGAAGATG \\
\hline 14 & hph_R & & AATCACCGGCAGTAAGCGAA \\
\hline
\end{tabular}




\title{
CHAPTER4. Phosphonates detection in Fusarium
}

\begin{abstract}
Phosphonates have been gaining much interest in the research area of bioactive natural compounds due to their applications in agriculture and medicine. Most advances have been done in bacteria-bioactive-phosphonates however, other organisms, including fungi, might also synthetize these compounds. Extraction and detection of polar molecules, such as phosphonates, is still a challenging task and that is the reason why most of these compounds often have gone undetected when the usual protocols for natural metabolites extraction and detection are employed. Fortunately, some methods including hydrophilic interaction chromatography (HILIC) coupled to electrospray ionization-mass spectrometry (ESI-MS) exist nowadays to identify and characterize phosphonates. In the present chapter, using similar methods, we identified putative phosphonates in $F$. avenaceum and F. oxysporum liquid cultures. The first possible phosphonate was predicted to be the already described fungal phosphonate fosfonochlorin showing a mass of $\mathrm{m} / \mathrm{z} 157$ after negative ionization. The second compound was predicted to be an unknown $\mathrm{P}$-containing molecule with a mass of $m / z 147$, a chemical formula of $\mathrm{C}_{5} \mathrm{H}_{9} \mathrm{O}_{3} \mathrm{P}$ and a molar mass of $148.0969 \mathrm{~g} / \mathrm{mol}$ as obtained from high resolution-MS analysis. The last compound showed a mass of $\mathrm{m} / \mathrm{z} 317$ and, is interesting, since it was produce by the fungi only when it was cultivated with bacteria. Although improvements and more studies to extract and detect phosphonates from Fusarium cultures should be still made, this is the first and the starting point for future research in fungal bioactive phosphonates.
\end{abstract}

Keywords: Fusarium, natural phosphonates, fosfonochlorin, polar compounds, TLC, HILIC, HPLC-ESI-MS. 


\section{Introduction}

Phosphonates are natural and synthetic compounds containing a direct $\mathrm{C}-\mathrm{P}$ bond, which makes them suitable for a wide range of applications. Bioactive phosphonates are mainly produced by bacteria and some of them are used in agriculture [e.g. the herbicide phosphinothricin-glufosinate (Wendler et al. 1990)] and in medicine [e.g. the antibiotic fosfomycin (Woodyer et al. 2006)]. Fosfonochlorin is the only bioactive phosphonate discovered in fungi time ago in 1989 (Takeuchi et al. 1989). This unique chlorinecontaining phosphonate $\left(\mathrm{C}_{2} \mathrm{H}_{4} \mathrm{O}_{4} \mathrm{PCl}\right)$, (MW: 158, [M-H] $]^{-} \mathrm{m} / \mathrm{z}$ 157), was identified in cultures of Fusarium avenaceum, F. oxysporum, F. tricinctum and Talaromyces flavus. It was described by the same authors as an acidic compound soluble in water, methanol and dimethylformamide and insoluble in acetone, ethyl acetate and chloroform. Fosfonochlorin was characterized as an antibiotic compound with a mode of action similar to fosfomycin $\left(\mathrm{C}_{3} \mathrm{H}_{7} \mathrm{O}_{4} \mathrm{P}\right)$. The chemical structures of both of them and of other representative natural phosphonates are shown in chapter 1 (Figure 1).

Despite the presumably abundance of phosphonates on Earth (Yu et al. 2013; Ju et al. 2014; Horsman and Zechel 2017), only some have been discovered so far. Their special chemistry could be the reason, since phosphonates are highly polar compounds that lack of chromophores which makes them difficult to extract, purify and detect using the usual methods for natural metabolites (Gao et al. 2014; Ju et al. 2014; Horsman and Zechel 2017). Phosphorus nuclear magnetic resonance spectroscopy $\left({ }^{31} \mathrm{P}\right.$ NMR) could be used to detect phosphonates due to the special chemical shift pattern (Nielsen et al. 1964; Turner et al. 2004) however, the high concentration needed for this technique (Pan and Raftery 2007) makes it difficult to use when microbial cultures are employed.

Despite the challenging for phosphonates purification and detection some advances have been done using bacteria cultures. In 2013, Evans and collaborators (Evans et al. 2013) developed a LC-MS/MS method in which, after removing the abundant phosphatesalts and esters $\left(\mathrm{PO}_{4}\right)$ from the samples, iron-immobilized affinity chromatography (IMAC) was used to select only phosphonates based on $\mathrm{Fe}-\mathrm{P}$ interaction. IMAC was coupled to hydrophilic interaction chromatography (HILIC) to separate them and to further detect the precursor ions by electrospray ionization-mass spectrometry (ESI-MS). In this way, 
phosphonates were detected by their fragmentation pattern which give characteristics negative ions of $\mathrm{m} / \mathrm{z}=79$ and 63 due to the elimination of $\mathrm{PO}^{3-}$ and $\mathrm{PO}^{2-}$ respectively (Evans et al. 2013). Using this approach together with a large-scale genome-based survey, in $2015 \mathrm{Ju}$ and collaborators discovered 11 new phosphonic acid natural products synthetized by actinomycetes ( $\mathrm{Ju}$ et al. 2015). Based on the genome information generated by these authors and others (Yu et al. 2013; Ju et al. 2014, 2015), it is possible to conclude that phosphonates natural products discovery is still in its infancy.

In chapter 2 we have demonstrated that, based on genome-based information and gene expression analysis is very likely that $F$. oxysporum biosynthesizes phosphonates. In this chapter, we cultivated $F$. avenaceum and $F$. oxysporum using the conditions for phosphonates production as described by Takeuchi et al. (1989) and we extracted them using mainly methanol. Then, thin layer chromatography (TLC) and/or high-performance liquid chromatography (HPLC)-MS using HILIC and ESI-MS were further used to detect the compounds in extracted concentrates of fungal liquid cultures.

The main objective of the present chapter was to induce and detect fosfonochlorin and other phosphonates in $F$. avenaceum and $F$. oxysporum cultures.

\section{Materials and methods}

\subsection{Establishment of a method for detection of phosphonates on TLC plates}

To establish a method for detection of phosphonates on TLC plates, two phosphonates standards were used: the antibiotic fosfomycin disodium salt (Sigma-Aldrich, Germany) and diethyl acetylphosphonate (DA) (Tokyo Chemical Industry, Japan). Serial dilutions from 0.1 to $0.4 \mathrm{M}$ of fosfomycin and from 0.1 to $2 \mathrm{M}$ of DA were prepared and used for TLC in which $5 \mu \mathrm{l}$ of sample was loaded on silica gel plates (No. $60 \mathrm{~F}_{254}$, Merck, Darmstadt, Germany) and developed with 2-propanol: $\mathrm{H}_{2} \mathrm{O}: \mathrm{NH}_{3}$ (6:3:1). Phosphonates were detected based on the molybdenum blue reaction for phosphonic acid detection (Maile et al. 1977), modified as follows: silica plates were sprayed with a freshly prepared visualization solution composed of $4.6 \%$ ammonium molybdate $\left[\left(\mathrm{NH}_{4}\right)_{2} \mathrm{Mo}_{7} \mathrm{O}_{24} \cdot \mathrm{H}_{2} \mathrm{O}\right]$ and 
$0.2 \%$ of cerium (IV) sulfate $\left[\mathrm{Ce}\left(\mathrm{SO}_{4}\right)_{2}\right]$ in $10 \%$ sulfuric acid. After drying and heating at $100{ }^{\circ} \mathrm{C}$ for 15 minutes, phosphonates were observed as blue spots on the TLC plates.

Phosphonates were extracted from TLC silica plates as follows: fosfomycin $(0.1 \mathrm{M})$ spots were scratched from the silica and extracted overnight at $180 \mathrm{rpm}$ using $100 \% \mathrm{MeOH}$. After this period, the extraction mixture was sonicated for $30 \mathrm{~s}$ and centrifuged at $12300 \mathrm{xg}$ for $15 \mathrm{~min}$ to remove silica residues. The supernatant was concentrated to dryness and dissolved in $25 \mu \mathrm{l}$ of $80 \% \mathrm{MeOH}$ for HPLC-MS analysis as described later in section 2.2.3.

\subsection{Phosphonates extraction and detection by TLC and HPLC-MS}

\subsubsection{Phosphates $\left(\mathrm{PO}_{4}\right)$ precipitation assay}

In order to remove $\mathrm{PO}_{4}$ from the analysis, an assay was conducted to ensure that the protocol for $\mathrm{PO}_{4}$ precipitation do not precipitate phosphonates. The assay was performed using either the induction medium (IM) described by Takeuchi et al. (1989) which includes $37 \mathrm{mM}$ of $\mathrm{KH}_{2} \mathrm{PO}_{4}\left(\mathrm{IM}+\mathrm{PO}_{4}\right)$ or the same medium but without $\mathrm{KH}_{2} \mathrm{PO}_{4}\left(\mathrm{IM}-\mathrm{PO}_{4}\right)$ as control. Each medium was supplemented or not with the phosphonates fosfomycin or DA using the same $\mathrm{P}$ molar concentration as in $\mathrm{KH}_{2} \mathrm{PO}_{4}$. After adjusting the $\mathrm{pH}$ to 10 using $\mathrm{KOH}$, a final concentration of $0.1 \mathrm{M}$ of $\mathrm{CaCl}_{2}$ was added to each medium to precipitate the $\mathrm{PO}_{4}$ (Evans et al. 2013). After 1 or $3 \mathrm{~h}$ of agitation at $180 \mathrm{rpm}$ the solutions were centrifuged for $15 \mathrm{~min}$ at $2700 \mathrm{xg}$ and the supernatant was discarded, the precipitates were dried and weighed.

\subsubsection{Phosphonates extraction from Fusarium cultures}

Phosphonates were induced in $F$. oxysporumDSM62291 and $F$. avenaceum DSM62161 for 11 days using $1 \mathrm{~L}$ of induction medium at $180 \mathrm{rpm}$ and $24^{\circ} \mathrm{C}$, as described by Takeuchi et al. (1989). The extraction was performed as follows: mycelium was separated from the medium by vacuum filtration and the $\mathrm{pH}$ of the filtrate was adjusted to 10 using $\mathrm{KOH}$ (7$10 \mathrm{M}$ ) to continue with the $\mathrm{PO}_{4}$ precipitation explained before (section 2.2.1). The mixture was incubated at $180 \mathrm{rpm}$ for 3 hours to precipitate all $\mathrm{PO}_{4}$ and, after centrifugation for 15 min at $2700 \mathrm{xg}, 0.1 \mathrm{M}$ of $\mathrm{NH}_{4} \mathrm{HCO}_{3}$ was added to the supernatant to precipitate the excess of calcium. The supernatant was collected after centrifugation for $15 \mathrm{~min}$ at $2700 \mathrm{xg}$ and used for further phosphonate extraction. 
Phosphonates were extracted overnight at $180 \mathrm{rpm}$ using $70 \% \mathrm{MeOH}$. Precipitates obtained after overnight incubation were discarded by filtration and the extracted solution was evaporated to dryness. Residues were dissolved in $50 \mathrm{ml}$ of $80 \% \mathrm{MeOH}$-water HPLC grade. Samples were diluted 1:1 using 80\% MeOH before TLC and HPLC-MS analysis. When an interesting mass was detected on HPLC-MS, the extracted mixture was concentrated 10 times (final volume of $5 \mathrm{ml}$ ) and used for further purification with Sephadex LH-20 (Sigma-Aldrich, Germany) as follows: $1 \mathrm{ml}$ of sample was applied to 20 $\mathrm{ml}$ of Sephadex previously equilibrated with $100 \% \mathrm{MeOH}$, compounds were eluted first using 2 bed volumes of water $(40 \mathrm{ml})$ and collected in fractions of $2 \mathrm{ml}$, then the column was washed using 2 bed volumes of $100 \% \mathrm{MeOH}(40 \mathrm{ml})$ and the whole pass-through was collected, concentrated to $1 \mathrm{ml}$ and applied again to the Sephadex column previously equilibrated with $100 \% \mathrm{MeOH}$. This time compounds were eluted using $100 \% \mathrm{MeOH}$ and collected in fractions of $2 \mathrm{ml}$. All fractions eluted with water and with $\mathrm{MeOH}$ were evaporated to dryness and the residues were dissolved in $200 \mu \mathrm{l}$ of $80 \% \mathrm{MeOH}$-water HPLC grade. Two replicates were performed per fungal species and the experiment was repeated twice.

In a next experiment the effect of bacteria on the production of phosphonates was evaluated. Bacterium used for this experiment was isolated from $F$. oxysporum DSM62291 cultures and identified by sequencing part of the bacterial 16S rRNA as follows: DNA was extracted using the CTAB method described by (Brandfass and Karlovsky 2008) and the PCR was done using 0.6 U of taq polymerase (New England Bioline, London, UK) as recommended by the company employing the bacterial primers $27 \mathrm{~F} \quad\left(5^{\prime}-\right.$ AGAGTTTGATCMTGGCTCAG) and 1100R (5'-AGGGTTGCGCTCGTTG) with the following conditions: $94^{\circ} \mathrm{C}$ for $30 \mathrm{sec}, 10$ cycles of: $94^{\circ} \mathrm{C}$ for $30 \mathrm{sec}, 62^{\circ} \mathrm{C}-53^{\circ} \mathrm{C}-$ $1^{\circ} \mathrm{C} /$ cycle for $40 \mathrm{~min}, 72^{\circ} \mathrm{C}$ for $1 \mathrm{~min}$ and 30 cycles of: $94^{\circ} \mathrm{C}$ for $30 \mathrm{sec}, 56^{\circ} \mathrm{C}$ for $40 \mathrm{~min}$, $72^{\circ} \mathrm{C}$ for $1 \mathrm{~min}$, with a final extension of $72^{\circ} \mathrm{C}$ for 5 minutes. PCR products were sequenced and the identification of the bacteria was done by sequence similarity using the nucleotide BLAST tool from the National Center for Biotechnology Information (NCBI, 12.2017).

For this experiment with bacteria, F. oxysporum was cultivated as described by Takeuchi et al. (1989) in $500 \mathrm{ml}$ of IM. A loop of the isolated bacteria was added into the fungal liquid cultures together with the fungus from the beginning. After 11 days, mycelium was separated by filtration and $\mathrm{PO}_{4}$ were precipitated as described before followed by overnight phosphonates extraction using $70 \% \mathrm{MeOH}$. Precipitates obtained after overnight 
incubation were discarded by filtration and the extracted solution was evaporated to dryness. Residues were dissolved in $20 \mathrm{ml} 80 \% \mathrm{MeOH}$-water and the samples were diluted 1:1 using the same solvent. Two replicates were performed per treatment (with and without bacteria).

\subsubsection{Phosphonates detection by TLC and HPLC-MS}

TLC was performed as described before for phosphonates standards (section 2.1), however in this case and, in order to extract the spots from TLC plates without contaminants, another silica plate was run in parallel but without visualization solution. The spots, without visualization solution, were scratched from the silica and extracted as explained before for phosphonates standards (section 2.1).

Extracted samples from liquid cultures and spots from TLC were separated by HPLC using a HILIC column [EC 150/2 Nucleoshell HILIC (2.0 x $150 \mathrm{~mm}, 2.7 \mu \mathrm{m}$ particle size), Macherey-Nagel, Duren, Germany] and the following gradient of solvent B: 0-6 min 95\% to $70 \%, 6-10 \min 70 \%$ to $50 \%, 10-25 \mathrm{~min}$ kept at 50\%, 25-26 $\min 50 \%$ to $95 \%, 26-35$ min kept at $95 \%$ and a flow rate of $0.2 \mathrm{ml} / \mathrm{min}$. Solvent A consisted of water plus $5 \%$ acetonitrile and solvent $\mathrm{B}$ of $99 \%$ acetonitrile plus $7 \mu \mathrm{M}$ acetic acid. Column was equilibrated for $10 \mathrm{~min}$ at $0.5 \mathrm{ml} / \mathrm{min}$ between each run using $95 \%$ acetonitrile. MS detection was carried out by ESI in positive and in negative mode using an ion trap 500 MS (Varian, Darmstadt, Germany) in full scan $(100-1000 \mathrm{~m} / \mathrm{z}$ ), by a specific mass scan range $(m / z, 150-170$ for fosfonochlorin or $m / z, 130-220$ for fosfomycin) or by specific mass fragmentation of $157 \mathrm{~m} / z-157.0>65: 167$ (-) [0.74V] (for ion fragment monitoring $\mathrm{m} / \mathrm{z} 79$ ). Some of the samples were chosen and analyzed in high resolution (HR) using a time-offlight (TOF)/Q-TOF Mass Spectrometer (Agilent Technologies, Santa Clara, USA) with a reverse phase C18 column [Acquity UPLC HSS T3 $(2.1 \times 100 \mathrm{~mm}, 1.8 \mu \mathrm{m}$ particle size), Waters, Massachusetts, USA] and the following gradient of solvent B: 0-3 min 20\%, 3-8 $\min 20 \%$ to $100 \%, 8-12 \min 100 \%$ and $12-12.1 \min 100 \%$ to $1 \%$ and a flow rate of 0.5 $\mathrm{mL} / \mathrm{min}$. Solvent A consisted of water plus $0.1 \%$ formic acid and solvent B of $100 \%$ acetonitrile plus $0.1 \%$ formic acid. MS detection was carried out by Dual Agilent Jet Stream (AJS) ESI in negative mode in full scan $(\mathrm{m} / \mathrm{z}$ 85-1700).Analysis was carried out by Dr. Kirstin Feußner in the Department of Plant Biochemistry of the Albrecht von Haller Institute, Goettingen University. 


\section{Results}

\subsection{Establishment of a method for detection of phosphonates on TLC plates}

A method for phosphonates detection on TLC plates was established. The antibiotic fosfomycin was observed on the plates as blue spots using concentrations between 0.1 to 0.4 M. Although DA were run on TLC plates using the same concentrations, nothing was observed on the plates until the concentration was increased at least to $0.5 \mathrm{M}$. Retention factors were 0.44 and 0.59 for fosfomycin and DA respectively (Figure 1A and C).
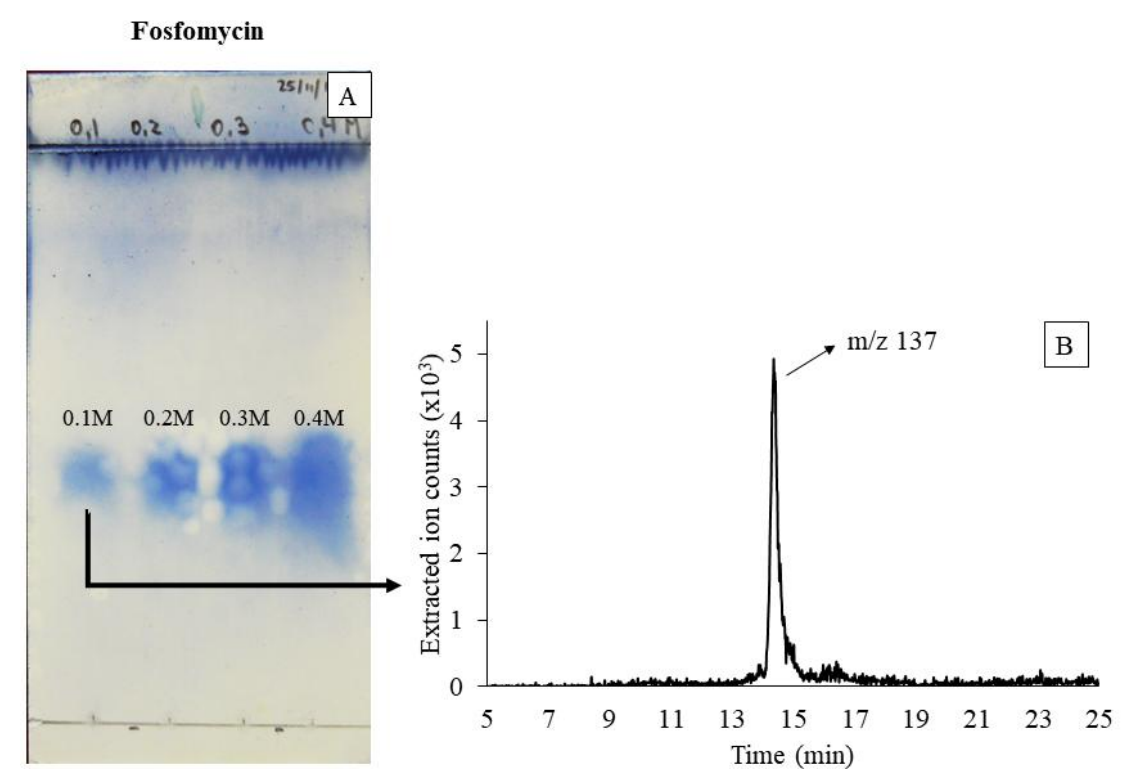

Diethyl acetylphosphonate

Figure 1. Phosphonates fosfomycin (A) and diethyl acetylphosphonate (DA) (C) on silica TLC plates. Developed with 2-propanol: $\mathrm{H}_{2} \mathrm{O}: \mathrm{NH}_{3}$ (6:3:1) and detected using a freshly prepared visualization solution composed of $4.6 \%$ ammonium molybdate and $0.2 \%$ of cerium (IV) sulfate in 10\% sulfuric acid. Fosfomycin was extracted from the TLC plates, separated by HPLC using a HILIC column and detected by ESI-MS in negative mode by specific mass scan range $m / z, 130-220$ (B).

The method for phosphonates extraction from silica TLC plates was successful since fosfomycin was extracted using $100 \% \mathrm{MeOH}$ and corroborated through HPLC-MS as shows in figure $1 \mathrm{~B}$.

\subsection{Phosphonates extraction and detection by TLC and HPLC-MS.}

\subsubsection{Phosphates $\left(\mathrm{PO}_{4}\right)$ precipitation assay}

Phosphonates fosfomycin and DA did not precipitate when the procedure for $\mathrm{PO}_{4}$ precipitation was used. The effectiveness of the procedure was corroborated when the 
phosphate $\mathrm{KH}_{2} \mathrm{PO}_{4}$, included in the medium, precipitated using $\mathrm{CaCl}_{2}$ while the phosphonates, added in the same $\mathrm{P}$ molar concentration $(37 \mathrm{mM})$, remains soluble (Table $1)$.

The assay for $\mathrm{PO}_{4}$ precipitation demonstrates that, using this procedure, organic phosphonates remains soluble and that it can be used for phosphonates extraction protocols in which $\mathrm{PO}_{4}$ should be precipitated at the beginning to reduce the interference of these compounds during HPLC-MS detection.

Table 1. Phosphates $\left(\mathrm{PO}_{4}\right)$ precipitates weight obtained after incubation of IM containing phosphate $\left(\mathrm{KH}_{2} \mathrm{PO}_{4}\right)$ and/or phosphonate (DA) with $0.1 \mathrm{M} \mathrm{CaCl}_{2}$ for 1 or 3 hours.

\begin{tabular}{c|c|c|}
\hline Treatment & Incubation (h) & Precipitate weight (mg) \\
\hline \hline \multirow{2}{*}{$\mathrm{IM}+\mathrm{PO}_{4}$ plus $\mathrm{CaCl}_{2}$} & 1 & 81.0 \\
\hline \multirow{2}{*}{$\mathrm{IM}-\mathrm{PO}_{4}$ plus $\mathrm{CaCl}_{2}$} & 3 & 137.1 \\
\hline \multirow{2}{*}{$\mathrm{IM}+\mathrm{PO}_{4}$ plus $\mathrm{CaCl}_{2}$ plus DA } & 1 & 0.0 \\
\hline \multirow{2}{*}{$\mathrm{IM}-\mathrm{PO}_{4}$ plus $\mathrm{CaCl}_{2}$ plus DA } & 3 & 0.0 \\
\hline
\end{tabular}

\subsubsection{Phosphonates detection by TLC and HPLC-MS}

After extraction from Fusarium liquid cultures, the samples were immediately analyzed by HPLC-MS and the calculated monoisotopic mass for fosfonochlorin $157.9535 \mathrm{Da}$, was searched between a mass scan range of $m / z, 150-170$ after positive and negative ionization; expected mass $[\mathrm{M}+\mathrm{H}]^{+} \mathrm{m} / \mathrm{z}$ 159and $[\mathrm{M}-\mathrm{H}]^{-} \mathrm{m} / \mathrm{z} 157$ respectively. The mass was only observed after negative ionization as expected for phosphonates, and in the two Fusarium species ( $F$. oxysporum and $F$. avenaceum). The peak height $(\mathrm{m} / \mathrm{z} 157)$ was similar in both species as well as the retention time (12-13 min) (Figure 2A).

To confirm the right peak identification as fosfonochlorin, two approaches were followed, one related with the chlorine isotope pattern expected from a chlorine-containing compound such as fosfonochlorin and, the other one, related with the expected ions after source fragmentation of phosphonates $(\mathrm{m} / \mathrm{z} 63$ and 79) (Evans et al. 2013). The expected 
chlorine isotope pattern ${ }^{35} \mathrm{Cl}:{ }^{37} \mathrm{Cl}$ (3:1) was observed in $F$. oxysporum and $F$. avenaceum samples as shown in figure $2 \mathrm{C}$, however it was not always exactly 3:1 (Figure 2D). Mass $\mathrm{m} / \mathrm{z}, 157$ fractionation released the negative ion $\mathrm{m} / \mathrm{z}$ 79(Figure 2B) expected from the phosphite anion $\left(\mathrm{PO}_{3}{ }^{-3}\right)$ and, since $\mathrm{PO}_{4}$ were removed from the samples at the beginning of the extraction method, is expected that the ion $\mathrm{m} / \mathrm{z}$ 79belongs only to a phosphonate. Moreover, the mass $\mathrm{m} / \mathrm{z}$ 157comes from the fungi metabolism since it was not found in the culture medium.
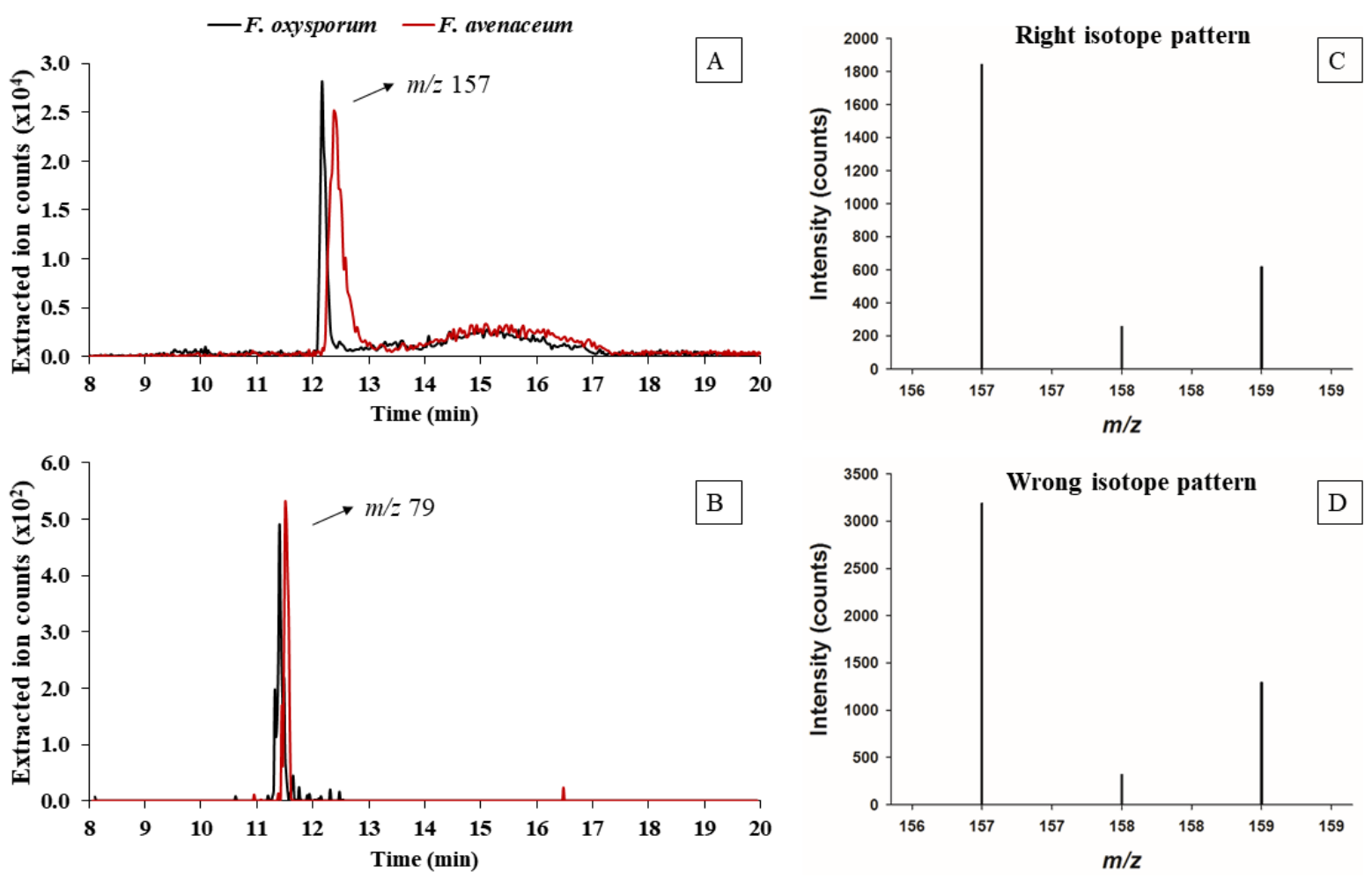

Figure 2. Extracted ion chromatograms of mass $\mathrm{m} / \mathrm{z} 157$ detected in $F$. oxysporum and $F$. avenaceum after phosphonates induction and extraction from liquid cultures. Compound was separated by HPLC using a HILIC column and detected after ESI-MS in negative mode by specific mass scan range screening $(\mathrm{m} / \mathrm{z}, 150-170)$ (A) or by specific mass fragmentation of $m / z 157(157.0>65: 167(-)[0.74 \mathrm{~V}])$ (B). Some examples of the tandem mass spectrum from the peak with a mass of $\mathrm{m} / \mathrm{z} 157$ obtained from two independent biological samples (C and D).

An important observation is that the peak with a mass of $\mathrm{m} / \mathrm{z}$. 157 and its fraction ion $\mathrm{m} / \mathrm{z} 79$ showed different retention times. In this regard, is important to clarify that the mass fractionation was done in different runs and that the retention time of the mass $\mathrm{m} / \mathrm{z}$. 157 was always changing between 11 to 13 minutes, every time that the samples were run on the same HILIC column and using the same conditions. Equilibration time of the column could 
play a role in this case since this problem was more evident in the first samples of every run.

The mass $m / z$ 157was not detected on Q-TOF-MS probably because the samples were run on a reverse phase C18 column which is already known not to be a proper column for separation of polar compounds (Hao et al. 2008; Onorato et al. 2010), such as phosphonates.

The same samples described before were run on TLC plates to detect the presence of phosphonates based on the molybdenum blue reaction. After visualization of the samples on the silica TLC plates one clear blue spot was observed only in $F$. oxysporum (Figure $3 \mathrm{~A})$ which showed a retention factor of 0.86 developed with 2-propanol: $\mathrm{H}_{2} \mathrm{O}: \mathrm{NH}_{3}(6: 3: 1)$. After HPLC-MS analysis of this blue spot, the mass $m / z 157$ was not detected however, a peak with a mass of $m / z 147$ was observed. QTOF-HR-MS analysis of this mass resulted in a monoisotopic mass of $148.029 \mathrm{Da}$ and, based on predictions, two chemical formulae were obtained: $\mathrm{C}_{5} \mathrm{H}_{9} \mathrm{O}_{3} \mathrm{P}$ (molar mass of $148.0969 \mathrm{~g} / \mathrm{mol}$ ) and $\mathrm{C}_{6} \mathrm{H}_{9} \mathrm{ClO}_{2}$ (molar mass of $148.5875 \mathrm{~g} / \mathrm{mol})$. However, based on the fact that the chloride isotope pattern was not observed, the second compound was discarded.

This mass $(m / z$ 147) was also eluted with water from Sephadex LH-20 column in the third fraction of $F$. oxysporum sample (Figure 3B). After Sephadex, the compound was quite pure since this was the predominant mass in a range screening of $m / z, 50-500$. Based on our observations, this unknown mass is expected to correspond to a water-soluble compound and a $\mathrm{P}$-containing molecule, possibly a phosphonate, based on the fact that did not precipitate during the $\mathrm{PO}_{4}$ precipitation procedure.

As for the compound with mass $m / z 157$, the mass $m / z 147$ also showed a shift in the retention time every time that it was separated on HILIC, meaning that conditions to run phosphonates in this column should be improved. 

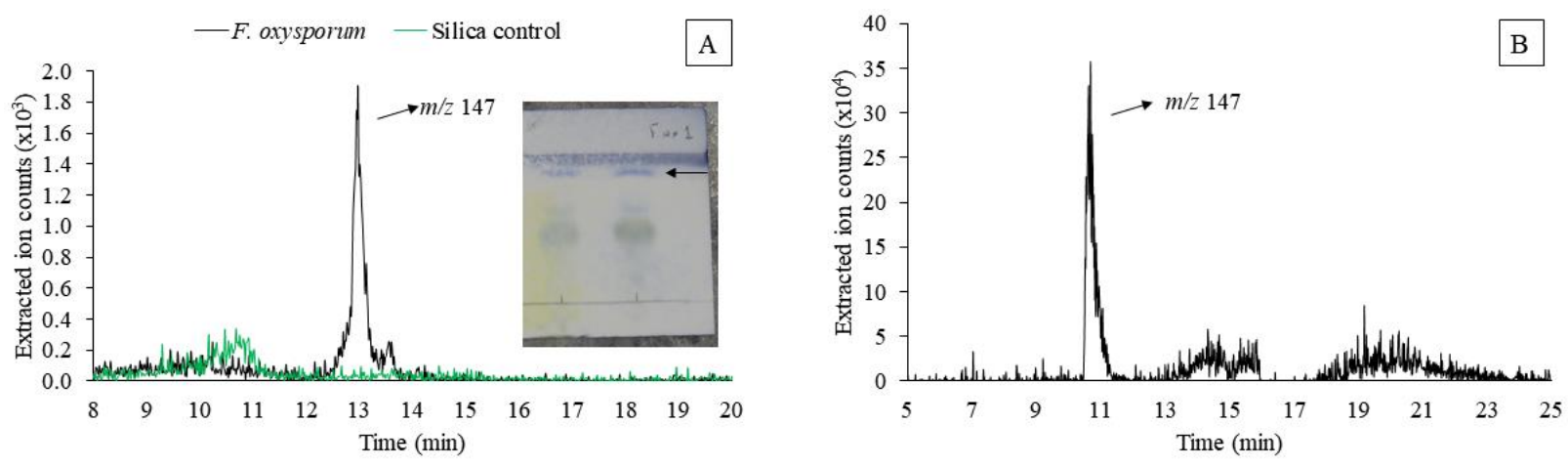

Figure 3. Extracted ion chromatograms of mass $\mathrm{m} / \mathrm{z}, 147$ detected in $F$. oxysporum after phosphonates induction and extraction from liquid cultures and separation on silica TLC plates [2-propanol: $\mathrm{H}_{2} \mathrm{O}: \mathrm{NH}_{3}$ (6:3:1)] (A) or eluted from Sephadex $\mathrm{LH}-20$ with water (B). Compound and silica control (silica without any sample) were extracted from silica TLC plates and separated by HPLC using a HILIC column and detected after ESI-MS in negative mode by specific mass range screening $\mathrm{m} / \mathrm{z}$ 130-220 (A) or $\mathrm{m} / \mathrm{z}$ 50-500 (B). Mass eluted from Sephadex LH-20 was confirmed using Q-TOF-MS on a C18 column showing a monoisotopic mass of $148.029 \mathrm{Da}$ and, by prediction, a possible chemical formula of $\mathrm{C}_{5} \mathrm{H}_{9} \mathrm{O}_{3} \mathrm{P}$ and a molar mass of $148.0969 \mathrm{~g} / \mathrm{mol}$.

After HPLC-MS full scan analysis of fractions eluted from Sephadex LH-20 using MeOH, a mass of $m / z 317$ was found in $F$. oxysporum and $F$. avenaceum (Figure 4A). This mass was observed mainly in fraction 7 in both species and it was not detected in the medium. The mass did not show any isotope pattern (Figure 4B) and, interestingly, it was also detected in a next experiment only when $F$. oxysporum was cultivated with bacteria (Figure 4C and D). This bacterium was isolated from a contaminated Fusarium culture in our laboratory and was used latter to carry out this experiment. We identified this bacterium as Bacillus megaterium (99\% identity), a gram-positive ubiquitous bacterium in the environment (Vary et al. 2007).

As deduced from the mass tandem spectrum (Figure 4B), the compound belonging to mass $\mathrm{m} / \mathrm{z} 317$ is quite pure since this is the predominant mass in a range screening of $\mathrm{m} / \mathrm{z} 50$ 500. This mass showed also a shift in the retention time between runs like the other compounds suggesting again that the conditions for HILIC must be improved. This mass 
was not detected on the QTOF-HR-MS possibly because of the type of column used to run the samples, a reverse phase $\mathrm{C} 18$ column.
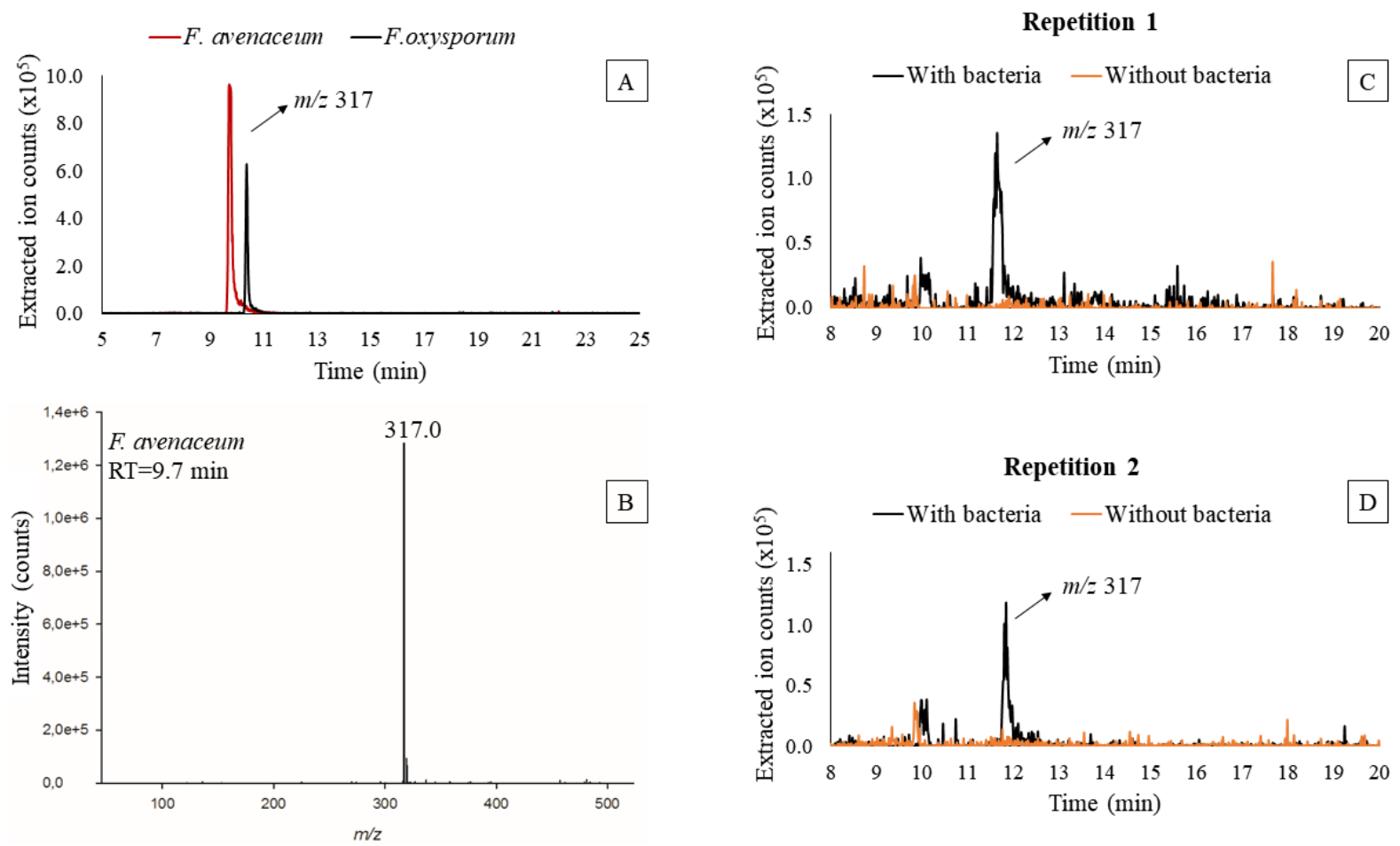

Figure 4. Extracted ion chromatogram (A) and tandem mass spectrum (B) of mass $\mathrm{m} / \mathrm{z}$ 317 detected in $F$. oxysporum and $F$. avenaceum after phosphonates induction and extraction from liquid cultures (C and D) or eluted from Sephadex LH-20 with $\mathrm{MeOH}$ (A). Extracted ion chromatogram of $m / z 317$ in $F$. oxysporum cultivated with or without bacteria and obtained after extraction from liquid cultures (C and D, biological replicate 1 and 2 respectively). In all cases, compound was separated by HPLC using a HILIC column and detected after electrospray ionization in negative mode by specific mass scan range screening $m / z, 50-500$ (A and B) or $m / z$ 50-1000 (C and D).

\section{Discussion}

Phosphonates extraction and detection is a difficult task due mainly to their high polarity and water solubility (Gao et al. 2014; Ju et al. 2014; Horsman and Zechel 2017). The hydrophilic solvent methanol is commonly used to extract natural phosphonates and HPLC using HILIC-based columns have been employed to separate them followed by detection using ESI-MS in negative mode (Evans et al. 2013; Ju et al. 2015). HILIC, as a variant of the normal phased, is an excellent option for separation of highly polar compounds (Hemström and Irgum 2006). 
Following similar approaches, in the present chapter, two different compounds were detected in Fusarium cultures that could be categorized as phosphonates. The first one was obtained from $F$. oxysporum and $F$. avenaceum cultures and showed the expected mass for fosfonochlorin after negative ionization $\left([\mathrm{M}-\mathrm{H}]^{-} \mathrm{m} / \mathrm{z}\right.$ 157) (Takeuchi et al. 1989). The second one $\left([\mathrm{M}-\mathrm{H}]^{-} m / z\right.$ 147.029, possible chemical formula: $\left.\mathrm{C}_{5} \mathrm{H}_{9} \mathrm{O}_{3} \mathrm{P}\right)$ was detected only in F. oxysporum, was eluted from Sephadex LH-20 with water, it was observed as blue spot on TLC plates and no isotope pattern was detected after HPLC-MS (using HILIC column) or -Q-TOF-MS (using C18 column).

From our results is likely that the first mass $(\mathrm{m} / \mathrm{z}, 157)$ belongs to fosfonochlorin based on five main reasons. First, the mass was produced by the fungi since it was not detected in the medium. Second, the monoisotopic mass of fosfonochlorin is $157.9535 \mathrm{Da}$, so the resulting mass after negative ionization, considering the sensitivity of the mass spectrometer should be $[\mathrm{M}-\mathrm{H}]^{-} \mathrm{m} / \mathrm{z}, 157$. Third, this mass was only detected after negative ionization, as expected for negatively (acidic)-charged molecules, capable of donate an $\mathrm{H}^{+}$(Henriksen et al. 2005), such as phosphonates. Fourth, the fragmentation of this mass gave rise one of the expected fragments for phosphonates $(\mathrm{m} / \mathrm{z}, 79)$ and fifth, the chlorine isotope pattern was observed. Regarding the fragmentation, characteristics patterns for phosphonates and phosphonic acids have been described (Evans et al. 2013; Bauer et al. 2017). Specifically, Evans et al. (2013) demonstrated that the most abundant fragmentation ions for phosphonates are $\mathrm{m} / \mathrm{z} 63$ and 79 . However, $\mathrm{m} / \mathrm{z}, 79$ could be also a fragment transition ion for $\mathrm{PO}_{4}$. In this case, the removal of $\mathrm{PO}_{4}$ before extraction and detection is a way to reduce the interference caused by the abundant $\mathrm{PO}_{4}$ in the samples, as it was done in the present study. Regarding the isotope pattern, the fluctuation could be explained by the ionization variation commonly described for small polar molecules (Henriksen et al. 2005) or due to the formation of the so-called corona discharge, an electrical discharge of the ESI capillary tip which causes the ionization of the gas-phase and the solvent around the needle resulting in the chemical ionization of the analyte (Glish and Vachet 2003). The corona discharge is the mechanism used for atmospheric pressure chemical ionization (APCI) (Glish and Vachet 2003) however not in ESI, where often occurs only in negative mode ionization and can destabilize and influence the MS signal (Cech and Enke 2001). Changes in the $\mathrm{pH}$ of the mobile phase can also cause alterations in the MS signal during negative ionization (Gioumouxouzis et al. 2015). 
The molecule with a mass of $\mathrm{m} / \mathrm{z} 147$ is likely to be a novel phosphonate since it was observed as a blue spot on TLC plates using a method developed for phosphonic acids (Maile et al. 1977). It has a possible chemical formula of $\mathrm{C}_{5} \mathrm{H}_{9} \mathrm{O}_{3} \mathrm{P}$ and a molar mass of $148.0969 \mathrm{~g} / \mathrm{mol}$ as determined using high resolution-MS. Any compound with this mass has been described so far in Fusarium.

The mass $m / z 317$ was detected in both, $F$. oxysporum and $F$. avenaceum, was eluted from Sephadex LH-20 using MeOH and no isotope pattern was observed after HPLC-MS. Interestingly this mass was also produced in another experiment only when the fungi was cultivated with a gram-positive bacterium previously isolated from Fusarium cultures (B.megaterium). The intensity of this mass was high and very pure as deduced from the mass tandem spectrum showed in figure 4B. From our results is not possible to categorize this mass as a phosphonate because more analysis should be done such as HR-MS and ${ }^{31} \mathrm{P}$ NMR, however a function as a defense compound against bacteria could be predicted.

Changes in the retention time were observed for all the analyzed compounds, even when the same sample and the same conditions and solvents were used. This suggests that the conditions for HILIC should be optimized. In this regard, equilibration times and buffer system can influence the retention time. For the specific case of HILIC columns, they need longer equilibration times (15-20 column volumes) than reverse phase columns and the separation mechanism is more complex. For instance, in HILIC, the primary retention mechanism is considered to be partitioning. However, also important interactions such as hydrogen bond and electrostatic interactions plays a role in HILIC-based separations (Buszewski and Noga 2012; Greco and Letzel 2013), which can be highly affected by the buffer system, especially in the case of ionizable compounds. In our case, column equilibration was done only for 10 minutes at $0.5 \mathrm{ml} / \mathrm{min}$ (too short for a long HILIC column of $150 \mathrm{~mm}$ which would need around $20 \mathrm{~min}$ ) and any buffer system was used.

From our results, is evident that more experiments should be done to detect phosphonates in Fusarium cultures. For instance, the phosphonate-disrupted strains generated in the present study (see chapter 3) could be used as fungal source to induce and extract 
phosphonates and to further detect them though a metabolic profiling using high resolution-MS. In this way, by metabolites comparison, phosphonates can be easily identified since they can be produced by $F$. oxysporum wild type but not by the knockouts. HILIC coupled to ESI-MS has been used already for metabolic profiling in bacteria (Schiesel et al. 2010; Cubbon et al. 2010).

\section{References}

Bai G, Shaner G (1996) Variation in Fusarium graminearum and cultivar resistance to wheat scab. Plant Dis 80:975-979

Bauer A, Luetjohann J, Rohn S, et al (2017) Determination of fosetyl and phosphonic acid at $0.010 \mathrm{mg} / \mathrm{kg}$ level by ion chromatography tandem mass spectrometry (IC-MS/MS). J Agric Food Chem 66:346-350

Bertani G (1951) Studies on lysogenesis. I. The mode of phage liberation by lysogenic Escherichia coli. J Bacteriol 62:293-300

Biasini M, Bienert S, Waterhouse A, et al (2014) SWISS-MODEL: modelling protein tertiary and quaternary structure using evolutionary information. Nucleic Acids Res 42:W252-W258

Black DM, Thompson DE, Bauer DC, et al (2000) Fracture risk reduction with alendronate in women with osteoporosis: the Fracture intervention trial. J Clin Endocrinol Metab $85: 4118-4124$

Blodgett JA, Zhang JK, Yu X, Metcalf WW (2016) Conserved biosynthetic pathways for phosalacine, bialaphos and newly discovered phosphonic acid natural products. J Antibiot (Tokyo) 69:15-25

Blodgett JA V, Zhang JK, Metcalf WW (2005) Molecular cloning, sequence analysis, and heterologous expression of the phosphinothricin tripeptide biosynthetic gene cluster from Streptomyces viridochromogenes DSM 40736. Antimicrob Agents Chemother 49:230-40

Borisova SA, Circello BT, Zhang JK, et al (2010) Biosynthesis of rhizocticins, antifungal phosphonate oligopeptides produced by Bacillus subtilis ATCC6633. Chem Biol $17: 28-37$

Bowman E, McQueney M, Barry RJ, Dunaway-Mariano D (1988) Catalysis and thermodynamics of the phosphoenolpyruvate/phosphonopyruvate rearrangement. 
Entry into the phosphonate class of naturally occurring organophosphorus compounds. J Am Chem Soc 110:5575-5576

Bowman ED, McQueney MS, Scholten JD, Dunaway-Mariano D (1990) Purification and characterization of the Tetrahymena pyriformis $\mathrm{P}-\mathrm{C}$ bond forming enzyme phosphoenolpyruvate phosphomutase. Biochemistry 29:7059-7063

Brandfass C, Karlovsky P (2008) Upscaled CTAB-based DNA extraction and real-time PCR assays for Fusarium culmorum and $F$. graminearum DNA in plant material with reduced sampling error. Int J Mol Sci 9:2306-2321

Brown DW, Butchko RAE, Busman M, Proctor RH (2007) The Fusarium verticillioides FUM gene cluster encodes a $\mathrm{Zn}(\mathrm{II}) 2 \mathrm{Cys} 6$ protein that affects FUM gene expression and fumonisin production. Eukaryot Cell 6:1210-8

Bustin SA, Benes V, Garson JA, et al (2009) The MIQE guidelines: minimum information for publication of quantitative real-time PCR experiments. Clin Chem 55:611-22

Buszewski B, Noga S (2012) Hydrophilic interaction liquid chromatography (HILIC)-a powerful separation technique. Anal Bioanal Chem 402:231-247

Cech NB, Enke CG (2001) Practical implications of some recent studies in electrospray ionization fundamentals. Mass Spectrom Rev 20:362-387

Chen CCH, Han Y, Niu W, et al (2006) Structure and kinetics of phosphonopyruvate hydrolase from Voriovorax sp. Pal2: new insight into the divergence of catalysis within the PEP mutase/isocitrate lyase superfamily. Biochemistry 45:11491-11504

Chomczynski P, Sacchi N (2006) The single-step method of RNA isolation by acid guanidinium thiocyanate-phenol-chloroform extraction: twenty-something years on. Nat Protoc 1:581-585

Cioni JP, Doroghazi JR, Ju K-S, et al (2014) Cyanohydrin phosphonate natural product from Streptomyces regensis. J Nat Prod 77:243-249

Circello BT, Eliot AC, Lee J-H, et al (2010) Molecular cloning and heterologous expression of the dehydrophos biosynthetic gene cluster. Chem Biol 17:402-411

Covert SF, Kapoor P, Lee M, et al (2001) Agrobacterium tumefaciens-mediated transformation of Fusarium circinatum. Mycol Res 105:259-264

Creamer JR, Bostock RM (1986) Characterization and biological activity of Phytophthora 
infestans phospholipids in the hypersensitive response of potato tuber. Physiol Mol Plant Pathol 28:215-225

Cubbon S, Antonio C, Wilson J, Thomas-Oates J (2010) Metabolomic applications of HILIC-LC-MS. Mass Spectrom Rev 29:671-684

de Groot MJA, Bundock P, Hooykaas PJ., Beijersbergen AGM (1998) Agrobacterium tumefaciens-mediated transformation of filamentous fungi. Nat Biotechnol 16:839842

Demain AL, Vaishnav P (2009) Production of recombinant proteins by microbes and higher organisms. Biotechnol Adv 27:297-306

Duyvesteijn RGE, Van Wijk R, Boer Y, et al (2005) Frp1 is a Fusarium oxysporum F-box protein required for pathogenicity on tomato. Mol Microbiol 57:1051-1063

Eliot AC, Griffin BM, Thomas PM, et al (2008) Cloning, expression, and biochemical characterization of Streptomyces rubellomurinus genes required for biosynthesis of antimalarial compound FR900098. Chem Biol 15:765-770

Evans BS, Zhao C, Gao J, et al (2013) Discovery of the antibiotic phosacetamycin via a new mass spectrometry-based method for phosphonic acid detection. ACS Chem Biol 8:908-913

Ferguson CG, Gorin BI, Thatcher GRJ (2000) Design of novel derivatives of phosphonoformate (Foscarnet) as prodrugs and antiviral agents. J Org Chem 65:12181221

Finn RD, Attwood TK, Babbitt PC, et al (2017) InterPro in 2017-beyond protein family and domain annotations. Nucleic Acids Res 45:D190-D199

Fox EM, Mendz GL (2006) Phosphonate degradation in microorganisms. Enzyme Microb Technol 40:145-150

Frandsen RJN (2011) A guide to binary vectors and strategies for targeted genome modification in fungi using Agrobacterium tumefaciens-mediated transformation. $\mathbf{J}$ Microbiol Methods 87:247-262

Gao J, Ju K-S, Yu X, et al (2014) Use of a phosphonate methyltransferase in the identification of the fosfazinomycin biosynthetic gene cluster. Angew Chemie Int Ed 53:1334-1337 
Geisen R, Schmidt-Heydt M, Karolewiez A (2006) A gene cluster of the ochratoxin A biosynthetic genes in Penicillium. Mycotoxin Res 22:134-141

Georgiou G, Segatori L (2005) Preparative expression of secreted proteins in bacteria: status report and future prospects. Curr Opin Biotechnol 16:538-545

Gioumouxouzis CI, Kouskoura MG, Markopoulou CK (2015) Negative electrospray ionization mode in mass spectrometry: A new perspective via modeling. $\mathrm{J}$ Chromatogr B 998-999:97-105

Glish GL, Vachet RW (2003) The basics of mass spectrometry in the twenty-first century. Nat Rev Drug Discov 2:140-150

Greco G, Letzel T (2013) Main interactions and influences of the chromatographic parameters in HILIC separations. J Chromatogr Sci 51:684-693

Gribble GW (2004) Natural organohalogens. Science Dossiers, Brussels, Belgium

Gunji S, Arima K, Beppu T (1983) Screening of antifungal antibiotics according to activities inducing morphological abnormalities. Agric Biol Chem 47:2061-2069

Guo Z, Döll K, Dastjerdi R, et al (2014) Effect of fungal colonization of wheat grains with Fusarium spp. on food choice, weight gain and mortality of meal beetle larvae (Tenebrio molitor). PLoS One 9:e100112

Hanahan D (1983) Studies on transformation of Escherichia coli with plasmids. J Mol Biol 166:557-580

Hao Z, Xiao B, Weng N (2008) Impact of column temperature and mobile phase components on selectivity of hydrophilic interaction chromatography (HILIC). J Sep Sci 31:1449-1464

Hemström P, Irgum K (2006) Hydrophilic interaction chromatography. J Sep Sci 29:17841821

Henriksen T, Juhler RK, Svensmark B, Cech NB (2005) The relative influences of acidity and polarity on responsiveness of small organic molecules to analysis with negative ion electrospray ionization mass spectrometry (ESI-MS). J Am Soc Mass Spectrom $16: 446-455$

Hidaka T, Mori M, Imai S, et al (1989) Studies on the biosynthesis of bialaphos (SF-1293). 9. Biochemical mechanism of C-P bond formation in bialaphos: Discovery of 
phosphoenolpyruvate phosphomutase which catalyzes the formation of phosphonopyruvate from phosphoenolpyruvete. J Antibiot (Tokyo) 42:491-494

Horiguchi M, Kandatstu M (1959) Isolation of 2-aminoethane phosphonic acid from rumen protozoa. Nature 184:901-902

Horsman GP, Zechel DL (2017) Phosphonate biochemistry. Chem Rev 117:5704-5783

Hothorn T, Bretz F, Westfall P (2008) Simultaneous inference in general parametric models. Biometrical J 50:346-363

Hove-Jensen B, Zechel DL, Jochimsen B (2014) Utilization of glyphosate as phosphate source: biochemistry and genetics of bacterial carbon-phosphorus lyase. Microbiol Mol Biol Rev 78:176-97

Huang Z, Wang K-KA, Lee J, van der Donk WA (2015) Biosynthesis of fosfazinomycin is a convergent process. Chem Sci 6:1282-1287

Jia Y, Lu Z, Huang K, et al (1999) Insight into the mechanism of phosphoenolpyruvate mutase catalysis derived from site-directed mutagenesis studies of active site residues. Biochemistry 38:14165-14173

Ju K-S, Doroghazi JR, Metcalf WW (2014) Genomics-enabled discovery of phosphonate natural products and their biosynthetic pathways. J Ind Microbiol Biotechnol 41:345356

Ju K-S, Gao J, Doroghazi JR, et al (2015) Discovery of phosphonic acid natural products by mining the genomes of 10,000 actinomycetes. Proc Natl Acad Sci U S A 112:12175-80

Kamat SS, Raushel FM (2013) The enzymatic conversion of phosphonates to phosphate by bacteria. Curr Opin Chem Biol 17:589-596

Katayama N, Tsubotani S, Nosaki Y, et al (1990) Fosfadecin and fosfocytocin, new nucleotide antibiotics produced by bacteria. J Antibiot (Tokyo) 43:238-246

Kaysser L, Bernhardt P, Nam S-J, et al (2012) Merochlorins A-D, cyclic meroterpenoid antibiotics biosynthesized in divergent pathways with vanadium-dependent chloroperoxidases. J Am Chem Soc 134:11988-11991

Kennedy K, Thompson G (1970) Phosphonolipids: localization in surface membranes of Tetrahymena. Science (80- ) 168:989-991 
Kim A, Kim J, Martin BM, Dunaway-Mariano D (1998) Isolation and characterization of the carbon-phosphorus bond-forming enzyme phosphoenolpyruvate mutase from the mollusk Mytilus edulis. J Biol Chem 273:4443-8

Kim AD, Baker AS, Dunaway-Mariano D, et al (2002) The 2-aminoethylphosphonatespecific transaminase of the 2-aminoethylphosphonate degradation pathway. $\mathrm{J}$ Bacteriol 184:4134-40

Kim J-E, Jin J, Kim H, et al (2006) GIP2, a putative transcription factor that regulates the aurofusarin biosynthetic gene cluster in Gibberella zeae. Appl Environ Microbiol $72: 1645-52$

Kim J, Dunaway-Mariano D (1996) Phosphoenolpyruvate mutase catalysis of phosphoryl transfer in phosphoenolpyruvate: kinetics and mechanism of phosphorus-carbon bond formation. Biochemistry 35:4628-4635

Kim SY, Ju K-S, Metcalf WW, et al (2012) Different biosynthetic pathways to fosfomycin in Pseudomonas syringae and Streptomyces species. Antimicrob Agents Chemother $56: 4175-83$

Kittredge JS, Roberts E (1969) A carbon-phosphorus bond in nature. Science (80- ) $164: 37-42$

Kleinboelting N, Huep G, Appelhagen I, et al (2015) The structural features of thousands of T-DNA insertion sites are consistent with a double- strand break repair-based insertion mechanism. Mol Plant 8:1651-1664

Kononova S V., Nesmeyanova MA (2002) Phosphonates and their degradation by microorganisms. Biochem 67:184-195

Koukol O, Novák F, Hrabal R (2008) Composition of the organic phosphorus fraction in basidiocarps of saprotrophic and mycorrhizal fungi. Soil Biol Biochem 40:2464-2467

Koukol O, Novák F, Hrabal R, Vosátka M (2006) Saprotrophic fungi transform organic phosphorus from spruce needle litter. Soil Biol Biochem 38:3372-3379

La Nauze JM, Coggins JR, Dixon HB (1977) Aldolase-like imine formation in the mechanism of action of phosphonoacetaldehyde hydrolase. Biochem J 165:409-11

La Nauze JM, Rosenberg H, Shaw DC (1970) The enzymic cleavage of the carbonphosphorus bond: Purification and properties of phosphonatase. Biochim Biophys Acta - Enzymol 212:332-350 
Lea P, Joy K, Ramos J, Guerrero M (1984) The action of 2-amino-4-(methylphosphinyl)butanoic acid (phosphinothricin) and its 2-oxo-derivative on the metabolism of cyanobacteria and higher plants. Phytochemistry 23:1-6

Lee KS, Metcalf WW, Wanner BL (1992) Evidence for two phosphonate degradative pathways in Enterobacter aerogenes. J Bacteriol 174:2501-10

Lelliott RA, Stead DE (1987) Methods for the diagnosis of bacterial diseases of plants. Blackwell Scientific Publications, Oxford, UK

Liang C-R, Rosenberg H (1968) On the distribution and biosynthesis of 2aminoethylphosphonate in two terrestrial molluscs. Comp Biochem Physiol 25:673681

Liu S, Lu Z, Han Y, et al (2004) Conformational flexibility of PEP mutase. Biochemistry 43:4447-4453

Liu S, Lu Z, Jia Y, et al (2002) Dissociative phosphoryl transfer in PEP mutase catalysis: structure of the enzyme/sulfopyruvate complex and kinetic properties of mutants. Biochemistry 41:10270-10276

Lutz MP, Feichtinger G, Défago G, Duffy B (2003) Mycotoxigenic Fusarium and deoxynivalenol production repress chitinase gene expression in the biocontrol agent Trichoderma atroviride P1. Appl Environ Microbiol 69:3077-84

Maciejczyk E, Wieczorek D, Zwyrzykowska A, et al (2015) Phosphorus profile of basidiomycetes. Phosphorus Sulfur Silicon Relat Elem 190:763-768

MacPherson S, Larochelle M, Turcotte B (2006) A fungal family of transcriptional regulators: the zinc cluster proteins. Microbiol Mol Biol Rev 70:583-604

Maier F, Malz S, Losch A, et al (2005) Development of a highly efficient gene targeting system for using the disruption of a polyketide synthase gene as a visible marker. FEMS Yeast Res 5:653-662

Maile R, Fischesser G, Anderson M (1977) Thin-layer chromatographic separation of phosphonic acid derivatives. J Chromatogr 132:366-368

Marquardt JL, Brown ED, Lane WS, et al (1994) Kinetics, stoichiometry, and identification of the reactive thiolate in the inactivation of UDP-GlcNAc enolpyruvoyl transferase by the antibiotic fosfomycin. Biochemistry 33:10646-10651 
Martinez A, Tyson GW, Delong EF (2010) Widespread known and novel phosphonate utilization pathways in marine bacteria revealed by functional screening and metagenomic analyses. Environ Microbiol 12:222-238

McGrath JW, Chin JP, Quinn JP (2013) Organophosphonates revealed: new insights into the microbial metabolism of ancient molecules. Nat Rev Microbiol 11:412-419

McSorley FR, Wyatt PB, Martinez A, et al (2012) PhnY and PhnZ comprise a new oxidative pathway for enzymatic cleavage of a carbon-phosphorus bond. J Am Chem Soc 134:8364-8367

Metcalf WW, van der Donk WA (2009) Biosynthesis of phosphonic and phosphinic acid natural products. Annu Rev Biochem 78:65-94

Meyer V (2008) Genetic engineering of filamentous fungi - Progress, obstacles and future trends. Biotechnol Adv 26:177-185

Michielse CB, Hooykaas PJJ, van den Hondel CAMJJ, Ram AFJ (2005) Agrobacteriummediated transformation as a tool for functional genomics in fungi. Curr Genet 48:117

Nakashita H, Watanabe K, Hara O, et al (1997) Studies on the biosynthesis of bialaphos. Biochemical mechanism of C-P bond formation: discovery of phosphonopyruvate decarboxylase which catalyzes the formation of phosphonoacetaldehyde from phosphonopyruvate. J Antibiot (Tokyo) 50:212-219

Nielsen ML, Pustinger J V., Strobel J (1964) Phosphorus-31 nuclear magnetic resonance chemical shifts of phosphorus compounds. J Chem Eng Data 9:167-170

Olsen DB, Hepburn TW, Lee S, et al (1992) Investigation of the substrate binding and catalytic groups of the P-C bond cleaving enzyme, phosphonoacetaldehyde hydrolase. Arch Biochem Biophys 296:144-151

Omura S, Murata M, Hanaki H, et al (1984) Phosalacine, a new herbicidal antibiotic containing phosphinothricin. Fermentation, isolation, biological activity and mechanism of action. J Antibiot (Tokyo) 37:829-835

Onorato JM, Langish R, Bellamine A, Shipkova P (2010) Applications of HILIC for targeted and non-targeted LC/MS analyses in drug discovery. J Sep Sci 33:923-929

Pan Z, Raftery D (2007) Comparing and combining NMR spectroscopy and mass spectrometry in metabolomics. Anal Bioanal Chem 387:525-527 
Park BK, Hirota A, Sakai H (1977) Studies on new antimetabolite produced by microorganism. III. Structure of plumbemycin A and B, antagonists of L-threonine from Streptomyces plumbeus. Agric Biol Chem 41:573-579

Peck SC, van der Donk WA (2013) Phosphonate biosynthesis and catabolism: a treasure trove of unusual enzymology. Curr Opin Chem Biol 17:580-588

Pfaffl MW (2001) A new mathematical model for relative quantification in real-time RTPCR. Nucleic Acids Res 29:45e-45

Punt PJ, Dingemanse MA, Kuyvenhoven A, et al (1990) Functional elements in the promoter region of the Aspergillus nidulans gpdA gene encoding glyceraldehyde-3phosphate dehydrogenase. Gene 93:101-109

R Core Team (2017) R: A language and environment for statistical computing. R Found. Stat. Comput.

Rai M, Padh H (2001) Expression systems for production of heterologous proteins. Curr Sci 80:1121-1128

Rao RN, Allen NE, Hobbs JN, et al (1983) Genetic and enzymatic basis of hygromycin B resistance in Escherichia coli. Antimicrob Agents Chemother 24:689-95

Reeves DS (1994) Fosfomycin trometamol. J Antimicrob Chemother 34:853-858

Rice P, Longden I, Bleasby A (2000) EMBOSS: the European molecular biology open software suite. Trends Genet 16:276-277

Rosano GL, Ceccarelli EA (2014) Recombinant protein expression in Escherichia coli: advances and challenges. Front Microbiol 5:172

Roseberg H, La Nauze JM (1967) The metabolism of phosphanates by microorganisms. The transport of aminoethylphosphonic acid in Basillus cereus. Biochim Biophys Acta 141:79-90

Rost B (1999) Twilight zone of protein sequence alignments. Protein Eng Des Sel 12:8594

Sander C, Schneider R (1991) Database of homology-derived protein structures and the structural meaning of sequence alignment. Proteins Struct Funct Genet 9:56-68

Sarkar M, Hamilton CJ, Fairlamb AH (2003) Properties of phosphoenolpyruvate mutase, the first enzyme in the aminoethylphosphonate biosynthetic pathway in Trypanosoma 
cruzi. J Biol Chem 278:22703-8

Schiesel S, Lämmerhofer M, Lindner W (2010) Multitarget quantitative metabolic profiling of hydrophilic metabolites in fermentation broths of $\beta$-lactam antibiotics production by HILIC-ESI-MS/MS. Anal Bioanal Chem 396:1655-1679

Schowanek D, Verstraete W (1990) Phosphonate utilization by bacterial cultures and enrichments from environmental samples. Appl Environ Microbiol 56:895-903

Seidel HM, Freeman S, Seto H, Knowles JR (1988) Phosphonate biosynthesis: isolation of the enzyme responsible for the formation of a carbon-phosphorus bond. Nature $335: 457-458$

Seidel HM, Pompliano DL, Knowles JR (1992) Phosphonate biosynthesis: molecular cloning of the gene for phosphoenolpyruvate mutase from Tetrahymena pyriformis and overexpression of the gene product in Escherichia coli. Biochemistry 31:25982608

Seto H, Imai S, Tsuruoka T, et al (1982) Studies on the biosynthesis of bialaphos (SF1293) 1. Incorporation of $13 \mathrm{C}$ - and $2 \mathrm{H}$-labeled precursors into bialaphos. J Antibiot (Tokyo) 35:1719-1721

Seto H, Kuzuyama T, Seto H, Kuzuyama T (1999) Bioactive natural products with carbonphosphorus bonds and their biosynthesis. Nat Prod Rep 16:589-596

Seweryn P, Van LB, Kjeldgaard M, et al (2015) Structural insights into the bacterial carbon-phosphorus lyase machinery. Nature 525:68-72

Shao Z, Blodgett JA V, Circello BT, et al (2008) Biosynthesis of 2hydroxyethylphosphonate, an unexpected intermediate common to multiple phosphonate biosynthetic pathways. J Biol Chem 283:23161-8

Sievers F, Wilm A, Dineen D, et al (2011) Fast, scalable generation of high-quality protein multiple sequence alignments using Clustal Omega. Mol Syst Biol 7:539

Sosa OA, Repeta DJ, Ferrón S, et al (2017) Isolation and characterization of bacteria that degrade phosphonates in marine dissolved organic matter. Front Microbiol 8:1786

Stead MB, Agrawal A, Bowden KE, et al (2012) RNAsnap : a rapid, quantitative and inexpensive, method for isolating total RNA from bacteria. Nucleic Acids Res 40:e156-e156 
Stutter MI, Shand CA, George TS, et al (2015) Land use and soil factors affecting accumulation of phosphorus species in temperate soils. Geoderma 257-258:29-39

Suchfort R (2016) Biological detoxification of enniatins. Georg-August-Universität Göttingen

Sugui JA, Chang YC, Kwon-Chung KJ (2005) Agrobacterium tumefaciens-mediated transformation of Aspergillus fumigatus: an efficient tool for insertional mutagenesis and targeted gene disruption. Appl Environ Microbiol 71:1798-802

Takahashi E, Kimura T, Nakamura K, et al (1995) Phosphonothrixin, a novel herbicidal antibiotic produced by Saccharothrix sp. ST-888. I. Taxonomy, fermentation, isolation and biological Properties. J Antibiot (Tokyo) 48:1124-1129

Takeuchi M, Nakajima M, Ogita T, et al (1989) Fosfonochlorin, a new antibiotic with spheroplast forming activity. J Antibiot (Tokyo) 42:198-205

Tate KR, Newman RH (1982) Phosphorus fractions of a climosequence of soils in New Zealand tussock grassland. Soil Biol Biochem 14:191-196

Terpe K (2006) Overview of bacterial expression systems for heterologous protein production: from molecular and biochemical fundamentals to commercial systems. Appl Microbiol Biotechnol 72:211-222

The Gene Ontology Consortium (2015) Gene Ontology Consortium: going forward. Nucleic Acids Res 43:D1049-D1056

Turner BL, Baxter R, Mahieu N, et al (2004) Phosphorus compounds in subarctic Fennoscandian soils at the mountain birch (Betula pubescens)-tundra ecotone. Soil Biol Biochem 36:815-823

Utermark J, Karlovsky P (2007) Role of zearalenone lactonase in protection of Gliocladium roseum from fungitoxic effects of the mycotoxin zearalenone. Appl Environ Microbiol 73:637-42

Vary PS, Biedendieck R, Fuerch T, et al (2007) Bacillus megaterium-from simple soil bacterium to industrial protein production host. Appl Microbiol Biotechnol 76:957967

Wackett LP, Shames SL, Venditti CP, Walsh CT (1987) Bacterial carbon-phosphorus lyase: products, rates, and regulation of phosphonic and phosphinic acid metabolism. J Bacteriol 169:710-7 
Wassef MK, Hendrix JW (1977) Ceramide aminoethylphosphonate in the fungus Pythium prolatum. Biochim Biophys Acta - Lipids Lipid Metab 486:172-178

Weld RJ, Plummer KM, Carpenter MA, Ridgway HJ (2006) Approaches to functional genomics in filamentous fungi. Cell Res 16:31-44

Wendler C, Barniske M, Wild A (1990) Effect of phosphinothricin (glufosinate) on photosynthesis and photorespiration of C3 and C4 plants. Photosynth Res 24:55-61

Woloshuk CP, Foutz KR, Brewer JF, et al (1994) Molecular characterization of aflR, a regulatory locus for aflatoxin biosynthesis. Appl Environ Microbiol 60:2408-14

Woo G, Tomlinson G, Nishikawa Y, et al (2010) Tenofovir and entecavir are the most effective antiviral agents for chronic hepatitis B: a systematic review and bayesian meta-analyses. Gastroenterology 139:1218-1229.e5

Woodyer RD, Li G, Zhao H, van der Donk WA (2007) New insight into the mechanism of methyl transfer during the biosynthesis of fosfomycin. Chem Commun 0:359-361

Woodyer RD, Shao Z, Thomas PM, et al (2006) Heterologous production of fosfomycin and identification of the minimal biosynthetic gene cluster. Chem Biol 13:1171-1182

Xu D, Guo H, Yun L, York DM (2005) Theoretical studies of dissociative phosphoryl transfer in interconversion of phosphoenolpyruvate to phosphonopyruvate: solvent effects, thio effects, and implications for enzymatic reactions. J Phys Chem B 109:13827-13834

Yin W, Keller NP (2011) Transcriptional regulatory elements in fungal secondary metabolism. J Microbiol 49:329-339

Yu X, Doroghazi JR, Janga SC, et al (2013) Diversity and abundance of phosphonate biosynthetic genes in nature. Proc Natl Acad Sci U S A 110:20759-64

Zechel DL (2016) PhnK: another piece of the carbon-phosphorus lyase puzzle. Structure $24: 3-4$

Zeleznick L, Myers T, Titchener E (1963) Growth of Escherichia coli on methyl-and ethylphosphonic acids. Biochim Biophys Acta 78:547-550

Zhang G, Dai J, Lu Z, Dunaway-Mariano D (2003) The phosphonopyruvate decarboxylase from Bacteroides fragilis. J Biol Chem 278:41302-8 


\section{CHAPTER 5. General discussion}

Natural phosphonates are synthetized by organisms such as bacteria, marine invertebrates and protozoa, being bacteria,mainly Streptomyces sp.,the responsible to produce the already known bioactive phosphonates. Strong evidence suggest that the number of phosphonates producers in nature could be much higher than expected (Yu et al. 2013; Ju et al. 2014; Horsman and Zechel 2017). In fungi, there is only one bioactive phosphonate identified so far, called fosfonochlorin and discovered in 1989 by Takeuchi and collaborators who described it as an antibiotic compound produced by Fusarium avenaceum, F. oxysporum, F. tricinctum and Talaromyces flavus(Takeuchi et al. 1989). Since then, no more information on fungal phosphonates has been published. However, based on the accumulated evidence nowadays about their abundance and distribution in nature (McGrath et al. 2013; Yu et al. 2013), is likely that other fungal-phosphonates exist.

From our genome-based survey we found some fungal species that can possibly synthetize phosphonates. For instance, $F$. oxysporum and $F$. avenaceum, but also $F$. fujikuroi, $F$. proliferatum, T. islandicus and Aspergillus nomius, have, all of them, the gene sequences that codifies for the main two enzymes related with phosphonates biosynthesis, i.e. phosphoenolpyruvate phosphomutase (pepm) and phosphonopyruvate decarboxylase (ppd) (chapter 2, table 1 and figures 2 and 3). Pepm enzyme is the responsible for the $\mathrm{C}-\mathrm{P}$ bond formation (Kim et al. 1998; Sarkar et al. 2003) and it has been used for the prediction of organisms that can biosynthesize phosphonates (Yu et al. 2013; Cioni et al. 2014; Ju et al. 2015). Ppd enzyme is essential since it moves the reaction forward after the $\mathrm{C}-\mathrm{P}$ bond formation (Zhang et al. 2003). F. oxysporum pepm protein showed a similarity of $40 \%$ with M. edulis (mollusk) and 31-33\% with Streptomyces (bacterium), whileppd from $B$. fragilis and Streptomyces sp. (bacteria) showed 53\% and $43 \%$ similarity to the homologous protein in F. oxysporum. Looking at the pepm and ppd gene neighbors and, based on the characteristics of the codifying enzymes, we were able to predict a biosynthetic genomic cluster for phosphonates and to propose a biosynthetic pathway for the fungal phosphonate fosfonochlorin (chapter 2, figure 4), which first steps resemble that ones from bacteria (Peck and van der Donk 2013; Horsman and Zechel 2017).Moreover, the up-regulation of pepm and ppd genes and of other neighboring genes in the putatively $F$. oxysporum 
genomic cluster, during fungal-bacteria interaction (chapter 2, figures 5 and 6) confirms that the genes are active and suggest that one possible function of phosphonates for the fungus is the defense against bacteria. This is in agreement with the fact that some of these compounds, including the fungal phosphonate fosfonochlorin, exhibits antibiotic activity (Park et al. 1977; Takeuchi et al. 1989; Woodyer et al. 2006; Circello et al. 2010; Ju et al. 2015).

The biological function of bioactive phosphonates is unknown, however due to the stability of the $\mathrm{C}-\mathrm{P}$ bond and the wide range of enzymatic reactions that phosphonates could inhibit (Kononova and Nesmeyanova 2002; Metcalf and van der Donk 2009; Yu et al. 2013), a function related with defense against other organisms in competitive environments could be suggested. In the case of $F$. oxysporum, the biological role of these compounds remains still unsolved. However, we generate phosphonates-disrupted strains that can be used in the future for more studies. Based on our results using the wild type and the phosphonatesdisrupted strains against bacteria, mycoparasitic fungi and larvae, any effect could be certainly attributed to the fungal phosphonates (chapter 3 ). In the specific case of bacteria, we suspect that a strong effect of phosphonates on bacteria growth was not observed because this microorganism has evolved to degrade phosphonates. For instance, many bacteria are known to have the non-substrate-specific mechanism for $\mathrm{C}-\mathrm{P}$ bond cleavage including Escherichia and Bacillus genera (Wackett et al. 1987; Kononova and Nesmeyanova 2002). A large percentage of bacteria genomes contain genes involved in phosphonates degradation (Horsman and Zechel 2017). Moreover, from our own genomebased survey we found that many bacteria, including species of Xanthomonas, can produce homologous proteins related with $\mathrm{C}-\mathrm{P}$ bond cleavage, meaning that phosphonates catabolism is a conserved mechanism among bacteria and that is very likely that all bacteria used in the present study could degrade phosphonates. The function of fungal phosphonates during Fusarium interaction against mycoparasitic fungi deserves more research since a clear inhibition zone was observed between Fusarium wild type and the mycoparasitic fungi which was not observed when the phosphonates-disrupted Fusarium strain was used. Defense mechanisms of Fusarium against mycoparasitic fungi might exist since they must coexist in the same soil environment and compete for resources. Information related with metabolites produced by the fungi in response to mycoparasitic fungi is scarce. In this regard, some studies have suggested that mycotoxins might play a 
role against mycoparasites such as Gliocladiumroseum(Utermark and Karlovsky 2007) and Trichoderma atroviride(Lutz et al. 2003).

In the present study, some possible phosphonates were found in Fusarium cultures confirming the results from Takeuchi and collaborators in 1989 (Takeuchi et al. 1989) and our observations and predictions based on genomic information. We detect a mass of [M$\mathrm{H}]^{-} m / z 157$ which, after fragmentation, gave rise an expected ion for phosphonates $(\mathrm{m} / \mathrm{z}$ 79) (Evans et al. 2013). The isotopic pattern for a chlorine-containing compound was also observed from this mass, supporting the fact that it possibly belongs to the fungal phosphonate fosfonochlorin. Besides fosfonochlorin, another two possible novel compounds were detected on Fusarium cultures. From our results is evident that improvements must be done to separate and detect these polar compounds using HPLCESI-MS. The difficulties for extraction and purification of the polar phosphonates have been already pointed out (McGrath et al. 2013; Gao et al. 2014; Ju et al. 2014). For instance, the variation in retention time observed during our analysis using hydrophilic interaction chromatography (HILIC) columns suggest that the retention on the column is not adequate due to factors such as the intermolecular interactions between the compound and the stationary phase, the compound and the mobile phase, and the stationary and mobile phases(Buszewski and Noga 2012). The use of a buffer systemwhen HILIC columns are used, which was not employed in the present study, is essential since the retention is affected by the $\mathrm{pH}$ (Hemström and Irgum 2006; Stead et al. 2012; Greco and Letzel 2013). On the other hand, the use of methanol and Sephadex LH-20 to extract and separate phosphonates seemed suitable. Both of them have been successfully used for the extraction and separation of several natural phosphonates from bacteria (Ju et al. 2015).

Although more studies are needed in order to demostrate the biological function of these compounds in Fusarium and to improve their extraction and detection, our study is the first and the starting point for future research in Fusarium phosphonates. Moreover, from our genome-based survey it seems that many other fungal species might be also able to produce phosphonates meaning that, as already sugested by others (Yu et al. 2013; Ju et al. 2014; Horsman and Zechel 2017), phosphonates research is still in the beginning and many interesting discoveries are expected to emerge in the comming years. 


\section{References}

Bai G, Shaner G (1996) Variation in Fusarium graminearum and cultivar resistance to wheat scab. Plant Dis 80:975-979

Bauer A, Luetjohann J, Rohn S, et al (2017) Determination of fosetyl and phosphonic acid at $0.010 \mathrm{mg} / \mathrm{kg}$ level by ion chromatography tandem mass spectrometry (IC-MS/MS). J Agric Food Chem 66:346-350

Bertani G (1951) Studies on lysogenesis. I. The mode of phage liberation by lysogenic Escherichia coli. J Bacteriol 62:293-300

Biasini M, Bienert S, Waterhouse A, et al (2014) SWISS-MODEL: modelling protein tertiary and quaternary structure using evolutionary information. Nucleic Acids Res 42:W252-W258

Black DM, Thompson DE, Bauer DC, et al (2000) Fracture risk reduction with alendronate in women with osteoporosis: the Fracture intervention trial. J Clin Endocrinol Metab $85: 4118-4124$

Blodgett JA, Zhang JK, Yu X, Metcalf WW (2016) Conserved biosynthetic pathways for phosalacine, bialaphos and newly discovered phosphonic acid natural products. $\mathrm{J}$ Antibiot (Tokyo) 69:15-25

Blodgett JA V, Zhang JK, Metcalf WW (2005) Molecular cloning, sequence analysis, and heterologous expression of the phosphinothricin tripeptide biosynthetic gene cluster from Streptomyces viridochromogenes DSM 40736. Antimicrob Agents Chemother 49:230-40

Borisova SA, Circello BT, Zhang JK, et al (2010) Biosynthesis of rhizocticins, antifungal phosphonate oligopeptides produced by Bacillus subtilis ATCC6633. Chem Biol $17: 28-37$

Bowman E, McQueney M, Barry RJ, Dunaway-Mariano D (1988) Catalysis and thermodynamics of the phosphoenolpyruvate/phosphonopyruvate rearrangement. Entry into the phosphonate class of naturally occurring organophosphorus compounds. J Am Chem Soc 110:5575-5576 
Bowman ED, McQueney MS, Scholten JD, Dunaway-Mariano D (1990) Purification and characterization of the Tetrahymena pyriformis $\mathrm{P}-\mathrm{C}$ bond forming enzyme phosphoenolpyruvate phosphomutase. Biochemistry 29:7059-7063

Brandfass C, Karlovsky P (2008) Upscaled CTAB-based DNA extraction and real-time PCR assays for Fusarium culmorum and $F$. graminearum DNA in plant material with reduced sampling error. Int J Mol Sci 9:2306-2321

Brown DW, Butchko RAE, Busman M, Proctor RH (2007) The Fusarium verticillioides FUM gene cluster encodes a Zn(II)2Cys6 protein that affects FUM gene expression and fumonisin production. Eukaryot Cell 6:1210-8

Bustin SA, Benes V, Garson JA, et al (2009) The MIQE guidelines: minimum information for publication of quantitative real-time PCR experiments. Clin Chem 55:611-22

Buszewski B, Noga S (2012) Hydrophilic interaction liquid chromatography (HILIC)-a powerful separation technique. Anal Bioanal Chem 402:231-247

Cech NB, Enke CG (2001) Practical implications of some recent studies in electrospray ionization fundamentals. Mass Spectrom Rev 20:362-387

Chen CCH, Han Y, Niu W, et al (2006) Structure and kinetics of phosphonopyruvate hydrolase from Voriovorax sp. Pal2: new insight into the divergence of catalysis within the PEP mutase/isocitrate lyase superfamily. Biochemistry 45:11491-11504

Chomczynski P, Sacchi N (2006) The single-step method of RNA isolation by acid guanidinium thiocyanate-phenol-chloroform extraction: twenty-something years on. Nat Protoc 1:581-585

Cioni JP, Doroghazi JR, Ju K-S, et al (2014) Cyanohydrin phosphonate natural product from Streptomyces regensis. J Nat Prod 77:243-249

Circello BT, Eliot AC, Lee J-H, et al (2010) Molecular cloning and heterologous expression of the dehydrophos biosynthetic gene cluster. Chem Biol 17:402-411

Covert SF, Kapoor P, Lee M, et al (2001) Agrobacterium tumefaciens-mediated transformation of Fusarium circinatum. Mycol Res 105:259-264

Creamer JR, Bostock RM (1986) Characterization and biological activity of Phytophthora infestans phospholipids in the hypersensitive response of potato tuber. Physiol Mol Plant Pathol 28:215-225 
Cubbon S, Antonio C, Wilson J, Thomas-Oates J (2010) Metabolomic applications of HILIC-LC-MS. Mass Spectrom Rev 29:671-684

de Groot MJA, Bundock P, Hooykaas PJ., Beijersbergen AGM (1998)

Agrobacteriumtumefaciens-mediated transformation of filamentous fungi. Nat Biotechnol 16:839-842

Demain AL, Vaishnav P (2009) Production of recombinant proteins by microbes and higher organisms. Biotechnol Adv 27:297-306

Duyvesteijn RGE, Van Wijk R, Boer Y, et al (2005) Frp1 is a Fusarium oxysporum F-box protein required for pathogenicity on tomato. Mol Microbiol 57:1051-1063

Eliot AC, Griffin BM, Thomas PM, et al (2008) Cloning, expression, and biochemical characterization of Streptomyces rubellomurinus genes required for biosynthesis of antimalarial compound FR900098. Chem Biol 15:765-770

Evans BS, Zhao C, Gao J, et al (2013) Discovery of the antibiotic phosacetamycin via a new mass spectrometry-based method for phosphonic acid detection. ACS Chem Biol 8:908-913

Ferguson CG, Gorin BI, Thatcher GRJ (2000) Design of novel derivatives of phosphonoformate (Foscarnet) as prodrugs and antiviral agents. J Org Chem 65:12181221

Finn RD, Attwood TK, Babbitt PC, et al (2017) InterPro in 2017-beyond protein family and domain annotations. Nucleic Acids Res 45:D190-D199

Fox EM, Mendz GL (2006) Phosphonate degradation in microorganisms. Enzyme Microb Technol 40:145-150

Frandsen RJN (2011) A guide to binary vectors and strategies for targeted genome modification in fungi using Agrobacterium tumefaciens-mediated transformation. $\mathbf{J}$ Microbiol Methods 87:247-262

Gao J, Ju K-S, Yu X, et al (2014) Use of a phosphonate methyltransferase in the identification of the fosfazinomycin biosynthetic gene cluster. Angew Chemie Int Ed 53:1334-1337

Geisen R, Schmidt-Heydt M, Karolewiez A (2006) A gene cluster of the ochratoxin A biosynthetic genes in Penicillium. Mycotoxin Res 22:134-141 
Georgiou G, Segatori L (2005) Preparative expression of secreted proteins in bacteria: status report and future prospects. Curr Opin Biotechnol 16:538-545

Gioumouxouzis CI, Kouskoura MG, Markopoulou CK (2015) Negative electrospray ionization mode in mass spectrometry: A new perspective via modeling. $\mathrm{J}$ Chromatogr B 998-999:97-105

Glish GL, Vachet RW (2003) The basics of mass spectrometry in the twenty-first century. Nat Rev Drug Discov 2:140-150

Greco G, Letzel T (2013) Main interactions and influences of the chromatographic parameters in HILIC separations. J Chromatogr Sci 51:684-693

Gribble GW (2004) Natural organohalogens. Science Dossiers, Brussels, Belgium

Gunji S, Arima K, Beppu T (1983) Screening of antifungal antibiotics according to activities inducing morphological abnormalities. Agric Biol Chem 47:2061-2069

Guo Z, Döll K, Dastjerdi R, et al (2014) Effect of fungal colonization of wheat grains with Fusarium spp. on food choice, weight gain and mortality of meal beetle larvae (Tenebrio molitor). PLoS One 9:e100112

Hanahan D (1983) Studies on transformation of Escherichia coli with plasmids. J Mol Biol $166: 557-580$

Hao Z, Xiao B, Weng N (2008) Impact of column temperature and mobile phase components on selectivity of hydrophilic interaction chromatography (HILIC). J Sep Sci 31:1449-1464

Hemström P, Irgum K (2006) Hydrophilic interaction chromatography. J Sep Sci 29:17841821

Henriksen T, Juhler RK, Svensmark B, Cech NB (2005) The relative influences of acidity and polarity on responsiveness of small organic molecules to analysis with negative ion electrospray ionization mass spectrometry (ESI-MS). J Am Soc Mass Spectrom $16: 446-455$

Hidaka T, Mori M, Imai S, et al (1989) Studies on the biosynthesis of bialaphos (SF-1293). 9. Biochemical mechanism of C-P bond formation in bialaphos: Discovery of phosphoenolpyruvate phosphomutase which catalyzes the formation of phosphonopyruvate from phosphoenolpyruvete. J Antibiot (Tokyo) 42:491-494 
Horiguchi M, Kandatstu M (1959) Isolation of 2-aminoethane phosphonic acid from rumen protozoa. Nature 184:901-902

Horsman GP, Zechel DL (2017) Phosphonate biochemistry. Chem Rev 117:5704-5783

Hothorn T, Bretz F, Westfall P (2008) Simultaneous inference in general parametric models. Biometrical J 50:346-363

Hove-Jensen B, Zechel DL, Jochimsen B (2014) Utilization of glyphosate as phosphate source: biochemistry and genetics of bacterial carbon-phosphorus lyase. Microbiol Mol Biol Rev 78:176-97

Huang Z, Wang K-KA, Lee J, van der Donk WA (2015) Biosynthesis of fosfazinomycin is a convergent process. Chem Sci 6:1282-1287

Jia Y, Lu Z, Huang K, et al (1999) Insight into the mechanism of phosphoenolpyruvate mutase catalysis derived from site-directed mutagenesis studies of active site residues. Biochemistry 38:14165-14173

Ju K-S, Doroghazi JR, Metcalf WW (2014) Genomics-enabled discovery of phosphonate natural products and their biosynthetic pathways. J Ind Microbiol Biotechnol 41:345356

Ju K-S, Gao J, Doroghazi JR, et al (2015) Discovery of phosphonic acid natural products by mining the genomes of 10,000 actinomycetes. Proc Natl Acad Sci U S A 112:12175-80

Kamat SS, Raushel FM (2013) The enzymatic conversion of phosphonates to phosphate by bacteria. Curr Opin Chem Biol 17:589-596

Katayama N, Tsubotani S, Nosaki Y, et al (1990) Fosfadecin and fosfocytocin, new nucleotide antibiotics produced by bacteria. J Antibiot (Tokyo) 43:238-246

Kaysser L, Bernhardt P, Nam S-J, et al (2012) Merochlorins A-D, cyclic meroterpenoid antibiotics biosynthesized in divergent pathways with vanadium-dependent chloroperoxidases. J Am Chem Soc 134:11988-11991

Kennedy K, Thompson G (1970) Phosphonolipids: localization in surface membranes of Tetrahymena. Science (80- ) 168:989-991

Kim A, Kim J, Martin BM, Dunaway-Mariano D (1998) Isolation and characterization of the carbon-phosphorus bond-forming enzyme phosphoenolpyruvate mutase from the 
mollusk Mytilus edulis. J Biol Chem 273:4443-8

Kim AD, Baker AS, Dunaway-Mariano D, et al (2002) The 2-aminoethylphosphonatespecific transaminase of the 2-aminoethylphosphonate degradation pathway. $\mathbf{J}$ Bacteriol 184:4134-40

Kim J-E, Jin J, Kim H, et al (2006) GIP2, a putative transcription factor that regulates the aurofusarin biosynthetic gene cluster in Gibberella zeae. Appl Environ Microbiol $72: 1645-52$

Kim J, Dunaway-Mariano D (1996) Phosphoenolpyruvate mutase catalysis of phosphoryl transfer in phosphoenolpyruvate: kinetics and mechanism of phosphorus-carbon bond formation. Biochemistry 35:4628-4635

Kim SY, Ju K-S, Metcalf WW, et al (2012) Different biosynthetic pathways to fosfomycin in Pseudomonas syringae and Streptomyces species. Antimicrob Agents Chemother $56: 4175-83$

Kittredge JS, Roberts E (1969) A carbon-phosphorus bond in nature. Science (80- ) $164: 37-42$

Kleinboelting N, Huep G, Appelhagen I, et al (2015) The structural features of thousands of T-DNA insertion sites are consistent with a double- strand break repair-based insertion mechanism. Mol Plant 8:1651-1664

Kononova S V., Nesmeyanova MA (2002) Phosphonates and their degradation by microorganisms. Biochem 67:184-195

Koukol O, Novák F, Hrabal R (2008) Composition of the organic phosphorus fraction in basidiocarps of saprotrophic and mycorrhizal fungi. Soil Biol Biochem 40:2464-2467

Koukol O, Novák F, Hrabal R, Vosátka M (2006) Saprotrophic fungi transform organic phosphorus from spruce needle litter. Soil Biol Biochem 38:3372-3379

La Nauze JM, Coggins JR, Dixon HB (1977) Aldolase-like imine formation in the mechanism of action of phosphonoacetaldehyde hydrolase. Biochem J 165:409-11

La Nauze JM, Rosenberg H, Shaw DC (1970) The enzymic cleavage of the carbonphosphorus bond: Purification and properties of phosphonatase. Biochim Biophys Acta - Enzymol 212:332-350

Lea P, Joy K, Ramos J, Guerrero M (1984) The action of 2-amino-4-(methylphosphinyl)- 
butanoic acid (phosphinothricin) and its 2-oxo-derivative on the metabolism of cyanobacteria and higher plants. Phytochemistry 23:1-6

Lee KS, Metcalf WW, Wanner BL (1992) Evidence for two phosphonate degradative pathways in Enterobacter aerogenes. J Bacteriol 174:2501-10

Lelliott RA, Stead DE (1987) Methods for the diagnosis of bacterial diseases of plants. Blackwell Scientific Publications, Oxford, UK

Liang C-R, Rosenberg H (1968) On the distribution and biosynthesis of 2aminoethylphosphonate in two terrestrial molluscs. Comp Biochem Physiol 25:673681

Liu S, Lu Z, Han Y, et al (2004) Conformational flexibility of PEP mutase. Biochemistry $43: 4447-4453$

Liu S, Lu Z, Jia Y, et al (2002) Dissociative phosphoryl transfer in PEP mutase catalysis: structure of the enzyme/sulfopyruvate complex and kinetic properties of mutants. Biochemistry 41:10270-10276

Lutz MP, Feichtinger G, Défago G, Duffy B (2003) Mycotoxigenic Fusarium and deoxynivalenol production repress chitinase gene expression in the biocontrol agent Trichoderma atroviride P1. Appl Environ Microbiol 69:3077-84

Maciejczyk E, Wieczorek D, Zwyrzykowska A, et al (2015) Phosphorus profile of basidiomycetes. Phosphorus Sulfur Silicon Relat Elem 190:763-768

MacPherson S, Larochelle M, Turcotte B (2006) A fungal family of transcriptional regulators: the zinc cluster proteins. Microbiol Mol Biol Rev 70:583-604

Maier F, Malz S, Losch A, et al (2005) Development of a highly efficient gene targeting system for using the disruption of a polyketide synthase gene as a visible marker. FEMS Yeast Res 5:653-662

Maile R, Fischesser G, Anderson M (1977) Thin-layer chromatographic separation of phosphonic acid derivatives. J Chromatogr 132:366-368

Marquardt JL, Brown ED, Lane WS, et al (1994) Kinetics, stoichiometry, and identification of the reactive thiolate in the inactivation of UDP-GlcNAc enolpyruvoyl transferase by the antibiotic fosfomycin. Biochemistry 33:10646-10651

Martinez A, Tyson GW, Delong EF (2010) Widespread known and novel phosphonate 
utilization pathways in marine bacteria revealed by functional screening and metagenomic analyses. Environ Microbiol 12:222-238

McGrath JW, Chin JP, Quinn JP (2013) Organophosphonates revealed: new insights into the microbial metabolism of ancient molecules. Nat Rev Microbiol 11:412-419

McSorley FR, Wyatt PB, Martinez A, et al (2012) PhnY and PhnZ comprise a new oxidative pathway for enzymatic cleavage of a carbon-phosphorus bond. J Am Chem Soc 134:8364-8367

Metcalf WW, van der Donk WA (2009) Biosynthesis of phosphonic and phosphinic acid natural products. Annu Rev Biochem 78:65-94

Meyer V (2008) Genetic engineering of filamentous fungi - Progress, obstacles and future trends. Biotechnol Adv 26:177-185

Michielse CB, Hooykaas PJJ, van den Hondel CAMJJ, Ram AFJ (2005) Agrobacteriummediated transformation as a tool for functional genomics in fungi. Curr Genet 48:117

Nakashita H, Watanabe K, Hara O, et al (1997) Studies on the biosynthesis of bialaphos. Biochemical mechanism of C-P bond formation: discovery of phosphonopyruvate decarboxylase which catalyzes the formation of phosphonoacetaldehyde from phosphonopyruvate. J Antibiot (Tokyo) 50:212-219

Nielsen ML, Pustinger J V., Strobel J (1964) Phosphorus-31 nuclear magnetic resonance chemical shifts of phosphorus compounds. J Chem Eng Data 9:167-170

Olsen DB, Hepburn TW, Lee S, et al (1992) Investigation of the substrate binding and catalytic groups of the P-C bond cleaving enzyme, phosphonoacetaldehyde hydrolase. Arch Biochem Biophys 296:144-151

Omura S, Murata M, Hanaki H, et al (1984) Phosalacine, a new herbicidal antibiotic containing phosphinothricin. Fermentation, isolation, biological activity and mechanism of action. J Antibiot (Tokyo) 37:829-835

Onorato JM, Langish R, Bellamine A, Shipkova P (2010) Applications of HILIC for targeted and non-targeted LC/MS analyses in drug discovery. J Sep Sci 33:923-929

Pan Z, Raftery D (2007) Comparing and combining NMR spectroscopy and mass spectrometry in metabolomics. Anal Bioanal Chem 387:525-527 
Park BK, Hirota A, Sakai H (1977) Studies on new antimetabolite produced by microorganism. III. Structure of plumbemycin A and B, antagonists of L-threonine from Streptomyces plumbeus. Agric Biol Chem 41:573-579

Peck SC, van der Donk WA (2013) Phosphonate biosynthesis and catabolism: a treasure trove of unusual enzymology. Curr Opin Chem Biol 17:580-588

Pfaffl MW (2001) A new mathematical model for relative quantification in real-time RTPCR. Nucleic Acids Res 29:45e-45

Punt PJ, Dingemanse MA, Kuyvenhoven A, et al (1990) Functional elements in the promoter region of the Aspergillus nidulans gpdA gene encoding glyceraldehyde-3phosphate dehydrogenase. Gene 93:101-109

R Core Team (2017) R: A language and environment for statistical computing. R Found. Stat. Comput.

Rai M, Padh H (2001) Expression systems for production of heterologous proteins. Curr Sci 80:1121-1128

Rao RN, Allen NE, Hobbs JN, et al (1983) Genetic and enzymatic basis of hygromycin B resistance in Escherichia coli. Antimicrob Agents Chemother 24:689-95

Reeves DS (1994) Fosfomycin trometamol. J Antimicrob Chemother 34:853-858

Rice P, Longden I, Bleasby A (2000) EMBOSS: the European molecular biology open software suite. Trends Genet 16:276-277

Rosano GL, Ceccarelli EA (2014) Recombinant protein expression in Escherichia coli: advances and challenges. Front Microbiol 5:172

Roseberg H, La Nauze JM (1967) The metabolism of phosphanates by microorganisms. The transport of aminoethylphosphonic acid in Basillus cereus. Biochim Biophys Acta 141:79-90

Rost B (1999) Twilight zone of protein sequence alignments. Protein Eng Des Sel 12:8594

Sander C, Schneider R (1991) Database of homology-derived protein structures and the structural meaning of sequence alignment. Proteins Struct Funct Genet 9:56-68

Sarkar M, Hamilton CJ, Fairlamb AH (2003) Properties of phosphoenolpyruvate mutase, the first enzyme in the aminoethylphosphonate biosynthetic pathway in Trypanosoma 
cruzi. J Biol Chem 278:22703-8

Schiesel S, Lämmerhofer M, Lindner W (2010) Multitarget quantitative metabolic profiling of hydrophilic metabolites in fermentation broths of $\beta$-lactam antibiotics production by HILIC-ESI-MS/MS. Anal Bioanal Chem 396:1655-1679

Schowanek D, Verstraete W (1990) Phosphonate utilization by bacterial cultures and enrichments from environmental samples. Appl Environ Microbiol 56:895-903

Seidel HM, Freeman S, Seto H, Knowles JR (1988) Phosphonate biosynthesis: isolation of the enzyme responsible for the formation of a carbon-phosphorus bond. Nature $335: 457-458$

Seidel HM, Pompliano DL, Knowles JR (1992) Phosphonate biosynthesis: molecular cloning of the gene for phosphoenolpyruvate mutase from Tetrahymena pyriformis and overexpression of the gene product in Escherichia coli. Biochemistry 31:25982608

Seto H, Imai S, Tsuruoka T, et al (1982) Studies on the biosynthesis of bialaphos (SF1293) 1. Incorporation of $13 \mathrm{C}$ - and $2 \mathrm{H}$-labeled precursors into bialaphos. J Antibiot (Tokyo) 35:1719-1721

Seto H, Kuzuyama T, Seto H, Kuzuyama T (1999) Bioactive natural products with carbonphosphorus bonds and their biosynthesis. Nat Prod Rep 16:589-596

Seweryn P, Van LB, Kjeldgaard M, et al (2015) Structural insights into the bacterial carbon-phosphorus lyase machinery. Nature 525:68-72

Shao Z, Blodgett JA V, Circello BT, et al (2008) Biosynthesis of 2hydroxyethylphosphonate, an unexpected intermediate common to multiple phosphonate biosynthetic pathways. J Biol Chem 283:23161-8

Sievers F, Wilm A, Dineen D, et al (2011) Fast, scalable generation of high-quality protein multiple sequence alignments using Clustal Omega. Mol Syst Biol 7:539

Sosa OA, Repeta DJ, Ferrón S, et al (2017) Isolation and characterization of bacteria that degrade phosphonates in marine dissolved organic matter. Front Microbiol 8:1786

Stead MB, Agrawal A, Bowden KE, et al (2012) RNAsnap : a rapid, quantitative and inexpensive, method for isolating total RNA from bacteria. Nucleic Acids Res 40:e156-e156 
Stutter MI, Shand CA, George TS, et al (2015) Land use and soil factors affecting accumulation of phosphorus species in temperate soils. Geoderma 257-258:29-39

Suchfort R (2016) Biological detoxification of enniatins. Georg-August-Universität Göttingen

Sugui JA, Chang YC, Kwon-Chung KJ (2005) Agrobacterium tumefaciens-mediated transformation of Aspergillus fumigatus: an efficient tool for insertional mutagenesis and targeted gene disruption. Appl Environ Microbiol 71:1798-802

Takahashi E, Kimura T, Nakamura K, et al (1995) Phosphonothrixin, a novel herbicidal antibiotic produced by Saccharothrix sp. ST-888. I. Taxonomy, fermentation, isolation and biological Properties. J Antibiot (Tokyo) 48:1124-1129

Takeuchi M, Nakajima M, Ogita T, et al (1989) Fosfonochlorin, a new antibiotic with spheroplast forming activity. J Antibiot (Tokyo) 42:198-205

Tate KR, Newman RH (1982) Phosphorus fractions of a climosequence of soils in New Zealand tussock grassland. Soil Biol Biochem 14:191-196

Terpe K (2006) Overview of bacterial expression systems for heterologous protein production: from molecular and biochemical fundamentals to commercial systems. Appl Microbiol Biotechnol 72:211-222

The Gene Ontology Consortium (2015) Gene Ontology Consortium: going forward. Nucleic Acids Res 43:D1049-D1056

Turner BL, Baxter R, Mahieu N, et al (2004) Phosphorus compounds in subarctic Fennoscandian soils at the mountain birch (Betula pubescens)-tundra ecotone. Soil Biol Biochem 36:815-823

Utermark J, Karlovsky P (2007) Role of zearalenone lactonase in protection of Gliocladium roseum from fungitoxic effects of the mycotoxin zearalenone. Appl Environ Microbiol 73:637-42

Vary PS, Biedendieck R, Fuerch T, et al (2007) Bacillus megaterium-from simple soil bacterium to industrial protein production host. Appl Microbiol Biotechnol 76:957967

Wackett LP, Shames SL, Venditti CP, Walsh CT (1987) Bacterial carbon-phosphorus lyase: products, rates, and regulation of phosphonic and phosphinic acid metabolism. J Bacteriol 169:710-7 
Wassef MK, Hendrix JW (1977) Ceramide aminoethylphosphonate in the fungus Pythium prolatum. Biochim Biophys Acta - Lipids Lipid Metab 486:172-178

Weld RJ, Plummer KM, Carpenter MA, Ridgway HJ (2006) Approaches to functional genomics in filamentous fungi. Cell Res 16:31-44

Wendler C, Barniske M, Wild A (1990) Effect of phosphinothricin (glufosinate) on photosynthesis and photorespiration of C3 and C4 plants. Photosynth Res 24:55-61

Woloshuk CP, Foutz KR, Brewer JF, et al (1994) Molecular characterization of aflR, a regulatory locus for aflatoxin biosynthesis. Appl Environ Microbiol 60:2408-14

Woo G, Tomlinson G, Nishikawa Y, et al (2010) Tenofovir and entecavir are the most effective antiviral agents for chronic hepatitis B: a systematic review and bayesian meta-analyses. Gastroenterology 139:1218-1229.e5

Woodyer RD, Li G, Zhao H, van der Donk WA (2007) New insight into the mechanism of methyl transfer during the biosynthesis of fosfomycin. Chem Commun 0:359-361

Woodyer RD, Shao Z, Thomas PM, et al (2006) Heterologous production of fosfomycin and identification of the minimal biosynthetic gene cluster. Chem Biol 13:1171-1182

Xu D, Guo H, Yun L, York DM (2005) Theoretical studies of dissociative phosphoryl transfer in interconversion of phosphoenolpyruvate to phosphonopyruvate: solvent effects, thio effects, and implications for enzymatic reactions. J Phys Chem B 109:13827-13834

Yin W, Keller NP (2011) Transcriptional regulatory elements in fungal secondary metabolism. J Microbiol 49:329-339

Yu X, Doroghazi JR, Janga SC, et al (2013) Diversity and abundance of phosphonate biosynthetic genes in nature. Proc Natl Acad Sci U S A 110:20759-64

Zechel DL (2016) PhnK: another piece of the carbon-phosphorus lyase puzzle. Structure $24: 3-4$

Zeleznick L, Myers T, Titchener E (1963) Growth of Escherichia coli on methyl-and ethylphosphonic acids. Biochim Biophys Acta 78:547-550

Zhang G, Dai J, Lu Z, Dunaway-Mariano D (2003) The phosphonopyruvate decarboxylase from Bacteroides fragilis. J Biol Chem 278:41302-8 


\section{Summary and outlook}

Phosphonates are natural or synthetic compounds with a direct carbon-phosphorus bond. Their similarity to the abundant phosphate esters and carboxylic acids and the stability of the $\mathrm{C}-\mathrm{P}$ bond makes them suitable for diverse applications in medicine and agriculture. Bioactive natural phosphonates are produce by many species of bacteria, most of them belonging to the Streptomyces genera. The interest in these compounds is increasing year by year since recent evidence suggest that their abundance in the biosphere is much higher than expected. In fungi only one phosphonate has been described so far named fosfonochlorin; a low molecular weight phosphonic acid with antibiotic activity produced by some species of Fusarium and one species of Talaromyces. The main objectives of the present study were to corroborate that Fusarium is able to produce phosphonates, to determine their biological function and to identify other phosphonates in the fungus.

Based on our Fusarium genome-based survey we have found homologous genes codifying the main enzymes involved in phosphonates biosynthesis [phosphoenolpyruvate phosphomutase (pepm) and phosphonopyruvate decarboxylase (ppd)] in several Fusarium species. This is an important finding since the first steps of phosphonates biosynthetic pathways are conserved among different organisms and pepm sequence can be used to predict phosphonates producers. Moreover, these genes together with others inside the putative cluster in $F$. oxysporum were up-regulated when the fungus was cultivated with bacteria, suggesting a function related with fungal-bacteria interaction. However, using phosphonates disrupted $F$. oxysporum strains and the wild type we could not observed any differential effect on bacteria growth that could be attributed to phosphonates. On the other hand, when the same $F$. oxysporum wt and disrupted strains were used against mycoparasitic fungi and mealworms, an effect was observed on their growth and feeding behavior, however more research is needed in order to corroborate the results. Finally, some possible phosphonates, including the already known fosfonochlorin was identified in F. oxysporum and F. avenaceum cultures, reinforcing our hypothesis that Fusarium can biosynthesize phosphonates. 
This is the first study related with fungal phosphonates in which a gene-based approach was followed in order to predict fungal species with the capacity to biosynthesize phosphonates. Based on our findings, one could anticipate that the discovery of new phosphonates of fungal origin is going to increase in the coming years. Although, the biological function of these compounds for Fusarium is still unclear, we generated phosphonates-disrupted strains that can be used, not only to clarify their biological function but also to identify novel $F$. oxysporum phosphonates through HR-MS and ${ }^{31} \mathrm{P}$ NMR. 


\section{Curriculum vitae}

\section{PERSONAL INFORMATION}

Name

Place of birth:

\section{EDUCATION}

October 2014 to date

August 2008 to August 2011

March 2002 to August 2007

February 1997 to Nov 2001

\section{WORK EXPERIENCE}

August 2011 to June 2014

April 2012 to August 2012

November 2007 to August 2011

\section{SCHOLARSHIPS}

February 2017 to April 2018

Abril 2014 to April 2018

April to August 2012

May to December 2010
María de los Ángeles VINAS Meneses

San José, Costa Rica

International PhD Program for Agricultural Sciences. Molecular Phytopathology and Mycotoxin Research. Goettingen University, Germany.

Master in Agricultural Sciences and Natural Resources, emphasis in biotechnology (hon.). Grain and Seed Research Centre (CIGRAS). University of Costa Rica (UCR), Costa Rica

Bachelor in Agricultural Engineering with emphasis on Phytotechnology. Faculty of Agriculture. UCR, Costa Rica

High school. La Salle high School, Costa Rica

Undergraduate and graduate course instructor. Faculty de Agronomy, UCR.

Internship in Institut für Lebensmittelwissenschaft und Biotechnologie. Hohenheim University, Germany

Laboratory assistant. Plant biotechnology laboratory. CIGRAS, UCR.

UCR-scholarship for PhD studies, UCR, Costa Rica

DAAD-scholarship for PhD studies, Goettingen University, Germany

Baden-Wurttemberg Stipendium, Hohenheim University, Germany

Research Centre in Microscopic Structures (CieMic). UCR

\section{PUBLICATIONS}

Vinas, M; Jiménez, V. 2016. Ocurrence and characterisation of calcium oxalate crystals in stems and fruits of Hylocereus costaricensis and Selenicereus megalanthus (Cactaceae: Hylocereeae). Micron. 89: 21-27.

Viñas, M; Fernández-Brenes, M; Azofeifa, A; Jiménez, V.M. 2012. In vitro propagation of purple pitahaya (Hylocereus costaricensis [F.A.C.Weber] Britton \& Rose) cv. Cebra. In Vitro Cellular and Developmental Biology - Plant. 48: 469-477. 


\section{Acknowledgements}

I would like to thank my supervisor Prof. Dr. Petr Karlovsky for giving me the opportunity to carry out my thesis in his group. For his unconditional support and guidance during these three years. I appreciate also, all the advices and support that I received from Dr. Franz Hadaceck, Dr. Katharina Pfohl and Dr. Anna Rathgeb.

Special thanks to Ruth Pilot, Heike Rollwage, Katharina Henze, Isabella Reitz, Ling Su, Wanying He and Yang Xu for their friendship, all the support, help and invaluable advices. Many thanks to all my friends in Karlovsky's lab: Rasoul, Vincent, Lukas, Jia Lai, Zana, Riyan, Pervin, Rosine, Albatol, Mohammad, Viviana, Matthäus, Aulia, Nilay, Jessica and Simon, for all the pleasant moments that we have spent together.

My gratitude goes also to my professors and colleagues in the University of Costa Rica: to Dr. Víctor Jiménez, Dr. Eric Guevara, Dr. Adriana Murillo and Dr. Luis Barboza, thanks for your trust and support always. To my Friends in CIGRAS: Ester, Andrea, Catalina, Mariana, Andrés, Paul, Álvaro, Danilo, Diego, Mauricio, Rosa, Isabel, Erika and Erik.

I would like to thank my sponsors for the financial support: the German Academic Exchange Service (DAAD) and the University of Costa Rica, including all the people behind that support my studies.

I am thankful to my family, specially my brother Rubén: many thanks for your unconditional support. Thanks also to my closest friends in Costa Rica: Sofía, Rox, Eglys, Tapia, Gaby, Luis and Cintia, thanks for always be there!

My deepest gratitude goes to my boyfriend Juan Carlos, thanks for your unconditional support and motivation during all these years.

“...Cuantas veces precisamos la vida entera para cambiar la vida, lo pensamos tanto, tomamos impulso y vacilamos, después volvemos al principio, pensamos y pensamos, nos movemos en los carriles del tiempo con un movimiento circular, como los remolinos que atraviesan los campos, levantando polvo, hojas secas, insignificancias, que a más no llegan sus fuerzas, mejor sería que viviéramos en tierra de tifones..."

José Saramago 


\section{Statutory declaration}

1. I, hereby, declare that this Ph.D. dissertation has not been presented to any other examining body either in its present or a similar form. Furthermore, I also affirm that I have not applied for a Ph.D. at any other higher school of education.

Göttingen,

María de los Ángeles VINAS Meneses

2. I, hereby, solemnly declare that this dissertation was undertaken independently and without any unauthorized aid.

Göttingen,

María de los Ángeles VINAS Meneses 